\author{
UNIVERSIDADE DE SÃO PAULO \\ ESCOLA DE ENGENHARIA DE SÃO CARLOS \\ INSTITUTO DE FÍSICA DE SÃO CARLOS \\ INSTITUTO DE QUÍMICA DE SÃO CARLOS
}

\title{
ESPECTROSCOPIA DE FLUORESCÊNCIA NA DETECÇÃO DE LESÕES QUIMICAMENTE INDUZIDAS POR AGENTE CARCINOGÊNICO NA BORDA \\ LATERAL DA LÍNGUA - ESTUDO IN VIVO
}

\section{USP/IFSC/SBI}

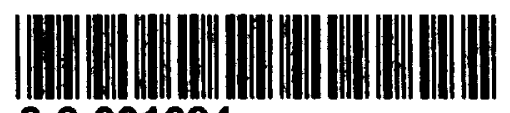

8-2-001684

\section{CRISTINA KURACHI}

Tese apresentada à Área de Interunidades em Ciências e Engenharia de Materiais, da Universidade de São Paulo, como parte dos requisitos para a obtenção do Título de Doutor em Ciência e Engenharia de Materiais.

Orientador: Prof. Dr. Tit. Vanderlei Salvador Bagnato

\section{São Carlos}

2005

IF 3C-USP SERVICOODE BIBLIOTECA
INFORMACAOO 


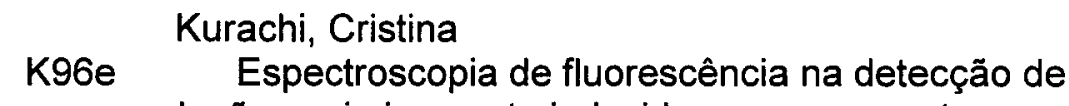
lesões quimicamente induzidas por um agente carcinogênico na borda lateral da língua - estudo in vivo / Cristina Kurachi.-- São Carlos, 2005.

$143 \mathrm{p}$.

Tese (Doutorado) - Escola de Engenharia de São Carlos/Instituto de Fisica de São Carlos/Instituto de Química de São Carlos-Universidade de São Paulo, 2005.

Orientador: Prof. Dr. Vanderlei Salvador Bagnato

1. Espectroscopia de fluorescência. 2. Carcinoma lingual. 3. Diagnóstico.4. Fotodetecção. 5. Laser 


\section{ciancia e Engenharia de Materiais}

MEMBROS DA COMISSÃo JULGADORA DA TESE DE DOUTORADO DE CRISTINA KURACHI APRESENTADA À ÁREA INTERUNIDADES CIÊNCIA E ENGENHARIA DE MATERIAIS, UNIVERSIDADE DE SÃO PAULO, EM 28/04/2005.

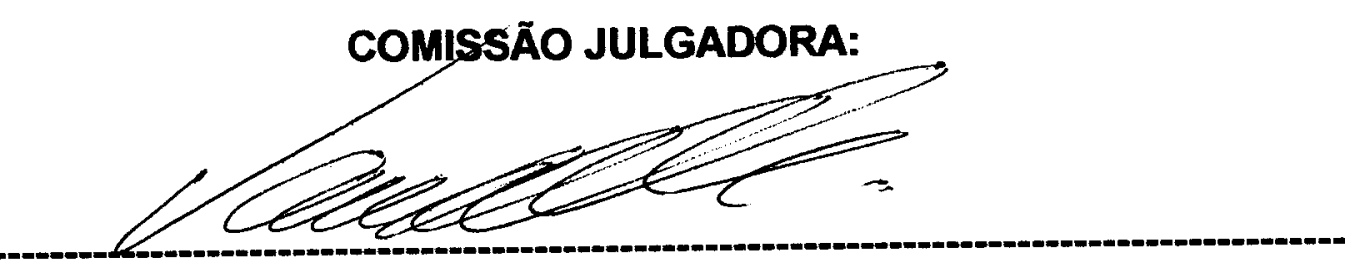

Prof. Dr. Vanderlei SalyactonBagnato (Orientador e Presidente) - IFSC/USP

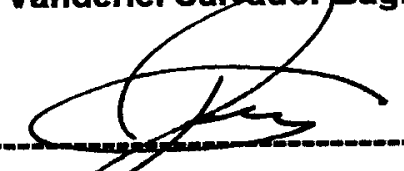

Prof. Dr. Decio dos Santos Pinto Junior - FO/USP

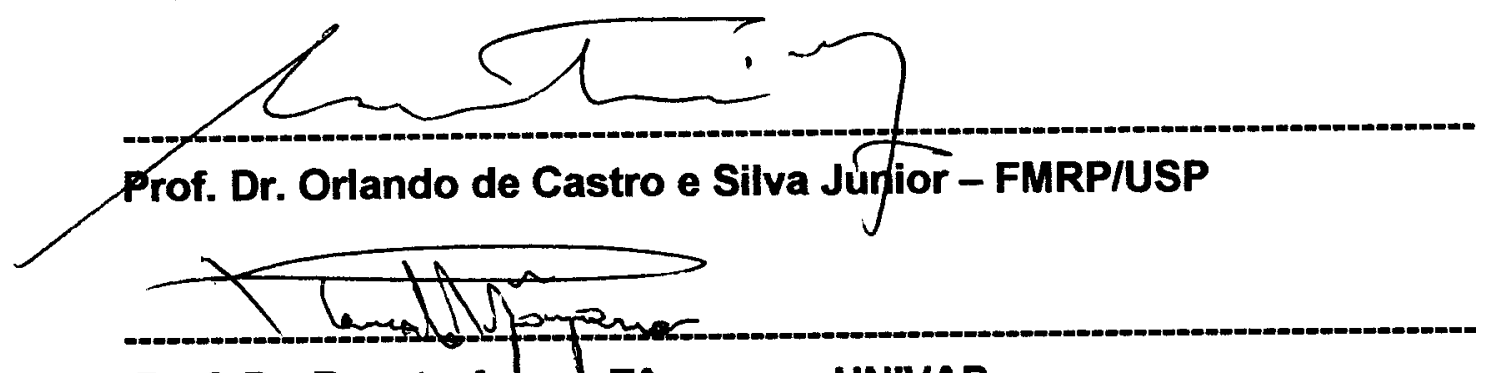

Prof. Dr. Renato Amaro Zângaro - UNIVAP

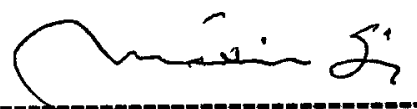

Prof. Dr. Máximo Siu Li - IFSC/USP 


\section{AGRADECIMENTOS}

- Ao Prof. Dr. Vanderlei Salvador Bagnato, meu orientador, pelo envolvente entusiasmo pela ciência, pela contagiante disposição ao trabalho, sempre aliados ao diário ensinamento foram valiosos para minha formação científica e pessoal.

- À minha família pelo amor e pela compreensão sempre presentes durante toda essa jornada.

- Ao Prof. Dr. Luiz Eduardo Blumer Rosa e à Faculdade de Odontologia de São José dos Campos (UNESP) pela intensa contribuição e apoio importantes para a viabilização desse trabalho.

- Ao Prof. Dr. Luís Gustavo Marcassa e à Profa. Dra. Natalia Bulgakova pelas contribuições e discussões científicas.

- À Profa. Dra. Márcia M.C. Ferreira pelo empréstimo do software de quimiometria e pelas discussões e sugestões realizadas.

- A Carla Raquel Fontana e Cláudia Adriana Sousa Melo, pelo companheirismo e auxílio na execução dos experimentos.

- Aos meus valiosos amigos Daniel, Kílvia e Lino, sempre prontos para me auxiliar, pela grande amizade e discussões científicas.

- Aos meus amigos de laboratório, a cada um, pela contribuição única e especial durante as horas de trabalho. Rosane, Juliana, Lílian, Augusto, Clóvis, Denis, Priscila, Emery, Fernando, pelas horas compartilhadas.

- A Isabel e Benê pelo grande apoio e pela ajuda dispensada ao longo dos anos. 


\section{SUMÁRIO}

I. INTRODUÇÃO _ 1

II. OBJETIVO 22

III. MATERIAIS E MÉTODO _ 23

1. Modelo animal para a carcinogênese quimicamente induzida ___ 23

2. Avaliação clínica das lesões ___ 26

3. Investigação pela espectroscopia de fluorescência ___ 27

IV. RESULTADOS E DISCUSSÃO _ 35

1. Avaliação do grupo controle (animais sadios) ___ 35

1.1. Análise histológica da borda lateral da língua ___ 36

1.2. Monitoramento do envelhecimento dos animais ___ 37

2. Avaliação dos animais dos grupos induzidos __ 55

2.1. Aspectos clínicos _ـ 55

2.2. Aspectos histopatológicos _ـ 59

2.3. Espectros de autofluorescência ___ 65

2.4. Monitoramento do Photogem na cavidade oral ___ 117

V. CONCLUSÕES __ 123

VI. REFERÊNCIAS BIBLIOGRÁFICAS __ 136 


\section{LISTA DE FIGURAS}

Figura 1 - Aplicação tópica da solução de DMBA na borda lateral esquerda de um dos animais

Figura 2 - O desenho esquemático do sistema de diagnóstico é apresentado em A e uma foto em B

Figura 3 - Leitura óptica sendo realizada na margem da lesão. Note o posicionamento da ponteira de aplicação.

Figura 4 - Desenho esquemático dos pontos de leitura na borda lateral da língua. Note que os pontos nessa região poderiam estar em áreas de tecido normal ou de lesão.

Figura 5 - Fotografia mostrando a direção do corte do material

Figura 6 - A foto A apresenta o aspecto clínico da borda lateral da língua do hamster do grupo controle. A fotomicrografia B mostra as características histológicas de uma região da borda lateral da língua $(\mathrm{Q}$, camada de queratina; $\mathrm{E}$, epitélio e LP, lâmina própria)............ 37

Figura 7 - Exemplo de um espectro de fluorescência coletado em borda lateral da língua do hamster com excitação em $442 \mathrm{~nm}$ 39

Figura 8 - Espectro de fluorescência típico obtido para a pata. Cada curva do gráfico representa um ponto de leitura

Figura 9 - Espectros de fluorescência típicos para excitação em $532 \mathrm{~nm}$ obtidos para a borda lateral da língua. Cada curva do gráfico representa uma leitura pontual

Figura 10 - Espectro de fluorescência típico obtido para o palato duro. Cada curva do gráfico representa um ponto de leitura

Figura 11 - Fotografia das rugas palatinas no palato duro de um animal

Figura 12 - Espectro de fluorescência típico obtido para a gengiva inserida. Cada curva do gráfico representa um ponto de leitura

Figura 13 - Espectro de fluorescência típico obtido para o dente. Cada curva do gráfico representa um ponto de leitura

Figura 14 - Comparação dos espectros de fluorescência obtidos para a pata em função do tempo de investigação 
Figura 15 - Comparação dos espectros de fluorescência obtidos para a mucosa jugal em função do tempo de investigação .............................................................................. 46 Figura 16 - Comparação dos espectros de fluorescência obtidos para o palato duro em função do tempo de investigação

Figura 17 - Comparação dos espectros de fluorescência obtidos para a borda lateral direita da língua em função do tempo de investigação 48

Figura 18 - Comparação dos espectros de fluorescência obtidos para a borda lateral esquerda da língua em função do tempo de investigação 49

Figura 19 - Comparação dos espectros de fluorescência obtidos para o dorso da língua em função do tempo de investigação 50

Figura 20 - Comparação dos espectros de fluorescência obtidos para o ventre da língua em função do tempo de investigação 5

Figura 21 - Comparação dos espectros de fluorescência obtidos para o assoalho bucal em função do tempo de investigação

Figura 22 - Comparação dos espectros de fluorescência obtidos para os incisivos inferiores em função do tempo de investigação

Figura 23 - Exemplos de diferentes tipos clínicos de lesões obtidas nos grupos experimentais

Figura 24 - Exemplos clínicos de lesões múltiplas e de diferentes aspectos clínicos na mesma lesão

Figura 25 - Localizações anatômicas fora da área de indução tópica

Figura 26 - Foto 1: carcinoma epidermóide com hiperparaqueratose, duplicação da camada basal e presença de pérolas córneas (setas). Foto 2: carcinoma epidermóide com crescimento exofítico, hiperparaqueratose e perda da estratificação. Foto 3: carcinoma epidermóide com áreas de ulceração e pérolas córneas (setas), note o escasso infiltrado inflamatório. Foto 4: ilhota neoplásica em proliferação e aparente desprendimento do epitélio (detalhe). Foto 5, 6 e 7: ilhotas neoplásicas. Foto 8: figuras de mitose

Figura 27A - Espectros de autofluorescência com excitação em $532 \mathrm{~nm}$ para a borda lateral direita (normal), hiperqueratose e lesão. $\mathrm{Na}$ fotografia do caso: a região com hiperqueratose (destaque branco) e a lesão (destaque preto)

Figura 27B - Espectros de autofluorescência com excitação em $442 \mathrm{~nm}$ para as mesmas regiões da fig.27A e também de pontos investigado nas margens da lesão 
Figura 28A - Espectros de autofluorescência com excitação em $532 \mathrm{~nm}$ comparando as bordas lateral direita e esquerda e a lesão com atipia moderada. Fotografia: lesão com crescimento exofítico

Figura 28B - Espectros de autofluorescência com excitação em $442 \mathrm{~nm}$ para as mesmas regiões da fig. $28 \mathrm{~A}$ e também das margens da lesão

Figura 29A - Espectros de autofluorescência com excitação em $532 \mathrm{~nm}$ comparando as bordas lateral direita e esquerda e a lesão (carcinoma epidermóide). Fotografia: lesão com crescimento exofítico e base pediculada

Figura 29B - Espectros de autofluorescência com excitação em $442 \mathrm{~nm}$ para as mesmas regiões da fig.29A e também das margens da lesão

Figura 30A - Espectros de autofluorescência com excitação em $532 \mathrm{~nm}$ comparando as bordas lateral direita e esquerda e a lesão (carcinoma epidermóide). Fotografia: lesão com crescimento exofítico e base pediculada

Figura 30B - Espectros de autofluorescência com excitação em $442 \mathrm{~nm}$ para as mesmas regiões da fig.30A e também das margens da lesão

Figura 31A - Espectros de autofluorescência com excitação em $532 \mathrm{~nm}$ comparando as bordas lateral direita e esquerda e a lesão (carcinoma epidermóide). Fotografia: lesão com crescimento exofítico e base séssil

Figura 31B - Espectros de autofluorescência com excitação em $442 \mathrm{~nm}$ para as mesmas regiões da fig.31A e também das margens da lesão

Figura 32A - Espectros de autofluorescência com excitação em $532 \mathrm{~nm}$ comparando as bordas lateral direita e esquerda e a lesão (carcinoma epidermóide). Fotografia: lesão com crescimento exofítico e áreas leucoplásicas e eritematosas

Figura 32B - Espectros de autofluorescência com excitação em $442 \mathrm{~nm}$ para as mesmas regiões da fig.32A e também das margens da lesão

Figura 33A - Espectros de autofluorescência com excitação em $532 \mathrm{~nm}$ comparando as bordas lateral direita e esquerda e a lesão (carcinoma epidermóide). Fotografia: lesão com crescimento exofítico e áreas leucoplásicas e eritematosas

Figura 33B - Espectros de autofluorescência com excitação em $442 \mathrm{~nm}$ para as mesmas regiões da fig.33A e também das margens da lesão

Figura 34A - Espectros de autofluorescência com excitação em $532 \mathrm{~nm}$ comparando as bordas lateral direita e esquerda e a lesão (carcinoma epidermóide). Fotografia: lesão ulcerada e com alto grau de invasividade 
Figura 34B - Espectros de autofluorescência com excitação em $442 \mathrm{~nm}$ para as mesmas regiões da fig.34A e também das margens da lesão

Figura 35 - Desenho esquemático da leitura com variação da distância radial (A) e da distância linear (B), em uma visão lateral da língua. O círculo central (verde) em A representa a sonda conduzindo o laser de excitação e os círculos periféricos (cinza) correspondem aos pontos de coleta com distribuição radial. Em B, a sonda de excitação e coleta posicionadas na mesma orientação vertical

Figura 36 - Desenho esquemático da absorção da fluorescência intrínseca pela hemoglobina tecidual. A seta azul representa a luz de excitação; as figuras em forma de sol, os fluoróforos endógenos emitindo fótons; e os círculos verdes, as hemoglobinas presentes no tecido

Figura 37 - Os espectros de fluorescência obtidos em tecido normal (borda D), carcinoma (lesão) e um ponto da margem da lesão (periferia) são comparados. Todo o espectro foi normalizado pela amplitude em $442 \mathrm{~nm} . Z_{1}$ e $Z_{2}$ representam as zonas de referência e interesse, respectivamente

Figura 38 - Os gráficos apresentam as quatro figuras determinadas para um animal. Note a comparação entre os diferentes sítios de investigação

Figura 39 - Gráficos Box-chart para o mesmo caso da figura 37 91

Figura 40 - Gráficos Box-chart para excitação em 442 e $532 \mathrm{~nm}$ de um animal com carcinoma epidermóide

Figura 41 - Gráficos Box-chart para excitação em 442 e 532 nm de um animal com carcinoma epidermóide

Figura 42 - Gráficos Box chart para excitação em 442 e $532 \mathrm{~nm}$ de um animal com carcinoma epidermóide

Figúra 43 - Gráficos Box-chart para excitação em 442 e 532 nm de um animal com carcinoma epidermóide

Figura 44 - Gráficos Box-chart para excitação em 442 e 532 nm de um animal com carcinoma epidermóide

Figura 45 - Coeficientes $A_{1}, A_{2}, A_{3}$, e $A_{4}$ determinados para a discriminação do tecido normal (azul) versus alterado (preto), que inclui as lesões com diagnóstico de atipias, carcinoma in situ e carcinoma epidermóide. Os resultados mostram a distribuição obtida em todos os animais dos grupos experimentais 
Figura 46 - Coeficientes $A_{1}, A_{2}, A_{3}$, e $A_{4}$ determinados para a discriminação do tecido normal (azul) versus carcinoma (vermelho). Os resultados mostram a distribuição obtida em todos os animais dos grupos experimentais 98

Figura 47 - Comparação dos coeficientes $\mathrm{A}_{1}, \mathrm{~A}_{2}, \mathrm{~A}_{2}$ e $\mathrm{A}_{4}$ determinados para cada tipo de tecido investigado: normal, hiperqueratose sem atipia, atipia leve, atipia moderada, atipia intensa, carcinoma in situ e carcinoma epidermóide

Figura 48 - Distribuição do número de amostras em função do limite normal versus carcinoma estabelecido para cada coeficiente

Figura 49 - Curvas ROC para os quatro coeficientes estabelecidos

Figura 50 - PCA para a investigação em $442 \mathrm{~nm}$, gráfico de PC1xPC2. As amostras em azul correspondem aos espectros coletados do tecido normal e as amostras em vermelho aos do carcinoma

Figura 51 - PCA para a investigação em $442 \mathrm{~nm}$, gráfico de PC2xPC3. As amostras em azul correspondem aos espectros coletados do tecido normal e as amostras em vermelho aos do carcinoma 107

Figura 52 - Resultados do KNN para excitação em 442 nm com o número de classificações falsas em função do número de vizinhos

Figura 53 - Comparação entre os índices de sensibilidade e especificidade obtidos para os fatores $A_{1}, A_{2}, A_{3}$ e $A_{4}$, e os melhores resultados para o KNN com excitação em $442 \mathrm{~nm}$ e $532 \mathrm{~nm}$ 110

Figura 54 - Curvas dos valores de sensibilidade e especificidade em função do limite para o coeficiente $\mathrm{A}_{1}$

Figura 55 - Curvas dos valores de sensibilidade e especificidade em função do limite para o coeficiente $\mathrm{A}_{3}$

Figura 56 - Espectros de fluorescência para a identificação e monitoramento temporal da porfirina, comparação entre quatro sítios de investigação 119

Figura 57 - Espectros de fluorescência para a identificação e monitoramento temporal da porfirina, comparação entre quatro sítios de investigação 120

Figura 58 - Espectros de fluorescência para a identificação e monitoramento temporal da porfirina, comparação entre quatro sítios de investigação 


\section{LISTA DE TABELAS}

Tabela I - Distribuição dos grupos experimentais

Tabela II - Diagnóstico das lesões para cada animal

Tabela III - Valores dos intervalos espectrais das zonas de referência e interesse

Tabela IV - Desempenho do diagnóstico pela espectroscopia de fluorescência (teste) em relação ao padrão ouro 100

Tabela V - Índices determinados para cada coeficiente. VP (verdadeiro-positivo), FN (falso-negativo), FP (falso-positivo), VN (verdadeiro-negativo), VPP (valor preditivo positivo), VPN (valor preditivo negativo)

Tabela VI - Matriz de erros para a análise KNN para as duas excitações. Entre parênteses está definido o número de vizinhos selecionado para a análise 108

Tabela VII - Índices de sensibilidade, especificidade e acurácia obtidos através da análise $\mathrm{KNN}$ para as duas excitações 109 


\section{RESUMO}

A validade da técnica de espectroscopia de fluorescência como método de diagnóstico de lesões induzidas em borda lateral da língua de hamsters sírios dourados foi avaliada no presente estudo. O modelo animal com indução química empregando o DMBA (dimetilbenzantraceno) foi escolhido por apresentar fases de carcinogênese comparáveis às encontradas no desenvolvimento do carcinoma oral em humanos. Os grupos experimentais foram avaliados a cada duas semanas após a $4^{\mathrm{a}}$ semana de indução por um período de até 26 semanas. $O$ sistema de espectroscopia de fluorescência utilizado é composto por: laser de excitação, sonda de investigação do tipo $\mathrm{Y}$, espectrômetro e computador. Dois comprimentos de onda foram empregados para excitação dos tecidos biológicos: 442 e $532 \mathrm{~nm}$. A sonda de investigação possui uma fibra central para entrega do laser de excitação e seis fibras concêntricas que coletam a luz re-emitida pelo tecido. A fluorescência é analisada no espectrômetro no intervalo entre 378 e $842 \mathrm{~nm}$. A investigação é pontual, e o resultado é um espectro por ponto. Após a leitura óptica, os animais foram sacrificados e a língua removida para análise histopatológica. A coleta dos espectros de autofluorescência foi realizada durante todo o desenvolvimento neoplásico e o estudo em função das características clínicas e principalmente do resultado histopatológico das lesões. Os espectros foram analisados de duas formas distintas: análise da correlação intra-espectral e análise inter-espectral através da análise de dados multivariados. A excitação em $442 \mathrm{~nm}$ produziu a melhor discriminação normal versus carcinoma. $O$ melhor resultado foi o obtido com o KNN, com índices de $95,7 \%$ de sensibilidade, $91,6 \%$ de especificidade e $94 \%$ de acurácia. No entanto, os resultados obtidos com a determinação dos coeficientes são considerados bons, quando da avaliação da validade do método, com 90,9\% de sensibilidade, $81,5 \%$ de especificidade e $87,1 \%$ de acurácia. Com a determinação adequada do limite de discriminação resultados semelhantes aos da quimiometria puderam ser obtidos. 


\begin{abstract}
The diagnostic validity of the fluorescence spectroscopy in the discrimination of induced lesions at lateral border of the tongue of hamsters was investigated in this study. The animal model using chemical induction with DMBA (dimethylbenzanthracene) was chosen for the carcinogenesis phases comparable to the ones observed at oral cancer development in humans. The experimental groups were evaluated at each two weeks after the first four induction weeks until a total of 26 weeks. The fluorescence spectroscopy system employed is composed by: excitation laser, Y-type investigation probe, spectrometer and a computer. Two excitation wavelengths were used: 442 and $532 \mathrm{~nm}$. The investigation probe has a central fiber for laser delivering and six concentric ones for reemitted light collection. The fluorescence is analyzed in the spectrometer in the 378-842 $\mathrm{nm}$ range. The optical investigation is punctual and the result is one spectrum per point. Then the animals were killed and the tongue removed for histopathological analysis. The spectra study was performed during the entire carcinogenesis process and the final analysis comparing to clinical and histopathological results. The spectra were evaluated in two ways: intra-spectral correlation analysis and inter-spectral analysis. The $442 \mathrm{~nm}$ excitation induced the best normal/carcinoma discrimination. The best result was achieved with the KNN analysis with $95.7 \%$ of sensitivity, $91.6 \%$ of specificity and $94 \%$ of accuracy. The discrimination using the intra-spectral analysis obtained $90.9 \%, 81.5 \%$ and $87.1 \%$ of sensitivity, respectively. However, using a discerning determination of the discrimination limit for classification it was possible to achieve similar results between the two employed analyses.
\end{abstract}




\title{
I. INTRODUÇÃO
}

O câncer é uma patologia que atinge cerca de dez milhões de pessoas da população mundial. O Relatório Mundial de Câncer, de três de abril de 2003, da Organização Mundial da Saúde (WHO - World Health Organization) alerta que as taxas globais de câncer podem aumentar em 50\%, resultando em cerca de 15 milhões de novos casos em 2020. O câncer em boca é englobado na classificação cabeça e pescoço ocupando atualmente a oitava posição dos tipos mais freqüentes [1]. Dados do ano de 2000 , relatam uma incidência mundial de 169.524 e 97.148 novos casos e mortalidade de 80.839 e 47.063 de pacientes do sexo masculino e feminino, respectivamente. $O$ Brasil contribui para esses números de incidência com 4\% para os homens e 2,16\% para as mulheres [2].

Nacionalmente, o câncer em cavidade oral, seguindo a tendência mundial, também é o oitavo tipo mais freqüente e as estimativas do INCa (Instituto Nacional do

\author{
IFSC-USP SERVICODE BIBLIOTECA
IUFORIMAÁ
}


Câncer) para o ano de 2005 é de que aproximadamente 13.880 novos casos sejam diagnosticados [3]. No entanto, as estatísticas sobre a incidência e a mortalidade não refletem fielmente o impacto que a doença tem sobre a qualidade de vida do paciente. $\mathrm{O}$ carcinoma bucal freqüentemente altera a aparência do paciente, a capacidade de comunicação e de alimentação e a aceitação social pela família e amigos.

O tabagismo e o etilismo são freqüentemente apontados como fatores associados ao aparecimento de tumores na cavidade oral, o tabaco está associado a $90 \%$ e $60 \%$ dos casos em pacientes do sexo masculino e feminino, respectivamente, e o álcool a $55 \%$ da totalidade dos casos [3]. O risco de desenvolvimento de câncer bucal está relacionado com a dose e o tempo de consumo, e o álcool e o tabaco quando associados atuam como co-fatores. Os hidrocarbonos aromáticos policíclicos são considerados os principais précarcinógenos do tabaco e são ativados a carcinógenos nas células por enzimas complexas microssomais, comumente referidas como hidroxilases aril-hidrocarbônica [4].

Wynder e colaboradores sugerem que o álcool age apenas como um promotor, e não um carcinógeno [5]. Rothman relata que o álcool age localmente como um solvente, - onde os carcinógenos do tabaco estão dissolvidos, promovendo um contato mais íntimo com o tecido susceptível [6]. McCoy ressalta que a oxidação do etanol nas células epiteliais pode alterar o metabolismo intracelular, criando um ambiente mais favorável para a ativação metabólica dos pró-carcinógenos [7]. Wight e Ogden citam três mecanismos pelos quais o álcool pode causar dano celular e contribuir para $o$ estabelecimento do carcinoma: o metabolismo do etanol produzindo o acetaldeído, uma substância altamente citotóxica; o aumento da permeabilidade das membranas celulares, 
secundário aos efeitos solventes diretos; e a disrupção do reparo do DNA [8]. O álcool e o tabaco, quando combinados atuam sinergicamente no processo de carcinogênese e não apenas com efeitos somatórios.

A anemia também é associada ao desenvolvimento de lesões no trato gastrointestinal superior. A deficiência em ferro promove alterações histológicas, o epitélio, mesmo com alta taxa de divisão celular, apresenta-se atrófico com depleção do compartimento de maturação. Como conseqüência, há uma maior população de células susceptíveis em divisão em um epitélio mais permeável [9].

Outros fatores que também são relacionados à complexa origem do câncer bucal são os viróticos e imunológicos. Parece existir uma predisposição genética para o aparecimento da doença, mas não é claro que seja um fator etiológico. Alguns agentes infecciosos, como o vírus do herpes simples, o Epstein-Barr e o papilomavírus, são associados como possíveis iniciadores da carcinogênese. Apesar de não ser clara a associação do desenvolvimento neoplásico e o fator imunológico, os pacientes imunodeprimidos são apontados por alguns autores como de alto risco para o desenvolvimento de várias lesões malignas, inclusive o câncer de boca $[4,10]$.

O carcinoma bucal normalmente acomete o paciente idoso do sexo masculino, etilista e tabagista, e a média de idade ao diagnóstico é ao redor de 60 anos [10]. O carcinoma epidermóide corresponde a mais de $90 \%$ dos casos de câncer oral e os principais sítios anatômicos afetados são lábio inferior, língua e o assoalho bucal $[4,10$, 11]. A localização em lábio também está associada à alta exposição solar, especialmente aos raios ultravioletas, sítio importante em países com alta exposição aos raios solares, como é o caso do Brasil. 
Clinicamente, o carcinoma epidermóide pode se apresentar como úlcera, leucoplásico e com uma forma exofítica, sendo as duas últimas os tipos de lesão mais freqüentes. A lesão ulcerada normalmente é assintomática e que não cicatriza, apresenta bordas elevadas, firmes e endurecidas. A base da úlcera pode apresentar uma superfície irregular, granular ou estar necrótica [10]

Cerca de $10 \%$ das lesões queratóticas em cavidade oral demonstram evidência histológica de displasia ou de transformação maligna. As placas são assintomáticas, um pouco elevadas, aderentes e podem ter áreas eritematosas entremeadas nas regiões leucoplásicas [10].

Quando como crescimentos exofíticos, os carcinomas podem apresentar-se como verrucoso, com a parte superior granulosa, papilar, com um pedúnculo largo. A lesão é firme e indolor e sua base pode mostrar-se eritematosa e endurecida [10].

A progressão neoplásica pode ser estimada por quatro níveis: (1) celular; (2) tecidual, avaliando o grau de extensão e a metástase nodal; (3) citocelular, como a variação do tamanho e da forma nuclear, e a textura da cromatina; e (4) molecular, como alterações genômicas. Classicamente, a progressão morfológica da neoplasia intraepitelial é iniciada por uma evidente hiperplasia das células da camada basal, sem anormalidades citológicas, e usualmente acompanhada pela presença de uma membrana basal irregular. A progressão para uma displasia leve, além do quadro anterior, apresenta alterações citológicas com aumento da razão núcleo/citoplasma, hipercromatismo nuclear e cromatina irregular, que estão restritas à camada basal, ou seja, a aproximadamente um terço da espessura total do epitélio. Na displasia moderada, essas alterações atingem cerca de metade do tecido epitelial, a porção superior da camada 
espinhosa é desorganizada e há perda da polaridade normal. A displasia severa ou o carcinoma in situ apresenta o envolvimento de quase a totalidade da espessura do epitélio, sem evidência de maturação. As células disqueratóticas são mais freqüentes e a camada espinhosa é desorganizada, sendo difícil sua identificação, no entanto, as camadas superficiais podem apresentar algum tipo de maturação. O carcinoma invasivo é caracterizado pelas alterações citológicas citadas, com a perda de coesão e o desprendimento de células do compartimento epitelial através da membrana basal como a principal evidência histológica [12]. A lesão iniciada em tecido epitelial pode progredir para os tecidos adjacentes acometendo o tecido conjuntivo, camadas musculares, assim como células neoplásicas podem invadir vasos sanguíneos e/ou linfáticos e serem transportadas para outras regiões do mesmo órgão ou até do restante do organismo.

O tratamento oncológico envolve desde a utilização de programas preventivos, passando por procedimentos de diagnóstico, até os recursos para o tratamento propriamente dito. Para qualquer tipo de câncer, o diagnóstico precoce é um dos fatores mais importantes para o prognóstico do paciente. As lesões iniciais são mais facilmente controladas e eliminadas, e no caso dos tumores orais, menor será a mutilação do paciente. A deteç̧ão e o diagnóstico da lesão inicial assintomática é um dos principais desafios do cirurgião-dentista na clínica diária.

Usualmente, o carcinoma oral somente é diagnosticado quando a lesão se torna sintomática e invasiva, ou quando ocorre metástase para os linfonodos cervicais [13]. Não raramente, o carcinoma na fase inicial é confundido com úlceras benignas, lesões traumáticas ou até alterações do tecido mole. Carcinomas gengivais podem ser, por 
exemplo, confundidos com uma alteração local ocasionada pela doença periodontal. As lesões iniciais do carcinoma oral podem se apresentar de diversas formas clínicas e não exibem as drásticas alterações associadas ao câncer, podendo ser assim diagnosticadas incorretamente. Além disso, a característica clínica do carcinoma de desenvolvimento assintomático e indolor, acarreta em muitos casos em um diagnóstico mais tardio, uma vez que o paciente, por não perceber a lesão ou então por não estar incomodado com o quadro, procura tratamento tardiamente.

As lesões iniciais podem aparecer como áreas assintomáticas com alteração superficial de coloração e textura; como lesões pontualmente avermelhadas, brancoavermelhadas ou leucoplásicas; áreas de endurecimento ou ulceração; ou como tumor infiltrativo [14].

As neoplasias são estadiadas, segundo o tamanho do tumor primário, comprometimento dos linfonodos regionais e presença ou não de metástases distantes $[10,15]$. Dependendo do estadiamento da lesão, o tratamento será planejado assim como o prognóstico é estabelecido. No caso das lesões orais, a maior preocupação se refere ao comprometimento dos nódulos linfáticos da cadeia submandibular e cervical, fator que leva à uma disseminação incontrolada.

A ressecção cirúrgica é o tipo de procedimento mais empregado para o tratamento das lesões orais neoplásicas, podendo ou não estar associada à radioterapia; a quimioterapia também pode ser utilizada para determinados tipos de lesões $[16,17]$. Mais recentemente outra técnica não cirúrgica passou a ser alternativa no tratamento de tumores da cavidade oral, a terapia fotodinâmica (PDT - Photodynamic Therapy), baseada no uso de um agente fotossensibilizador, com afinidade por células neoplásicas, 
que ao ser fotoativado e na presença de oxigênio molecular, desencadeia uma série de reações citotóxicas, promovendo processos de morte celular por necrose e/ou apoptose [18-20].

Para qualquer um dos procedimentos terapêuticos, o tratamento das lesões é simplificado quando em estágio inicial, nestes casos, a resseç̧ão cirúrgica promove uma menor deformação residual, a irradiação de tecidos sadios é minimizada e conseqüentemente os efeitos colaterais adversos são mais restritos. O diagnóstico precoce seguido pelo tratamento pode aumentar a taxa de sobrevida de $50 \%$ a aproximadamente $80 \%$ [21]. Em vista disso, torna-se evidente a importância do desenvolvimento de novas e das já existentes técnicas de diagnóstico para a deteção precoce de lesões neoplásicas, principalmente considerando maiores porcentagens de especificidade e sensibilidade, minimizando os resultados falso-positivos e falsonegativos.

Convencionalmente, o diagnóstico de lesões em tecidos moles da cavidade oral é realizado baseado na avaliação clínica e histopatológica. Após a determinação pelo clínico de uma área suspeita, o paciente é submetido a uma biópsia, procedimento cirúrgico no qual uma amostra tecidual da lesão ou a sua totalidade é removida, e o material coletado é processado para coloração em hematoxilina e eosina que permite a análise em microscopia de luz das características celulares e estruturais do tecido [22]. $O$ padrão considerado ouro para o diagnóstico de lesões é a histopatologia, porém, a determinação do tipo da patologia depende da sensibilidade e experiência do patologista em reconhecer os sinais celulares e teciduais representativos de cada entidade. Aumento do tamanho celular, densidade, pleomorfismo e a hipercromasia (aumento do conteúdo 
de cromatina) são características chaves usadas pelos patologistas para discriminação de displasias. Adicionados a essas características, os sinais de malignidade estão presentes quanto maiores forem as variações em comparação ao padrão celular e histológico normal como diminuído grau de organização das camadas celulares, presença de diferenciação celular, hiper-população celular, alta atividade mitótica, desprendimento de ilhotas de células epiteliais, dentre outros. Em alguns casos dois patologistas podem discordar em relação ao diagnóstico final e isso terá efeito direto no planejamento do tratamento, assim considera-se o diagnóstico final apenas após a avaliação de pelo menos três profissionais. Além disso, nos casos em que o clínico não realizou uma adequada escolha do sítio de biópsia o material coletado pode não ser representativo da lesão. Desta forma, mesmo com índice de $99 \%$ de acerto, o que se pode aferir é que a técnica convencional para o diagnóstico de lesões malignas é subjetiva, dependente da experiência do clínico e do patologista.

O desenvolvimento de técnicas baseadas em critérios de diagnóstico mais objetivos é uma tendência atual e é de grande relevância para minimizar o grau de subjetividade da técnica convencional. Nesse sentido, a biópsia óptica vem sendo apresentada como uma técnica para a deteç̧ão de lesões, e, portanto, auxiliar no diagnóstico. Existem dois tipos de análise: uma baseada na fluorescência (emissão espontânea) e a outra no espalhamento inelástico (espectroscopia Raman). A fluorescência pode ser utilizada na investigação por imagem, microscopia e espectroscopia. Todas essas técnicas buscam uma análise mais quantitativa, na tentativa de graduar as lesões, partindo do tecido normal, passando por displasias e tumores benignos, até as neoplasias [23-26]. 
A fotodeteção por fluorescência vem sendo apontada como uma técnica alternativa para a diferenciação dos tecidos biológicos, não apenas para o diagnóstico de lesões tumorais, como também para a investigação de alterações no estado metabólico das células [23-27].

Quando um material é fotoexcitado, a energia recebida na forma de fótons faz com que os elétrons sejam transferidos de uma camada de menor energia para uma de maior energia. Esse estado não é estável e os elétrons excitados decairão retornando à camada de menor energia, liberando o excesso de energia. Uma das formas permitidas do processo de decaimento é um fenômeno radiativo denominado fluorescência, ou seja, a re-emissão de fótons [28-30].

A fluorescência é definida como uma transição radiativa entre dois estados eletrônicos de mesma multiplicidade spin (singlete ou triplete). A maioria das moléculas orgânicas possui elétrons emparelhados na sua configuração orbital do estado molecular fundamental. Os spins são equilibrados $(\mathrm{S}=0)$ e a multiplicidade spin é singlete. Quando ocorre uma inversão de spin do elétron excitado, o resultado são dois elétrons desemparelhados com spin de mesma orientação ( $\mathrm{S}=1$ ), e conseqüentemente, o estado triplete. O tipo mais comum é a transição singlete-singlete, especialmente entre o primeiro estado singlete excitado $(\mathrm{S} 1)$ e o estado fundamental $(\mathrm{S}=0)$ [28].

O processo de absorção de energia envolve a interação da molécula em S0 com um fóton, promovendo a transferência de um elétron de um orbital molecular de menor energia para um de maior energia. O tipo mais simples de fluorescência, em termos fotofísicos, seria o inverso do processo de absorção, i.e., emissão de luz de comprimento de onda idêntico ao da luz absorvida. Esse tipo de fluorescência, denominado 
ressonante, pode ser observado proveniente de átomos ou gases moleculares a pressões muito baixas, no entanto, não é usualmente observado em moléculas maiores nos estados condensados, como líquidos e sólidos. Isso pode ser explicado pelo fato de que a perda de energia por vibração, através de colisões intermoleculares, ocorre mais rapidamente do que o processo de emissão de fluorescência. Como resultado, a fluorescência geralmente é proveniente do menor nível vibracional do estado eletrônico excitado. A energia do fóton emitido será significantemente inferior à do fóton absorvido e a fluorescência é deslocada em direção à região do vermelho do espectro eletromagnético, considerando a absorção. A transição associada à emissão de um fóton é tão rápida, que não é observada nenhuma alteração na configuração nuclear durante o processo [28-30].

O espectro de emissão resultante da fluorescência reflete os níveis vibracionais do estado eletrônico fundamental, desta forma podendo ser empregado para a caracterização e identificação da molécula [29, 30].

A técnica de fluorescência é muito utilizada no estudo de materiais para a determinação da sua composição química. Isso é possível uma vez que cada composto tem uma fluorescência característica dependendo da energia de excitação, permitindo a sua diferenciação dentre diversos componentes. Nos materiais de estrutura cristalina é até possível a quantificação ou determinação da concentração de determinado analito dentro de uma mistura, já que a intensidade de fluorescência será diretamente proporcional à quantidade presente. No tecido biológico, onde a complexidade química e estrutural é bem maior, a avaliação passa a ser bastante difícil. A luz re-emitida pelo 
tecido será resultante de diversos fatores, sendo complexa a análise isolada de cada fator.

Os cromóforos presentes no tecido biológico são de três tipos principais: fluoróforos (grupos químicos que podem converter a luz absorvida em fluorescência), absorvedores (grupos químicos que absorvem luz e não produzem fluorescência) e espalhadores (estruturas que alteram a direção do fóton incidente, mas conservam sua energia). As propriedades ópticas de cada cromóforo dependerão do comprimento de onda de excitação e do tipo de tecido, uma vez que a maioria dos cromóforos é sensível ao ambiente em que se encontra, e em particular ao estado metabólico tecidual [28, 30].

Os tecidos biológicos são opticamente turvos, em decorrência disso, os fenômenos de espalhamento e absorção têm maior probabilidade de ocorrer do que a conversão em fluorescência. Uma luz monocromática incidente na superfície do tecido será espalhada intersticialmente, sendo que pode ser absorvida ou difusamente refletida. A luz absorvida pode ser convertida para fluorescência, que por sua vez será espalhada e pode ser reabsorvida ou re-emitida pela superfície do tecido. Um exemplo da reabsorção da luz fluorescente que pode ocorrer é a promovida pela hemoglobina. A fluorescência re-emitida detectada na superfície tecidual é resultado da contribuição não apenas dos fluoróforos, mas também dos absorvedores e espalhadores teciduais [30, 31].

Além da composição química, outro fator relevante para a fluorescência é a arquitetura do tecido alvo e suas características ópticas, alterando a interação luz/tecido. Assim, a razão para a eficácia da biópsia óptica, é a de que a lesão, diferindo do tecido normal em composição química e em arquitetura, produzirá uma fluorescência distinta, possibilitando a discriminação dos tecidos. 
A utilização de sistemas laser para a excitação do tecido a ser investigado pode ser interessante, uma vez que a monocromaticidade possibilita uma maior seletividade de excitação dos fluoróforos tornando o processo mais eficiente e, portanto, mais evidente a sua identificação. A região mais usada para excitação de tecidos biológicos é a região ultravioleta do espectro eletromagnético, com fótons de alta energia e com alta absorção pelos tecidos biológicos. A região inicial do espectro visível - violeta, azul e verde - também pode ser empregada com ligeiro aumento do volume tecidual excitado uma vez que a profundidade de penetração no tecido biológico é comparativamente maior. Dependendo da luz de excitação empregada, a absorção pelos componentes teciduais será diferente e conseqüentemente haverá a contribuição de biomoléculas distintas para a fluorescência resultante.

Os principais fluoróforos endógenos são os nucleotídeos piridínicos, os aminoácidos aromáticos, as proteínas estruturais e as porfirinas [28, 31, 32]. DaCosta e colaboradores realizaram um extenso estudo com a determinação das matrizes de emissão-excitação para os conhecidos e prováveis fluoróforos e cromóforos biologicamente relevantes [33].

A nicotinamida adenina dinucleotídeo é o principal receptor de elétron, o anel nicotinamínico da sua forma reduzida (NADH) é fluorescente. A flavina adenina dinucleotídeo é outro importante receptor de elétrons, sua forma oxidada (FAD) é fluorescente. O NADH e as flavinas têm importante função no metabolismo energético da célula $[28,30,31,33]$.

Dentre os aminoácidos aromáticos, o triptofano é o principal contribuinte da fluorescência emitida pelas proteínas, os outros são a tirosina e a fenilalanina. Para 
comprimentos de onda acima de $295 \mathrm{~nm}$ apenas o triptofano é excitado, sendo que sua emissão é sensível à polaridade do ambiente [28, 30,31,33].

O colágeno e a elastina são as proteínas estruturais que contribuem para a autofluorescência tecidual. A emissão está associada à presença das ligações cruzadas entre as cadeias de aminoácidos [28, 30, 31, 33].

As porfirinas são comumente citadas especialmente na fotodeteç̧ão de tecidos tumorais como um dos principais responsáveis pela fluorescência vermelha emitida. Isso pode ser explicado pela maior concentração das porfirinas em tecidos neoplásicos, em comparação com os tecidos normais [28].

Lipopigmentos, produtos finais do metabolismo de lipídeos também são apontados como contribuintes da autofluorescência dos tecidos biológicos $[28,30,31$, 33].

Os absorvedores que influenciam o espectro de fluorescência mensurado no tecido, na região UV e visível são as proteínas e a hemoglobina, que podem absorver a fluorescência mascarando e minimizando a luz que será coletada da superfície tecidual investigada [30].

O espalhamento elástico da luz nos tecidos biológicos ocorre devido às heterogeneidades microscópicas dos índices de refração entre componentes extracelulares, celulares e subcelulares. $\mathrm{O}$ intenso espalhamento permite a propagação da luz visível de 0,5 a $1,0 \mathrm{~mm}$ dentro do tecido, e assim, a extração não-invasiva de informação desse volume tecidual. A complexidade e variabilidade das estruturas celulares e dos componentes teciduais fazem com que seja muito difícil prever o 
comportamento da luz no interior dos tecidos biológicos, e conseqüentemente da fluorescência produzida [30].

A fluorescência pode ser utilizada para a obtenção de uma imagem ou então para avaliação espectroscópica. No primeiro caso, é possível a visualização macroscópica da lesão, e em algumas até a delimitação das margens com o tecido sadio adjacente [3437]. A imagem é obtida após a excitação do tecido com uma luz de comprimento de onda adequado e posterior coleta através de uma câmera com filtro, selecionando a região da fluorescência característica [28, 32]. A espectroscopia de fluorescência permite uma análise mais detalhada da luz emitida, com a obtenção da intensidade para cada comprimento de onda, neste caso a investigação é por ponto analisado. Usualmente um sistema composto por um laser de excitação, uma ponteira de aplicação para entrega e coleta da luz e um monocromador é utilizado. Nessas duas técnicas o contraste fornecido pela fluorescência é baixo, uma vez que outros fenômenos radiativos como o espalhamento e a absorção são muito mais evidentes. Além disso, as heterogeneidades nas propriedades ópticas do complexo tecido biológico ocasionam uma alta variabilidade da autofluorescência. Isso é especialmente observado na espectroscopia pontual onde o espectro de fluorescência resultante pode ser alterado dependendo da pressão exercida durante a leitura e conseqüente remoção momentânea do aporte sanguíneo, além dos efeitos de interface. Na iluminação de uma grande área, como é o caso da fluorescência por imagem, a distorção pode ser decorrente das heterogeneidades na absorção e no espalhamento da luz no tecido alvo e a intensidade do sinal detectado dependerá da distância detetor/superfície tecidual [32]. 
$\mathrm{Na}$ investigação da autofluorescência para a discriminação dos tecidos neoplásicos e normais, os principais fluoróforos endógenos apontados como biomarcadores da malignização são: porfirinas, NADH, flavinas e colágeno. Alterações bioquímicas e estruturais decorrentes do processo de carcinogênese são responsáveis pela variação nas concentrações desses compostos, assim como nas dos absorvedores e espalhadores, como conseqüência, o espectro emitido é modificado.

Devido à complexidade e variabilidade dos cromóforos e fluoróforos endógenos, vários estudos vêm sendo realizados para a determinação do melhor comprimento de onda para excitação da autofluorescência para cada tipo tecidual. Em alguns estudos são selecionados alguns comprimentos de onda [38-40], em outros se determinam as matrizes de fluorescência excitação/emissão, utilizando uma lâmpada para excitação e uma série de filtros para a seleção de regiões espectrais [25, 27, 33, 41].

A porfirina vem sendo relatada como um dos possíveis componentes que mais contribuem para a fluorescência das lesões neoplásicas, já que é encontrada naturalmente em maior quantidade em comparação aos tecidos sadios. As porfirinas produzem uma fluorescência na região vermelha do espectro eletromagnético, com picos de emissão característicos [42, 43].

A protoporfirina IX é uma complexa estrutura orgânica na forma de anel que compõe um grupo prostético denominado heme. Um átomo de ferro no estado ferroso $\mathrm{Fe}^{2+}$ se liga ao anel porfirínico e somente neste estado possibilita o transporte do oxigênio. Esse grupo prostético é encontrado principalmente ligado a proteínas transportadoras de oxigênio, hemoglobina e mioglobina, e a outras proteínas como o citocromo que participa das reações de óxido-redução (transferência de elétrons) [44]. 
M. Inaguma e K. Hashimoto estudaram a autofluorescência espectral in vivo de lesões orais malignas e benignas com comportamento semelhante à fluorescência da porfirina (porfirina-fluorescência). Nas lesões benignas o resultado negativo, i.e. sem porfirina-fluorescência, foi obtido em $93 \%$ e nas lesões malignas o resultado positivo em $85 \%$ das lesões histologicamente comprovadas. A eletroforese por capilar realizada no material de três biópsias de carcinoma epidermóide revelou a presença da protoporfirina IX e Zn-protoporfirina IX, no entanto os autores relatam a grande variabilidade qualitativa e quantitativa da excreção de porfirina que pode estar presente em cada carcinoma sendo provavelmente decorrente de uma correlação entre o metabolismo da porfirina e o câncer oral individualmente [45].

Vários autores relatam a fluorescência emitida, após excitação no ultravioleta (UV) próximo, na região de $500 \mathrm{~nm}$ reduzida em tecidos tumorais comparando com tecidos sadios adjacentes, como resultado da diminuição das flavinas na forma reduzida e da quantidade relativa de $\mathrm{NADH}[46,47]$.

B.K. Majunath e colaboradores estudaram a autofluorescência induzida por laser pulsado em diferentes comprimentos de onda em material de biópsia oral e verificaram que a razão entre o $\mathrm{NAD}(\mathrm{P}) \mathrm{H}$ e o colágeno parece ser um bom fator de discriminação para tecido normal versus neoplásico, quando da excitação em 325 nm [40]. Outro trabalho que também apresenta o NADH e o colágeno como importantes biomarcadores para alterações pré-malignas é o de I. Georgakoudi e colaboradores apresentando resultados para a detecção de displasia no epitélio escamoso da cérvice uterina e no epitélio colunar do esôfago de Barrett [48]. 
Uma tendência atual é a associação de duas ou mais técnicas para o diagnóstico óptico, uma delas é conhecida como espectroscopia trimodal, onde são investigadas a autofluorescência intrínseca, a reflectância difusa e a luz espalhada. Em um estudo in vivo em pacientes, M.G. Müller e colaboradores avaliaram as alterações morfológicas e bioquímicas presentes no carcinoma oral na fase inicial. Os autores obtiveram uma sensibilidade de $96 \%$ e uma especificidade de $96 \%$ para a discriminação dos tecidos alterados (displasia/carcinoma) em função dos tecidos normais e uma sensibilidade de $64 \%$ e especificidade de $90 \%$ na discriminação entre displasia e carcinoma [27].

Um método para amplificar o sinal de fluorescência emitido e assim o contraste entre o normal e o neoplásico, é o uso de precursores de fluoróforos endógenos ou de fluoróforos exógenos marcadores de malignidade. O precursor de fluoróforo endógeno mais comum é o ácido aminolevulínico (ALA), que entra na cadeia de biossíntese da protoporfirina IX [49-51]. Os fluoróforos exógenos mais empregados são os agentes fotossensibilizadores empregados na terapia fotodinâmica, como os derivados de hematoporfirina, que permanece retido em maior concentração em tecidos neoplásicos [52-54]. No caso da imagem por fluorescência, a coloração avermelhada ou alaranjada da lesão sensibilizada se torna mais evidente em comparação com o tecido sadio, e na espectroscopia, os picos de emissão da porfirina podem ser mais facilmente identificados. A grande vantagem dessa fluorescência marcada é o aumento proporcionado da intensidade de emissão, mas ainda não está completamente esclarecido se existe realmente um maior contraste entre o tecido normal e o alterado e entre o tecido displásico e o tecido maligno, podendo haver uma maior quantidade de resultados falso-positivos, principalmente quando da sensibilização sistêmica do 
marcador. Isso dependerá principalmente do poder de seletividade do corante empregado, porém as razões para a maior seletividade de interação corante/célula maligna ainda não estão bem definidas. A grande desvantagem do uso dos marcadores exógenos é a possibilidade de toxicidade ao organismo; no caso dos fotossensibilizadores para terapia fotodinâmica, existe a fotossensibilidade dérmica induzida. Nesse sentido, o uso da fluoresceína como marcador exógeno pode ser uma alternativa.

V.V Lazarev e colaboradores investigaram o uso da fluoresceína e um sistema endoscópico de fluorescência por imagem na detecção de lesões pré-malignas quimicamente induzidas em hamsters. Os autores obtiveram como resultados uma sensibilidade de $90 \%$ na discriminação tecido normal versus displasia, no entanto não obtiveram resposta na diferenciação dos diversos graus de displasia. Além disso, eles comentam que os resultados de um outro grupo investigando em câncer de mama o uso da fluoresceína, mostraram um mesmo nível de valor crítico (razão da concentração do marcador), podendo significar que a discriminação entre displasia e carcinoma também pode não ser viável [55].

A informação fornecida pela espectroscopia de fluorescência apresenta muitas variáveis, i.e. para cada amostra e cada excitação, a resposta é fornecida pela intensidade emitida em cada comprimento de onda no intervalo espectral de coleta. Os diversos comprimentos de onda de emissão são as variáveis do conjunto de dados obtidos. Em algumas situações, comprimentos de onda diversos podem ter um comportamento semelhante, fornecendo o mesmo tipo de informação. A análise de dados multivariados vem sendo utilizada para o tratamento desse tipo de dados para estabelecer componentes 
principais com maior número de informações relevantes para a resposta que se deseja extraídos a partir de um conjunto de dados complexos. $O$ objetivo final desse tipo de análise é, no caso do diagnóstico, aumentar os índices de sensibilidade, especificidade e acurácia, fatores que são usados para avaliar a validade de um instrumento ou técnica de diagnóstico. Até uma nova área da química foi estabelecida, a quimiometria, que inicialmente foi empregada apenas nessa área, mas que atualmente vem sendo utilizada em diversas áreas como as da saúde, das indústrias de alimentos e farmacêutica dentre outras [56]. Softwares de quimiometria são encontrados no mercado para a análise dos dados multivariados com diversas ferramentas matemático-computacionais, assim como rotinas para o Matlab estão disponíveis gratuitamente na internet [57].

Vários trabalhos vêm sendo apresentados usando a análise de dados multivariados e os resultados obtidos mostram alta sensibilidade e especificidade para a discriminação entre tecido normal e alterado, porém a sensibilidade é baixa para a discriminação displasia versus carcinoma $[25,26,58]$. Ainda é preciso estabelecer todas as fases envolvidas no processo de carcinogênese e quais as alterações nos componentes celulares e teciduais que induzem modificações qualitativas e quantitativas no espectro de fluorescência intrínseca.

As vantagens apontadas para a biópsia óptica em comparação com a biópsia convencional são: procedimento não-invasivo, resposta em tempo real, possibilidade de varredura de áreas extensas e multifocais. Esses fatores são relevantes quando o câncer oral é considerado, uma vez que devido à etiologia da doença, as lesões são freqüentemente multicêntricas, além de poder auxiliar na escolha do sítio mais adequado para coleta do material para a biópsia convencional, procedimento de grande 
importância para o diagnóstico [10,13-17]. Os pacientes oncológicos de cavidade oral devem ser constantemente monitorados, pois o aparecimento de novos focos de cancerização é freqüente.

A melhor indicação da biópsia óptica seria na deteç̧ão de lesões pré-clínicas e de lesões cancerizáveis, ou seja, o diagnóstico de lesões que clinicamente não são detectáveis ou que possuem identificação duvidosa. Nesses casos, essa técnica seria extremamente valiosa como auxiliar no diagnóstico, já que a deteç̧ão de francos carcinomas normalmente não gera dúvidas. O clínico poderá utilizar os dados fornecidos pela fluorescência como mais uma informação a ser analisada para o estabelecimento do diagnóstico, tornando o resultado mais confiável.

Inicialmente é necessária a determinação de padrões de fluorescência dos diversos tipos de tecidos, normais e alterados, e das diversas regiões anatômicas da cavidade oral. A partir do estabelecimento dessas "identidades, impressões digitais, ou assinaturas espectroscópicas" do normal e do patológico, pode-se realizar a identificação de estruturas de fluorescência que evidenciem uma alteração espectral anterior a alterações clínicas.

O estudo em modelo experimental é uma alternativa bastante viável para a realização da investigação em diferentes fases do processo de carcinogênese, permitindo a determinação dos padrões de fluorescência e sua comparação com as características clínicas e os achados histológicos do tecido normal e das lesões analisadas. Os modelos em animais para estudo do processo de carcinogênese utilizam principalmente meios químicos para a indução [59-61]. Os trabalhos de tumores em cavidade oral utilizam principalmente um composto hidrocarbono aromático policíclico, o 
dimetilbenzantraceno (DMBA) em diversas localidades sendo as principais em mucosa da bolsa jugal, borda lateral da língua e palato de hamsters.

O potencial carcinogênico do DMBA foi amplamente estudado, sendo que sua ação é relatada nos três fenômenos biológicos fundamentais da carcinogênese, iniciação, promoção e progressão, simplificando a indução química com uma única droga [62].

A escolha pela borda lateral da língua como o sítio de indução química das lesões ocorreu devido à localização anatomica freqüentemente encontrada nos pacientes de câncer oral, além de constituir um sito anatômico de complexa evolução terapêutica quando em estágios mais avançados [63, 64]. Fassoni e colaboradores [61], no estudo em borda lateral da língua de hamsters sírios dourados (Mesocricetus auratus), relatam que o DMBA produz lesões cancerizáveis e carcinomas passíveis de serem acompanhados macro e microscopicamente em vários períodos experimentais a serem estabelecidos. 


\section{OBJETIVO}

O objetivo desse estudo foi a avaliação da validade da espectroscopia de fluorescência induzida com laser em 442 e 532 nanômetros como método de diagnóstico in vivo de lesões quimicamente induzidas em borda lateral da língua de hamsters sírios dourados. 


\section{MATERIAIS E MÉTODO}

1. Modelo animal para a carcinogênese quimicamente induzida

A indução química do carcinoma em cavidade oral com DMBA - (dimetilbenzantraceno) é usualmente empregada em modelos animais para estudos com enfoque oncológico. A escolha por um modelo em borda lateral da língua de hamsters foi realizada em função da localização, que é um dos principais sítios de câncer na cavidade oral e por ser um trabalho já bastante reproduzido.

Nesse trabalho a indução química foi realizada através da aplicação tópica do DMBA $(7,12$ dimetilbenzantraceno, Sigma-Aldrich) na borda lateral esquerda da língua de hamsters sírios dourados, seguindo o modelo proposto Fassoni et al [61]. 
A indução química foi realizada através do pincelamento na porção médiaposterior da borda lateral esquerda dos animais, com um pincel de pêlo de camelo, três vezes por semana por um período total de até 26 semanas, na concentração de $0,5 \% \mathrm{em}$ acetona (figura 1). A primeira aplicação foi realizada nos animais com 4 semanas de idade e peso aproximado de $125 \mathrm{~g}$. Os animais eram mantidos sem o bebedouro por um período de seis horas após a aplicação do DMBA, para minimizar a deglutição e o espalhamento da solução pelo restante da cavidade oral. Durante todo o período do experimento, os animais foram mantidos em gaiolas com até seis indivíduos, ração balanceada e água ad libitum. A distribuição dos grupos experimentais é apresentada na tabela I, mostrando os tempos de investigação do estudo. Inicialmente, cada grupo era constituído por seis animais, no entanto, alguns óbitos ocorreram durante o experimento, principalmente nos grupos com maiores tempos de indução. $O$ grupo controle foi constituído por 10 animais que não tiveram nenhum contato com o DMBA, uma vez que apesar da aplicação tópica, não é possível evitar que parte da substância carcinogênica seja espalhada pela cavidade oral em decorrência da presença da saliva e deglutição, fato que poderia mascarar e alterar os resultados comparativos com o tecido normal da borda lateral sem indução química. 


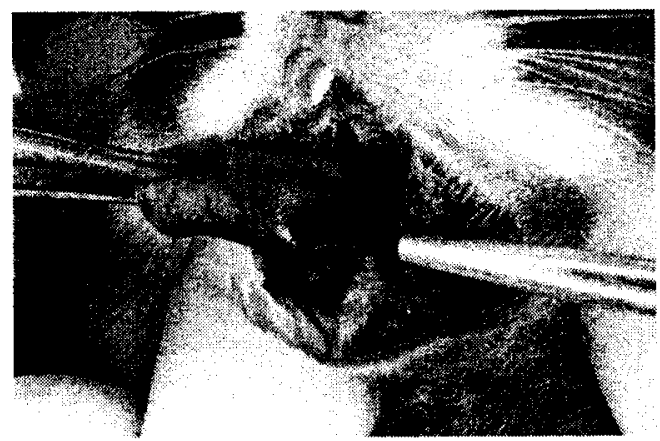

Fig. 1 - Aplicação tópica da solução de DMBA na borda lateral esquerda de um dos animais.

Os animais foram manipulados sem o auxílio de métodos anestésicos, apenas com a mobilização, abertura bucal e tracionamento da língua, evitando assim maiores problemas decorrentes da administração periódica e prolongada de drogas anestésicas.

Essa parte do projeto foi desenvolvida no Biotério da Faculdade de Odontologia de São José dos Campos da Universidade Estadual Paulista Júlio de Mesquita Filho, sob coordenação do Prof. Dr. Luiz Eduardo Blumer Rosa, do Departamento de Biociências e Diagnóstico Bucal.

Os grupos experimentais diferiram entre si pelo tempo de indução química da lesão. Os animais foram investigados a partir da quarta semana de indução e com um intervalo de 2 semanas entre um grupo e outro. 


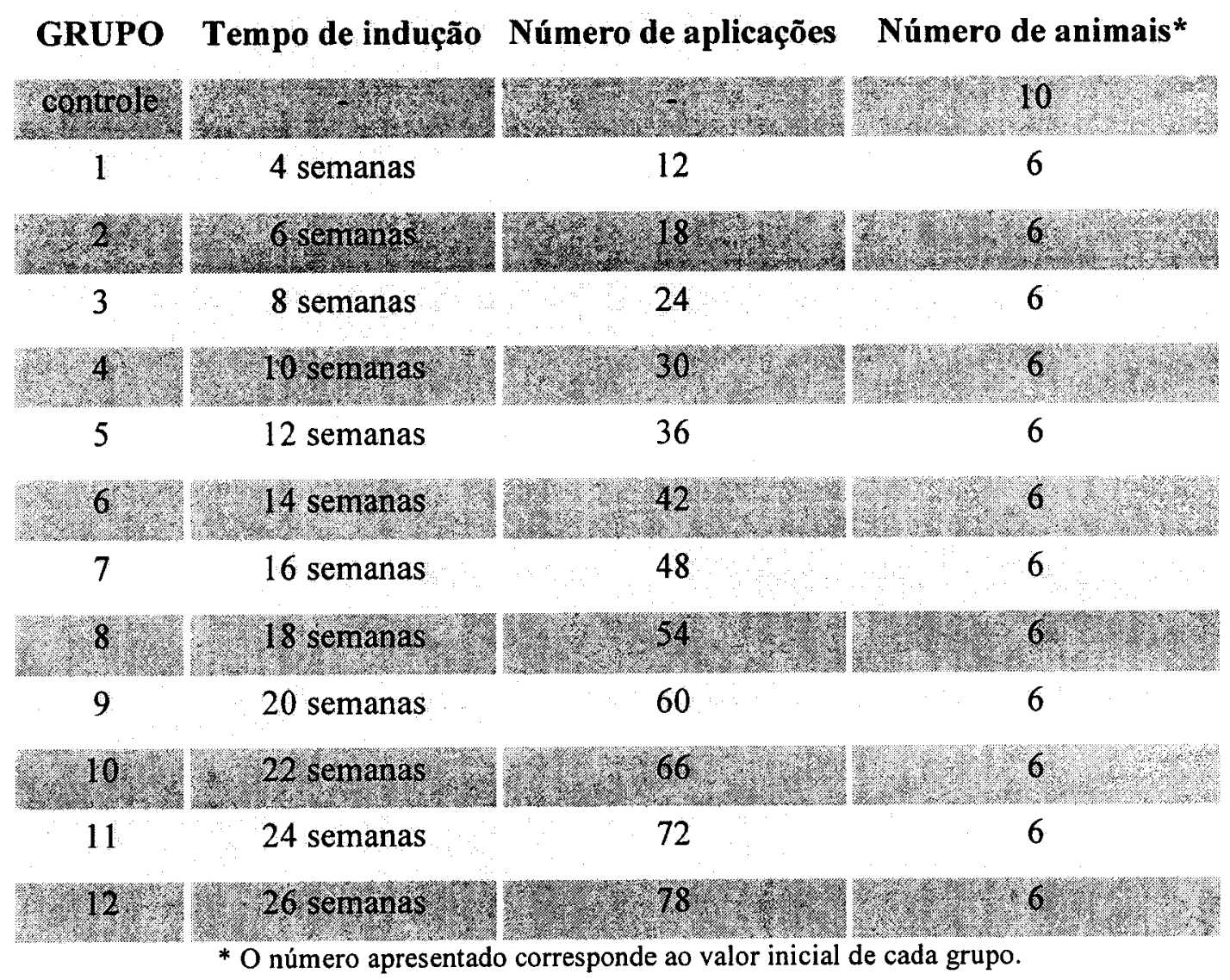

\section{Avaliação clínica das lesões induzidas}

Os animais foram previamente anestesiados com uma solução de $0,08 \mathrm{ml} / 100 \mathrm{~g}$ de ketamina (Francotar ${ }^{\circledR}$, Virbac do Brasil Ind. e Com. Ltda, Roseira, SP, Brasil) associada a $0,04 \mathrm{ml} / 100 \mathrm{~g}$ de cloridrato de xilazina (Virbaxyl ${ }^{\circledR}$, Virbac do Brasil Ind. E Com. Ltda, Roseira, SP, Brasil) via intramuscular. A cavidade oral foi higienizada usando hastes 
plásticas com pontas de algodão embebidas em solução de cloreto de sódio $0,9 \%$ para remoção de resíduos de alimento. Nenhuma solução pigmentada ou de desinfecção química foi utilizada para evitar alterações teciduais superficiais, como alteração de cor ou desidratação.

As mucosas orais e a língua, mais detalhadamente, foram avaliadas considerando alterações superficiais de cor e forma que pudessem evidenciar o estabelecimento clínico de alteração da normalidade. As lesões em borda lateral esquerda da língua foram fotografadas digitalmente e lesões em outras regiões anatômicas também foram identificadas, no entanto, apenas as lesões do sítio de indução foram utilizadas para a análise histopatológica.

\section{Investigação pela espectroscopia de autofluorescência}

\subsection{Sistema de diagnóstico}

O sistema de diagnóstico utilizado nesse estudo é composto por um laser de excitação, uma sonda de aplicação do tipo Y, um espectrômetro e um computador ("Spectr-Cluster", Cluster, Moscou, Rússia), apresentado na figura 2. Foram utilizados dois lasers para excitação, um na região violeta em $442 \mathrm{~nm}$ (laser de $\mathrm{HeCd}$ ) com potência aproximada de $15 \mathrm{~mW}$ e outro na região verde em $532 \mathrm{~nm}$ (laser de $\mathrm{Nd}: Y A G$ com gerador intracavitário de segundo harmônico), com potência ao redor de $10 \mathrm{~mW}$. A potência na ponta da sonda de investigação é entre 7 e $10 \mathrm{~mW}$ para ambos os lasers de 
excitação. A ponteira de aplicação é ligada em uma extremidade ao laser de excitação e em outra ao espectrômetro, possui uma fibra óptica central (110 $\mu \mathrm{m}$ de diâmetro) para entrega do laser e seis fibras concêntricas (100 $\mu \mathrm{m}$ de diâmetro cada) para coleta da luz re-emitida pelo tecido investigado. O monocromador possibilita a análise entre $378 \mathrm{~nm}$ e $842 \mathrm{~nm}$ do espectro eletromagnético, avaliando a intensidade de luz para cada comprimento de onda emitido. Na entrada do monocromador um filtro para minimizar a quantidade de luz do mesmo comprimento de onda de excitação é selecionado, nesse sistema estão à disposição os filtros de 450, 540 e 640 nm. A grade esférica, com dimensões de $36 \times 36 \mathrm{~mm}^{2}$, possui 300 sulcos $/ \mathrm{mm}$ e forma o espectro em um campo plano de $12 \mathrm{~mm}$ de largura. O fotodetetor multicanal constituído por uma CCD com arranjo linear utiliza, para esse sistema, 970 detetores de silício. A resolução espectral resultante é de $5 \mathrm{~nm}$. O programa de computador utilizado para aquisição dos dados é o LightView-Med (LVM.exe).

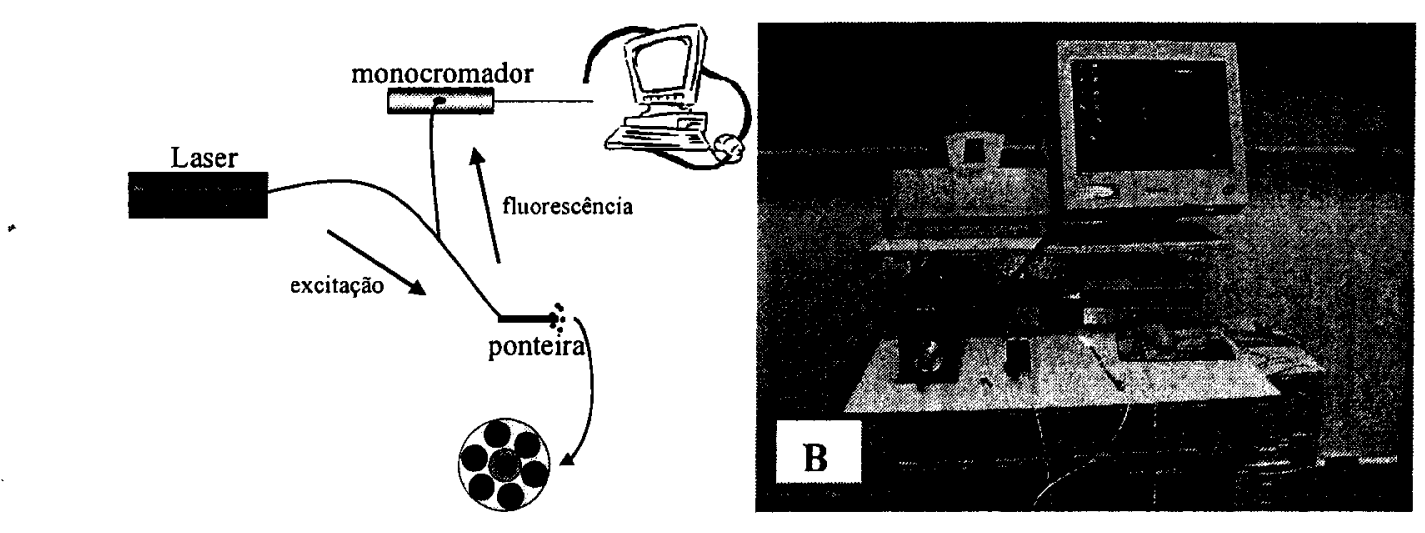

Fig. 2 - $O$ desenho esquemático do sistema de diagnóstico é apresentado em A e uma foto em $B$. 


\subsection{Leituras de detecção óptica}

Foram investigadas as seguintes regiões anatômicas: pata, mucosa da bolsa jugal, palato, bordas lateral direita e esquerda da língua e assoalho bucal. Nos animais onde a lesão era clinicamente visível, pontos de investigação no interior da lesão e nas suas margens foram também coletados. A ponta de aplicação foi posicionada em contato, o mais perpendicularmente possível, à superficie do tecido alvo. Foram coletadas seis leituras para cada região e, para lesão e margens, pontos suficientes para cobrir toda área relevante. A figura 3 apresenta um exemplo de leitura óptica em um animal com lesão. A coleta da fluorescência ocorre simultaneamente à excitação.

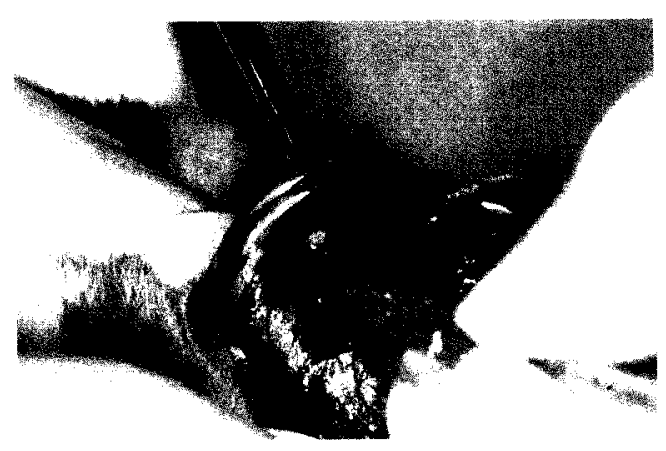

Fig. 3 - Leitura óptica sendo realizada na margem da lesão. Note o posicionamento da ponteira de aplicação. 
A ponteira de aplicação foi protegida com um filme de PVC e substituída a cada animal. Entre uma região e outra, a ponteira foi higienizada com solução de $\mathrm{H}_{2} \mathrm{O}_{2}$ e solução de cloreto de sódio e seca antes da nova leitura. A leitura é pontual, podendo ser realizada até cobrir toda a área desejada. No caso da borda lateral da língua, a leitura foi realizada "varrendo" a região de posterior para anterior. A figura 4 apresenta um desenho esquemático da obtenção dos pontos de investigação na borda lateral da língua. A sonda foi posicionada em leve contato com a superfície do tecido, sem exercer pressão para evitar alterações na microcirculação local, e conseqüentes variações na quantidade de hemoglobina presente no tecido. Além disso, o posicionamento normal à superfície possibilitou uma melhor excitação e coleta da luz re-emitida pelo tecido alvo.
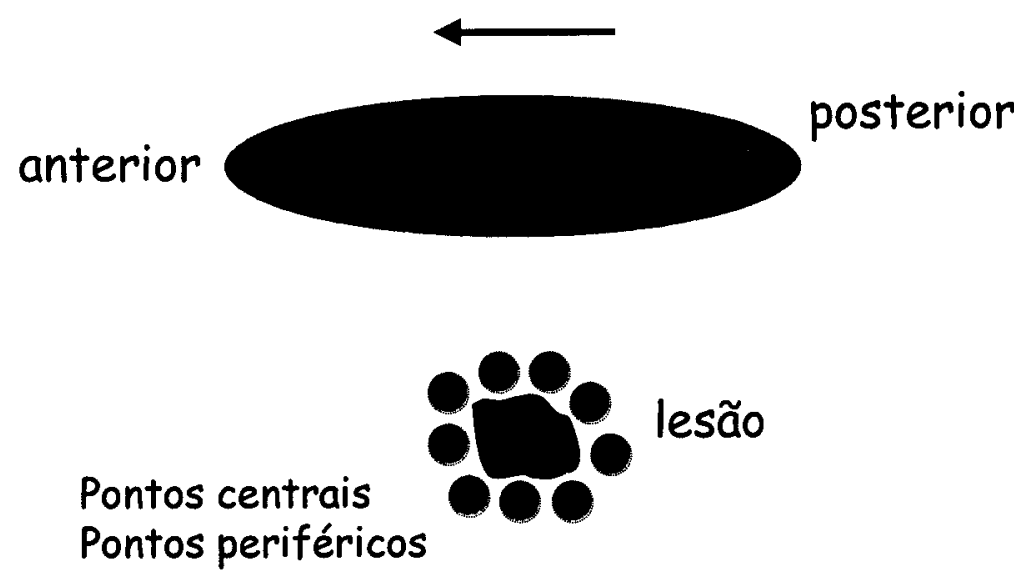

Fig.4 - Desenho esquemático dos pontos de leitura na borda lateral da língua. Note que os pontos nessa região poderiam estar em áreas de tecido normal ou de lesão. 
a. Monitoramento do envelhecimento através da espectroscopia de fluorescência

Uma investigação da autofluorescência tecidual em animais sadios foi realizada para monitorar o envelhecimento natural durante o mesmo período total de indução dos grupos experimentais. $\mathrm{O}$ objetivo desse estudo foi verificar se alterações ocasionadas pelo envelhecimento contribuiriam para modificações na estrutura do espectro de fluorescência. Nesse estudo todos os animais eram sadios e não tiveram nenhum contato com a substância utilizada para a indução das lesões.

Foram utilizados dez hamsters sírios dourados com 2 meses no início do estudo, monitorados até completar o oitavo mês de idade. Os tempos de investigação foram: 2 meses ( 4 semanas), 4 meses (12 semanas), 6 meses (20 semanas) e 8 meses (28 semanas). Os valores em parênteses correspondem ao tempo em semanas caso os animais fossem submetidos ao experimento de indução da carcinogênese.

Além das regiões investigadas nos grupos experimentais, nesses animais a autofluorescência da gengiva inserida, do dorso e do ventre linguais, e dos dentes incisivos inferiores também foi analisada.

\section{b. Leitura da autofluorescência nos animais dos grupos experimentais}

Os animais foram submetidos a uma avaliação clínica prévia para a determinação das lesões. Nesses casos, além dos pontos pré-determinados outras leituras foram obtidas na lesão, cobrindo a totalidade da sua extensão, quando possível, assim como 
foram também coletados pontos nas margens da lesão. Em lesão com características clínicas regionais distintas, os espectros também foram individualizados.

\section{Fotossensibilização dos animais e leitura de fluorescência marcada}

Após a leitura da autofluorescência tecidual, os animais foram fotossensibilizados com um derivado de hematoporfirina utilizado em terapia fotodinâmica (Photogem ${ }^{\circledR}$, Photogem, Moscou, Rússia). A droga é adquirida na forma de pó e diluída em solução de cloreto de sódio a $0,9 \%$ na proporção de $5 \mathrm{mg} / \mathrm{ml}$ para administração via endovenosa. A dose utilizada do fotossensibilizador foi de $2,0 \mathrm{mg} / \mathrm{kg}$, similar à dose empregada em humanos. A veia lingual direita foi escolhida para administração pela facilidade de acesso e calibre do vaso.

As leituras foram repetidas nos mesmos sítios investigados na autofluorescência após 6 horas $(t+6 h), 12$ horas $(t+12 h)$ e 24 horas $(t+24 h)$ da sensibilização sistêmica.

\section{Sacrificio e processamento do material para análise histológica}

Os animais foram sacrificados, ainda sedados, com overdose de solução anestésica e a língua foi removida. O material foi processado para a obtenção das 
lâminas com coloração de hematoxilina-eosina. O corte do material foi realizado na direção direita/esquerda de maneira que possibilitasse a melhor visualização longitudinal da borda lateral da língua (figura 5). Todo o processamento foi realizado no Departamento de Biociências e Diagnóstico Bucal da Faculdade de Odontologia de São José dos Campos da Universidade Estadual Paulista Júlio de Mesquita Filho.

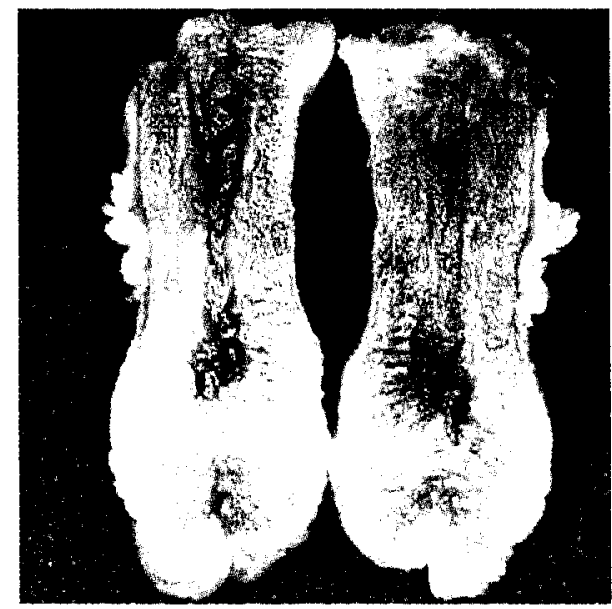

Fig.5 - Fotografia mostrando a direção do corte do material

As lesões foram classificadas em mucosa normal, hiperplasia e hiperquertose, displasia (atipia leve, moderada, intensa), carcinoma in situ e carcinoma invasivo, segundo os critérios de atipia propostos por Bánóczy \& Csiba de 1976. 


\section{Análise dos espectros de fluorescência}

Os espectros coletados para os diversos pontos de investigação foram analisados em função das diferentes localidades anatômicas e do tecido alterado (lesão), em comparação com o tecido normal. Os resultados espectrais foram confrontados com o diagnóstico histopatológico de cada animal. Diferentes tipos de processamento dos espectros foram realizados buscando a melhor discriminação tecido normal versus tecido neoplásico.

O projeto foi avaliado e aprovado pelo Comitê de Ética em Pesquisa da Faculdade de Odontologia de São José dos Campos da Universidade Estadual Paulista Júlio de Mesquita Filho, de acordo com os Princípios Éticos na Experimentação Animal adotado pelo Colégio Brasileiro de Experimentação Animal (COBEA), protocolo apresentado no anexo 1. 


\section{RESULTADOS E DISCUSSÃO}

\section{Avaliação do grupo controle (animais sadios)}

$\mathrm{O}$ animal escolhido para estudo foi o hamster sírio dourado uma vez que o modelo animal de indução química da carcinogênese em cavidade oral já foi amplamente investigado e é utilizado comumente. A borda lateral da língua foi a região de indução determinada, sendo que a região é uma das áreas de maior acometimento do carcinoma oral.

Com o intuito de verificar se alterações ocasionadas pelo envelhecimento natural do animal contribuiriam para modificações na estrutura do espectro de fluorescência, a investigação teve início com um monitoramento da autofluorescência tecidual durante o 
tempo total do experimento principal. Nesse estudo todos os animais eram sadios e não tiveram nenhum contato com a substância utilizada para a indução das lesões.

\subsection{Análise histológica da borda lateral da língua}

O principal sítio de investigação foi a borda lateral da língua de hamsters sírios dourados, assim a análise histológica será restrita à descrição dessa região anatômica. Clinicamente, a borda lateral da língua é uma região de transição entre a mucosa do dorso, com a presença das papilas gustativas e a mucosa do ventre, com uma superfície comparativamente mais lisa (figura 6A).

A borda lateral da língua dos hamsters é composta por uma mucosa revestida por um epitélio estratificado e um tecido conjuntivo escasso. A lâmina própria possui uma espessura estreita e a seguir uma ampla faixa de musculatura estriada esquelética pode ser observada (figura 6B). O epitélio de superfície apresenta poucas camadas de células e com retificação dos cones epiteliais (setas). A escassa quantidade de tecido conjuntivo entre o epitélio e o tecido muscular difere em comparação à mesma região anatômica em humanos, desta forma, a resposta inflamatória frente à indução química e também com o carcinoma já instalado não foi observada de maneira exacerbada, nos animais do experimento. 

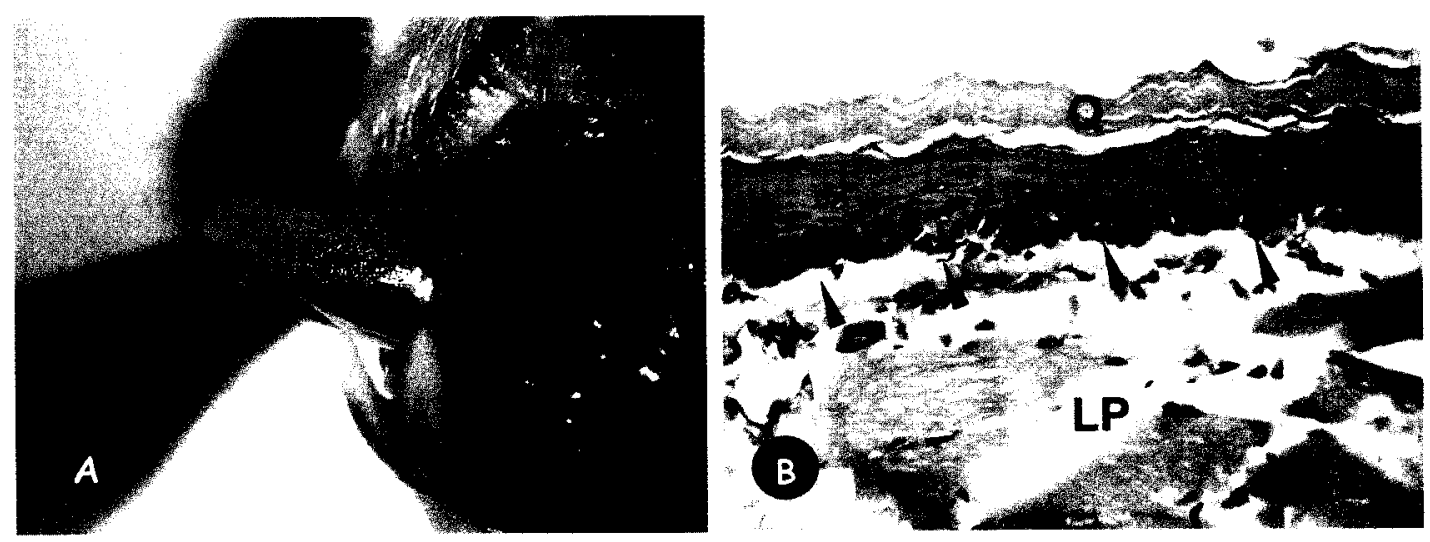

Fig.6 - A foto A apresenta o aspecto clínico da borda lateral da língua do hamster do grupo controle. A fotomicrografia $B$ mostra as características histológicas de uma região da borda lateral da língua $(Q$, camada de queratina; $E$, epitélio e $L P$, lâmina própria).

O grau de estratificação e as características celulares e teciduais de normalidade foram preservados durante o envelhecimento do animal, nos períodos investigados, apenas algumas variações na quantidade de queratinização foram observadas. Desta forma, as alterações observadas nos grupos experimentais podem ser inferidas pela atuação do agente carcinogênico.

\subsection{Monitoramento do envelhecimento dos animais}

Foram investigados dez animais realizando um acompanhamento da espectroscopia de fluorescência nos tecidos da cavidade oral determinados para o 
estudo, excedendo em 2 semanas o período total de avaliação dos grupos experimentais, ou seja, 28 semanas após o início da indução. Os animais não tiveram contato algum com o DMBA, uma vez que o objetivo era a análise da variação espectral em função do envelhecimento natural dos tecidos da cavidade oral, especialmente da borda lateral da língua, principal sítio de estudo.

Os dados coletados pelo espectrômetro através do programa LightView apresentam valores de intensidade em função do comprimento de onda, como no exemplo apresentado na figura 7. O primeiro pico, do lado esquerdo do gráfico representa a luz coletada do tecido alvo de mesmo comprimento de onda que o laser de excitação $\left(Z_{1}\right)$, essa porção da luz é resultante do retroespalhamento e da fluorescência de igual energia da excitação. O restante da curva corresponde à fluorescência que será avaliada neste trabalho, i.e., a luz re-emitida pelo tecido de freqüências distintas da excitação $\left(Z_{2}\right)$. A parte $Z_{2}$ do gráfico é a que trará informações relevantes, dependendo das características do tecido investigado, a fluorescência emitida será diferente. A região $Z_{1}$ pode sofrer alterações intrínsecas da medida como inclinação da sonda, película de saliva, variando a quantidade do retroespalhamento durante a leitura.

IFSC-USP SERVICO de binLioteca

INFOSRIAL 


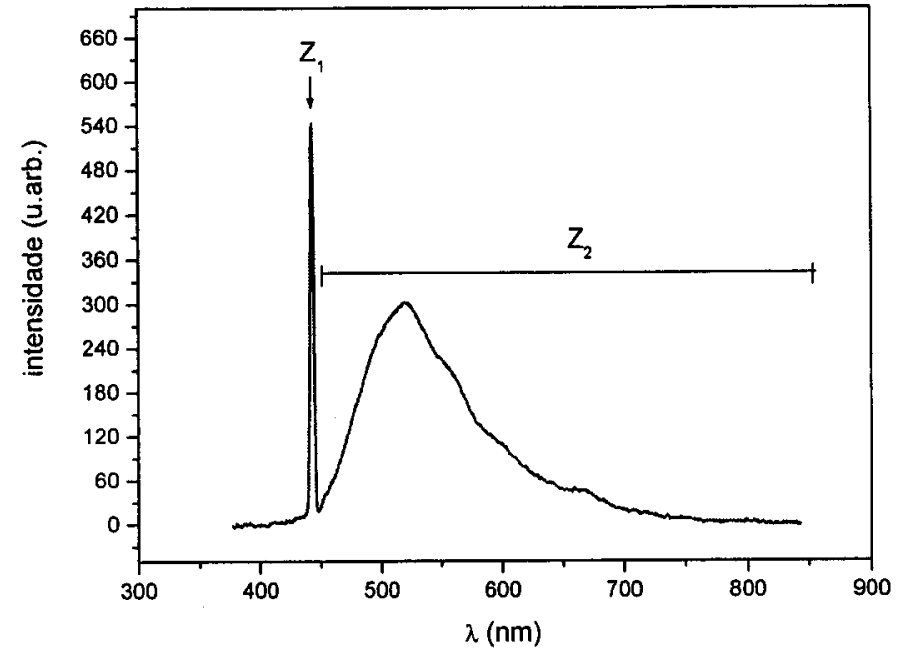

Fig. 7 - Exemplo de um espectro de fluorescência coletado em borda lateral da língua do hamster com excitação em $442 \mathrm{~nm}$.

A investigação dos tecidos alvos - pele, mucosa oral e dente - com características morfológicas distintas possibilitou a comparação das identidades espectroscópicas de cada um. Os gráficos apresentados nas figuras 8, 9, 10, 12 e 13, são exemplos da fluorescência observada tipicamente nos animais controle estudados.

Os espectros de fluorescência observados para a pele da pata (figura 8) apresentam uma intensidade comparativamente superior à dos sítios linguais e assoalho, e equivalentes à do palato e da gengiva inserida na região dos incisivos inferiores. A intensidade máxima observada para a pata foi ao redor de 3930 e para a borda lateral em torno de 1720 em unidades arbitrárias, e de 340 e 150 para a região $Z_{2}$, respectivamente. Esse comportamento foi observado em todos os tempos investigados nos animais monitorados e também nos dois comprimentos de onda de excitação, 442 e $532 \mathrm{~nm}$. No 
entanto, as intensidades observadas para excitação em $442 \mathrm{~nm}$ foram relativamente inferiores. A língua e o assoalho são tecidos altamente vascularizados, e a hemoglobina é o principal componente que apresenta alta absorção de fótons na região do espectro eletromagnético utilizado para excitação, i.e., azul-verde, assim como da fluorescência re-emitida pelo tecido nessa região espectral. Isso provavelmente ocasionou uma maior interação luz/tecido, e conseqüente menor conversão da energia na forma da fluorescência re-emitida.

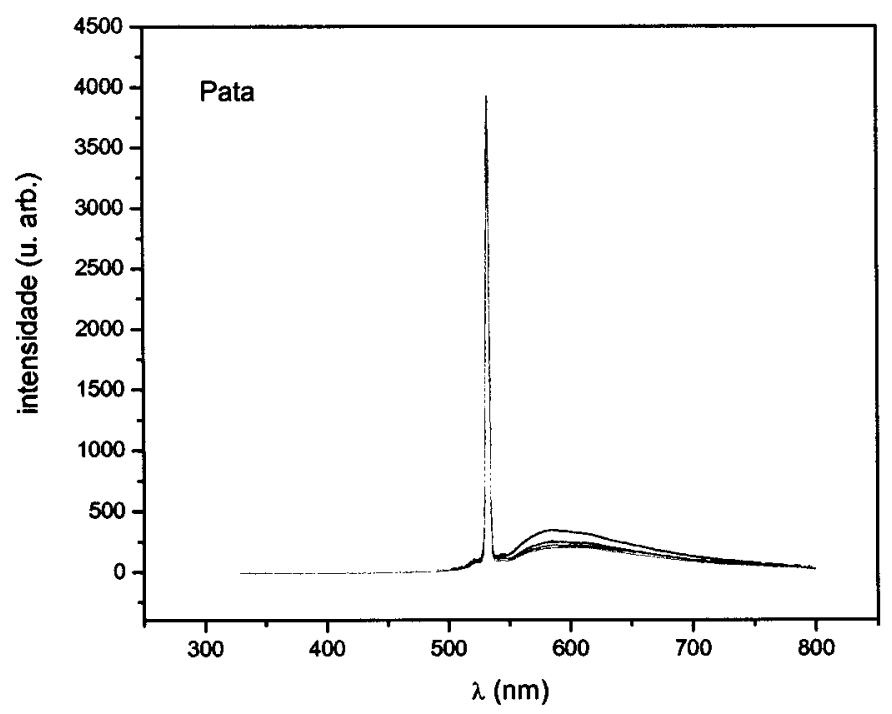

Fig.8 - Espectro de fluorescência típico obtido para a pata. Cada curva do gráfico representa um ponto de leitura.

A mucosa oral do palato duro (figura 10) não apresentou um comportamento semelhante das outras regiões da cavidade oral, as intensidades 
encontradas foram da mesma ordem da pele. Provavelmente isso foi observado, uma vez que a mucosa dessa região possui uma coloração mais clara, o que deve ter contribuído para uma menor absorção da luz de excitação, e maior contribuição dos fenômenos de espalhamento. $\mathrm{O}$ epitélio do palato duro é composto por uma camada de queratina mais abundante em comparação com outras mucosas orais. Além disso, as curvas obtidas para essa região não foram todas semelhantes, as rugas palatinas (figura 11) podem ter contribuído para os espectros distintos por serem áreas de difícil higienização e conseqüente maior contenção de resíduos alimentares e microrganismos.

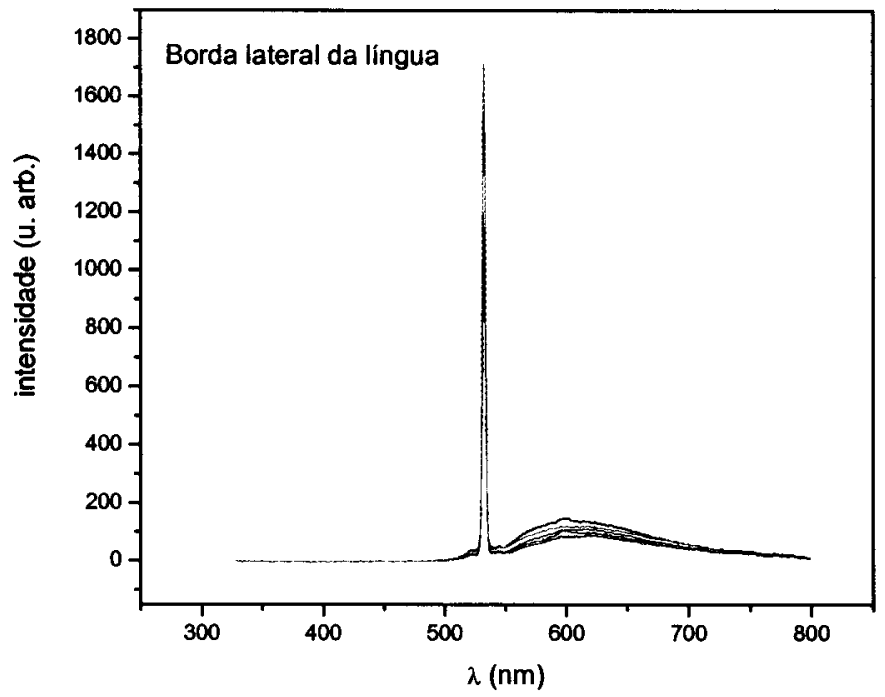

Fig.9 - Espectros de fluorescência típicos para excitação em $532 \mathrm{~nm}$ obtidos para a borda lateral da língua. Cada curva do gráfico representa uma leitura pontual. 


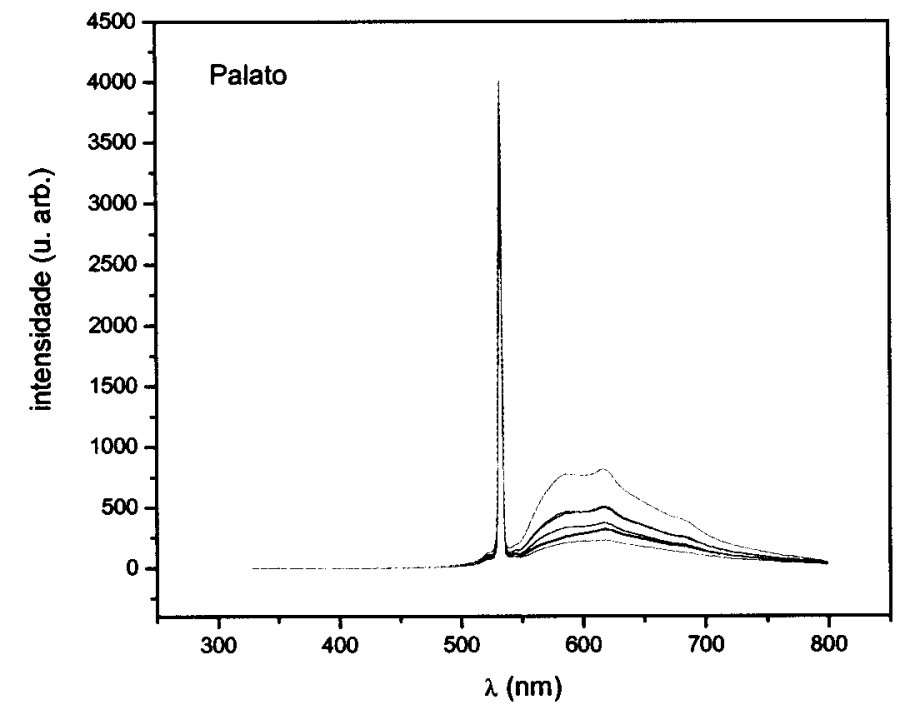

Fig.10 - Espectro de fluorescência típico obtido para o palato duro. Cada curva do gráfico representa um ponto de leitura.

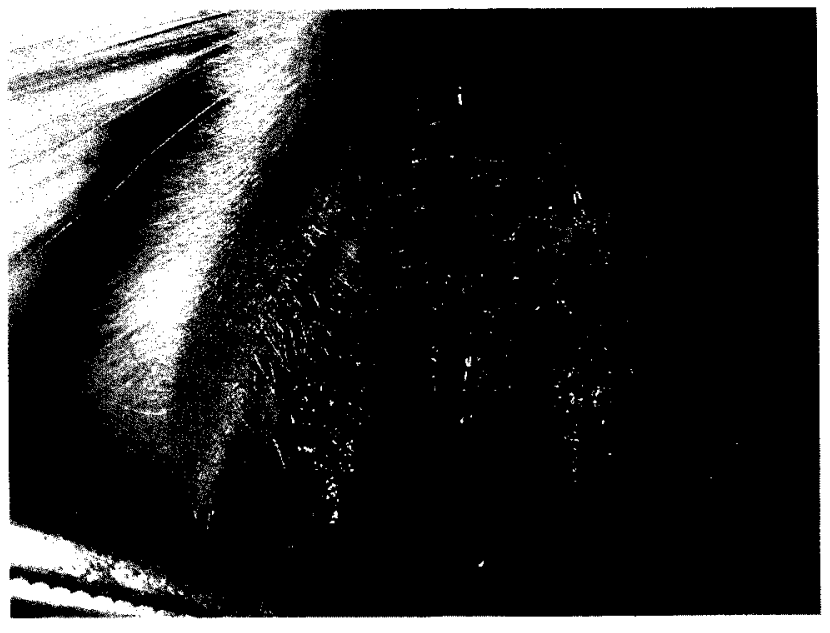

Fig.11 - Fotografia das rugas palatinas no palato duro de um animal. 
A gengiva inserida (figura 12) e o incisivo inferior (figura 13) também apresentaram intensidades maiores do que da mucosa da língua e assoalho bucal. A gengiva apresenta uma coloração rósea clara e sua superficie lisa contribui para um maior reflexão da luz e, no caso do dente, sua estrutura cristalina, além de sua coloração branco-amarelada também favorece esse fenômeno.

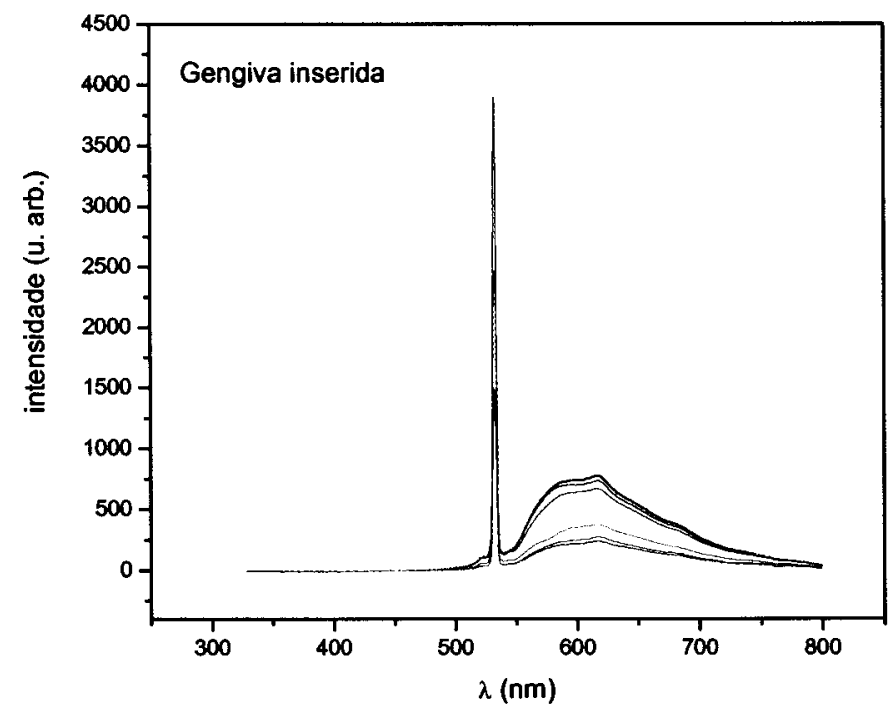

-Fig.12 - Espectro de fluorescência típico obtido para a gengiva inserida com excitação em $532 \mathrm{~nm}$. Cada curva do gráfico representa um ponto de leitura.

Os espectros observados para a gengiva apresentaram dois comportamentos distintos. O primeiro se assemelha ao comportamento da mucosa oral da língua e assoalho, e o segundo ao do dente. Isso pode ser explicado devido à pequena espessura 
da gengiva inserida próximo ao colo dental, o que permitiu a influência da fluorescência dental que também foi coletada em algumas leituras gengivais.

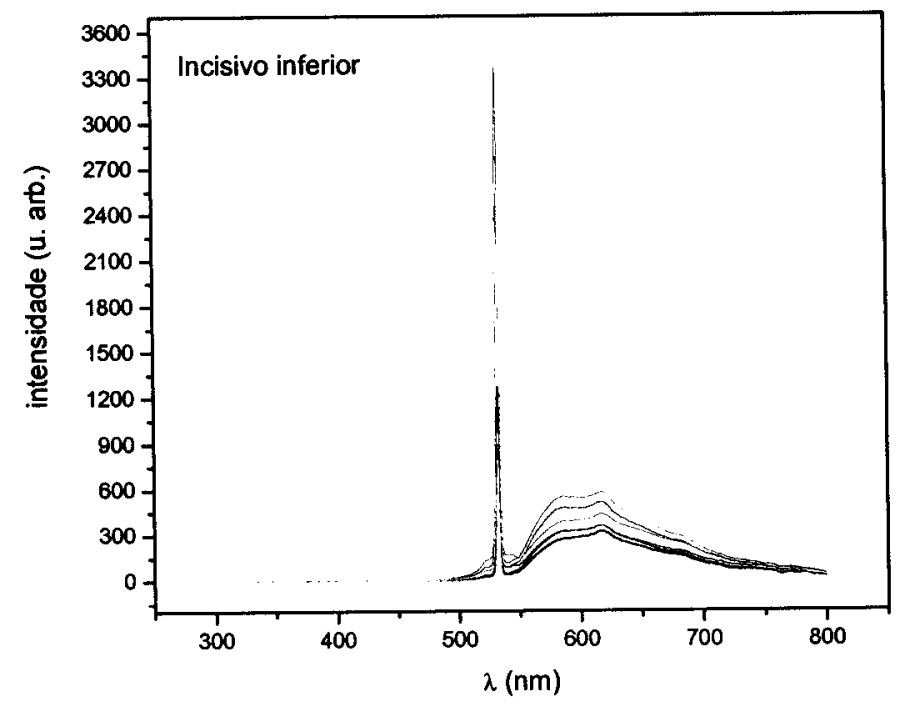

Fig. 13 - Espectro de fluorescência típico obtido para o dente. Cada curva do gráfico representa um ponto de leitura.

Os gráficos apresentados nas figuras 14 a 23 foram obtidos a partir das médias dos espectros obtidos nos 10 animais investigados. Os espectros foram previamente normalizados pela amplitude no comprimento de onda de excitação para possibilitar a comparação entre os dados. Variações de intensidade entre as leituras são decorrentes do posicionamento da sonda, sua angulação e pressão aplicada e das diferenças regionais do tecido. Os gráficos apresentam as variações encontradas em função da idade do animal para ambas excitações. 

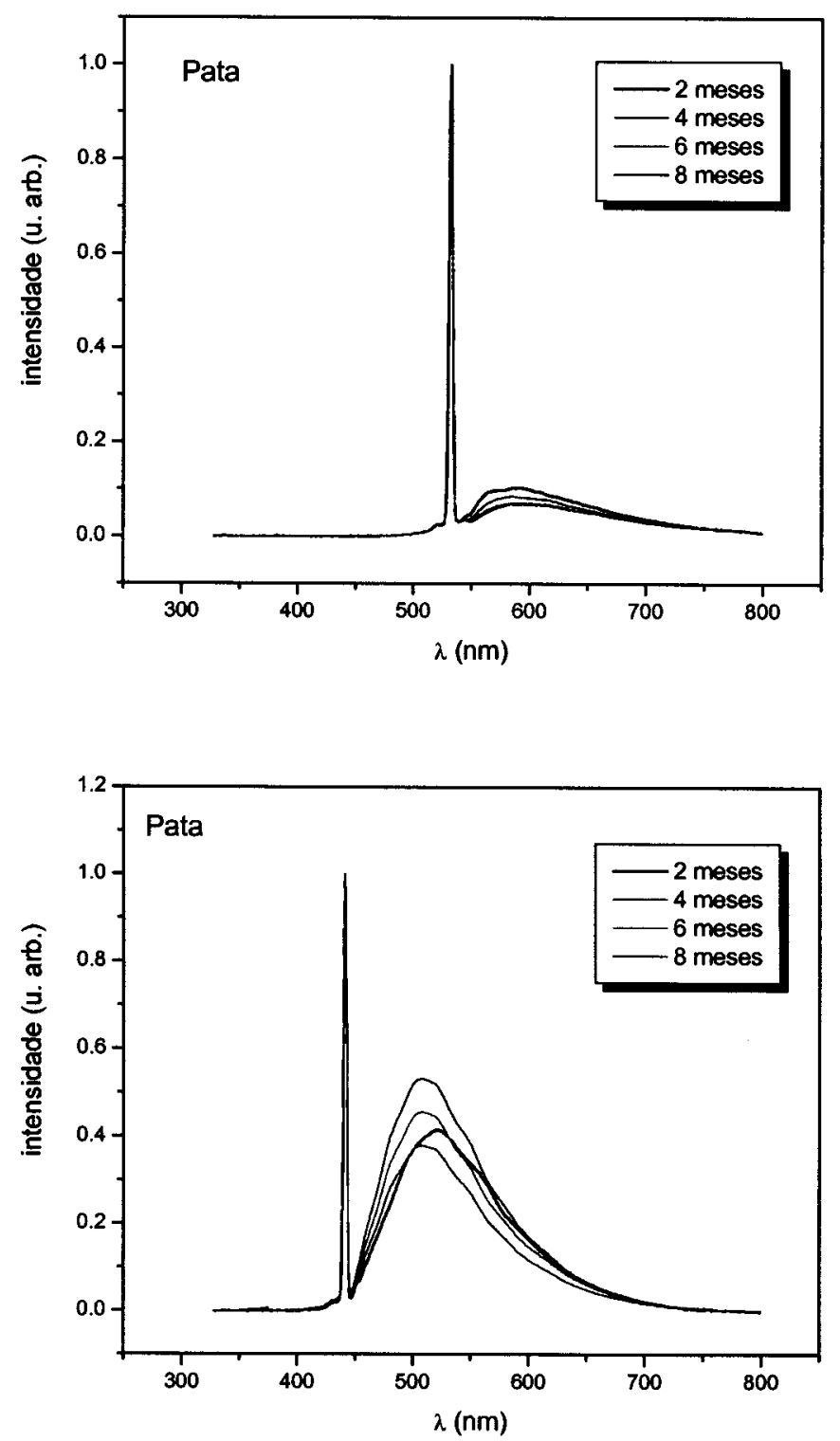

Fig.14 - Comparação dos espectros de fluorescência obtidos para a pata em função do tempo de investigação. $O$ gráfico superior apresenta a fluorescência com excitação em $532 \mathrm{~nm}$ e o inferior em $442 \mathrm{~nm}$. 

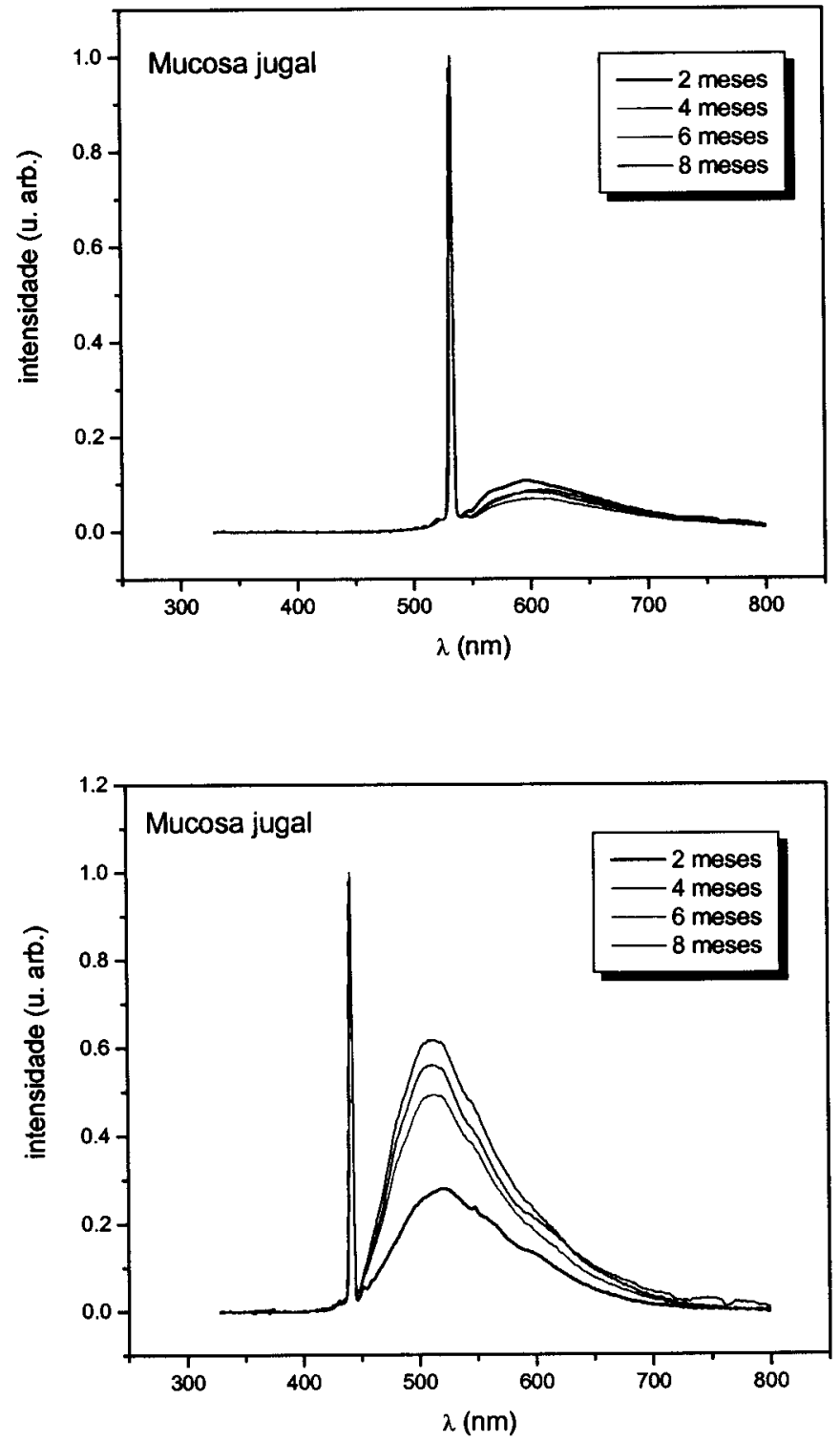

Fig.15 - Comparação dos espectros de fluorescência obtidos para a mucosa jugal em função do tempo de investigação. IFSC-USP SERVICO OE RIBLIOTECA 

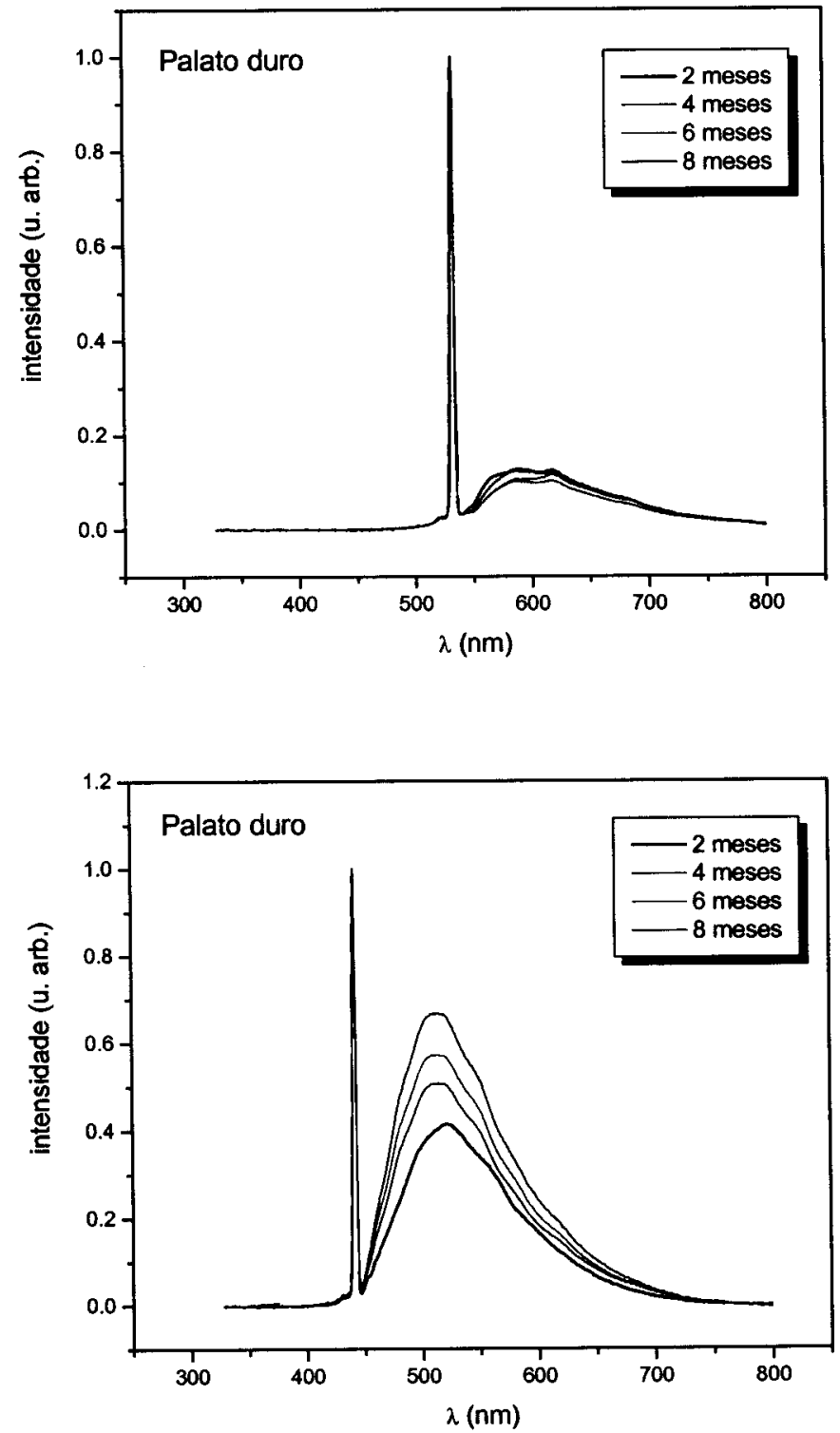

Fig.16 - Comparação dos espectros de fluorescência obtidos para o palato duro em função do tempo de investigação. 

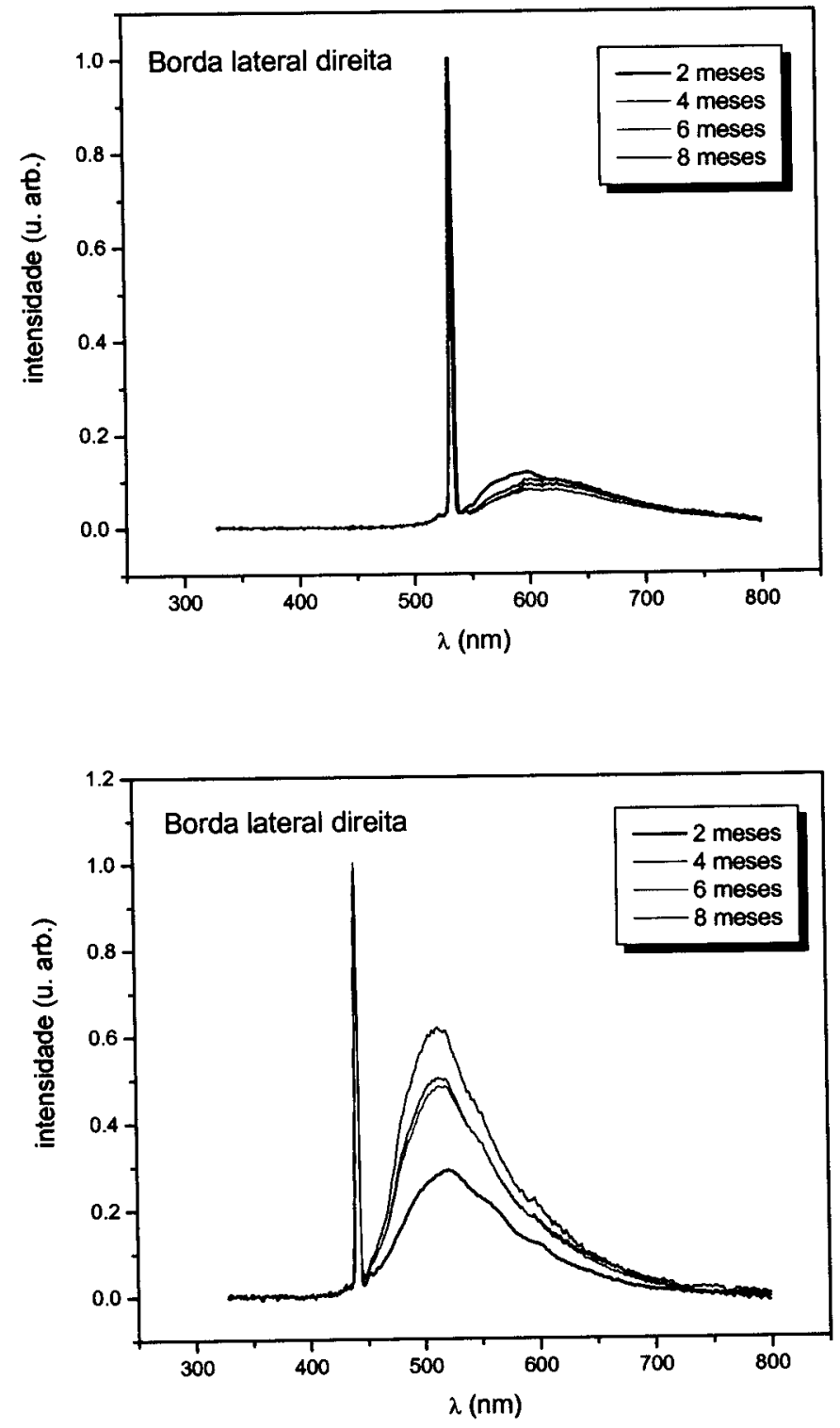

Fig.17 - Comparação dos espectros de fluorescência obtidos para a borda lateral direita da língua em função do tempo de investigação. 

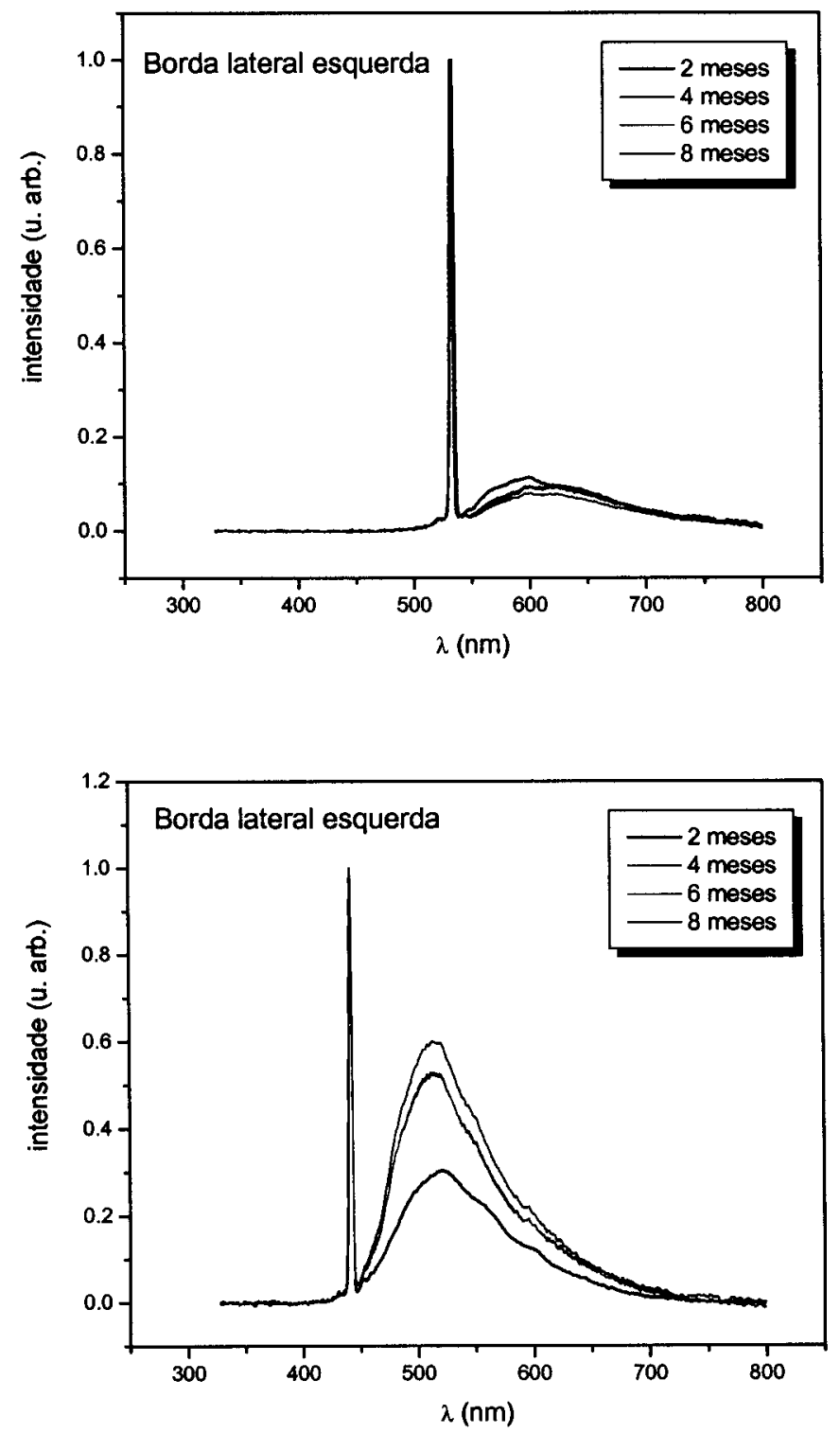

Fig.18 - Comparação dos espectros de fluorescência obtidos para a borda lateral esquerda da língua em função do tempo de investigação. 

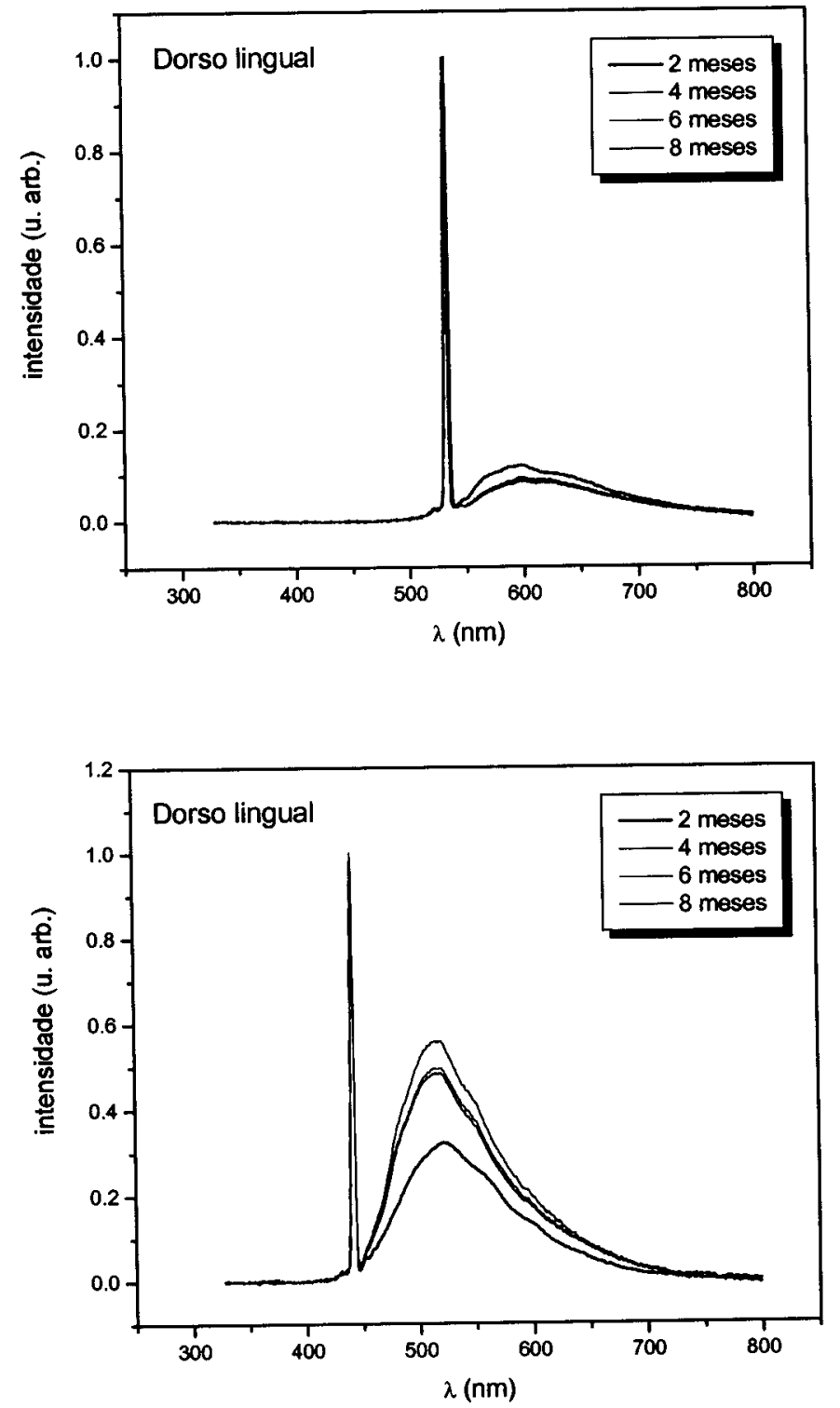

Fig.19-Comparação dos espectros de fluorescência obtidos para o dorso da língua em função do tempo de investigação.

IFSG-USP SERVICODE BIBLIOTECA 

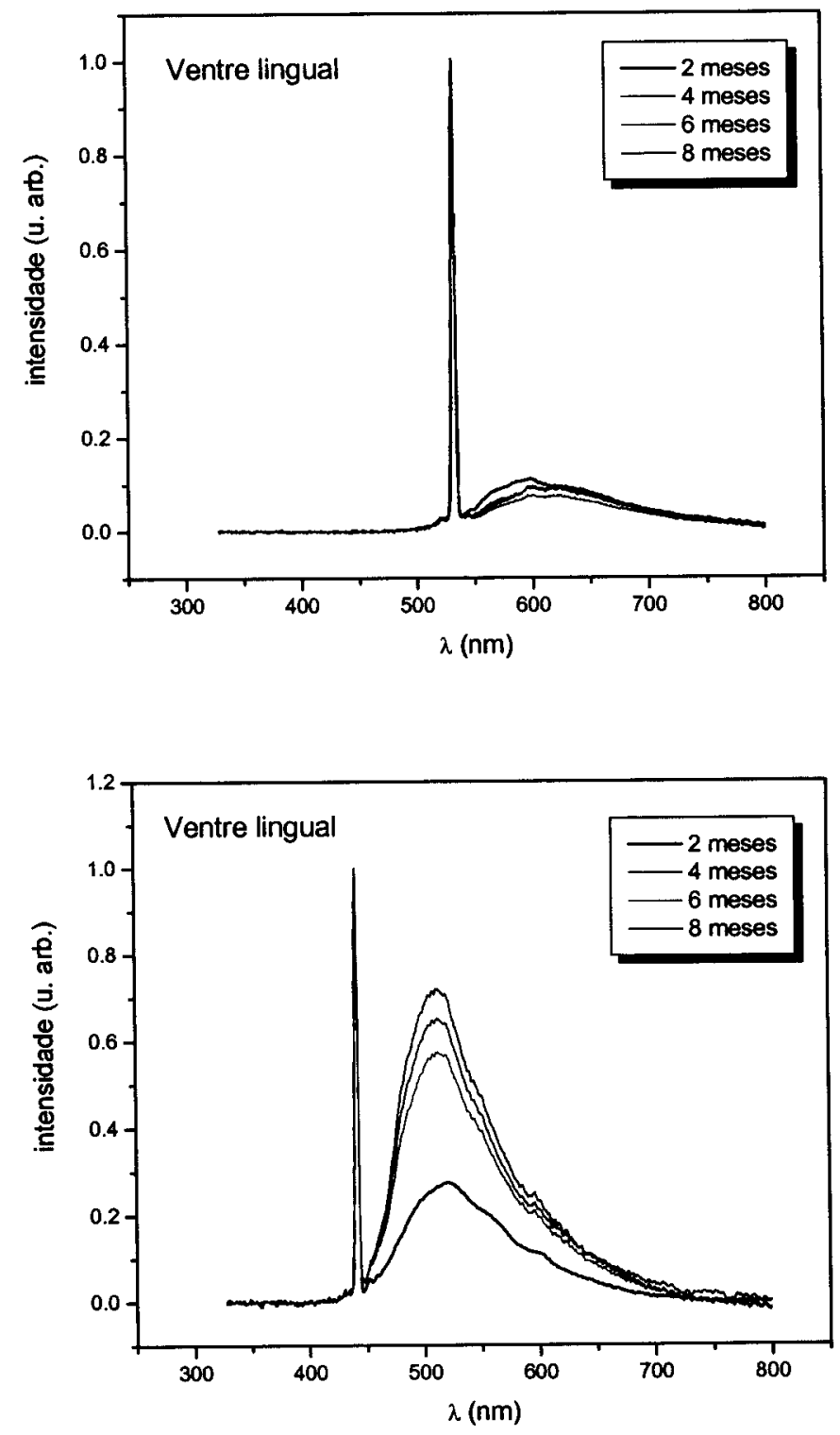

Fig. 20 - Comparação dos espectros de fluorescência obtidos para o ventre da língua em função do tempo de investigação. 

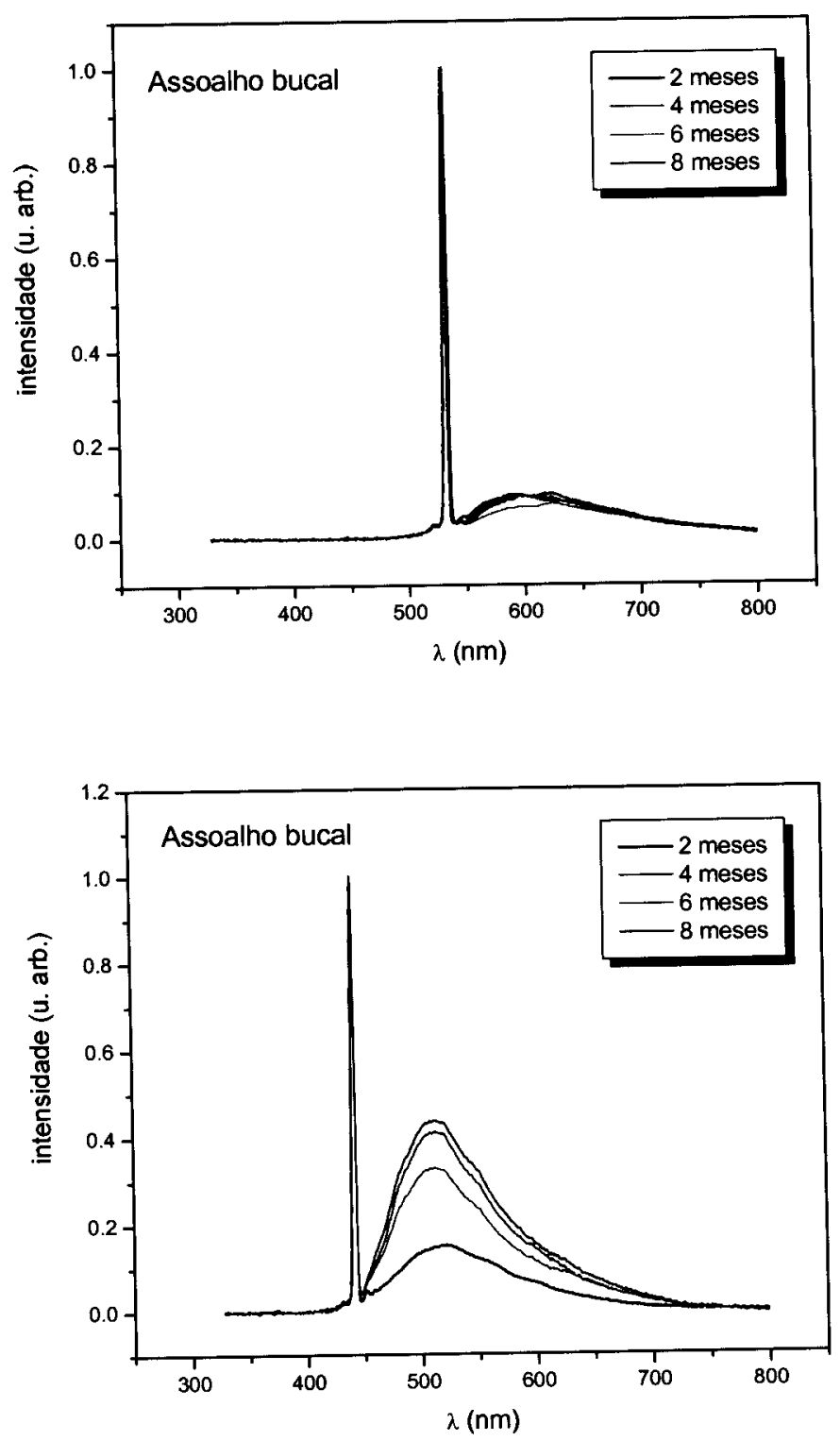

Fig.21 - Comparação dos espectros de fluorescência obtidos para o assoalho bucal em função do tempo de investigação. 

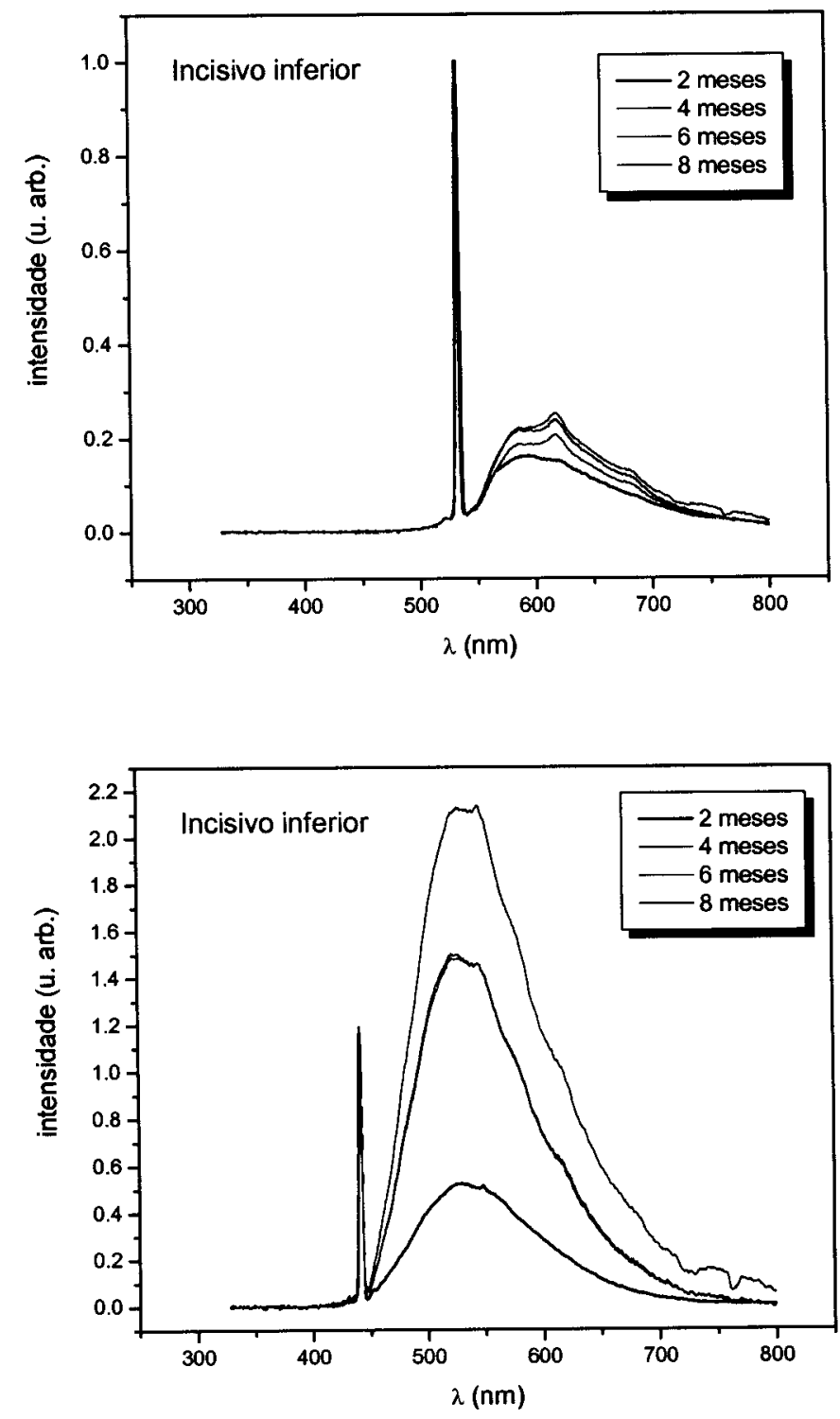

Fig.22 - Comparação dos espectros de fluorescência obtidos para os incisivos inferiores em função do tempo de investigação.

Com exceção dos espectros do dente incisivo inferior, as maiores variações em função do envelhecimento natural dos tecidos foram em intensidade de emissão. A 
excitação em $442 \mathrm{~nm}$ induziu a melhor discriminação das diferenças espectrais decorrentes da idade. Com $532 \mathrm{~nm}$ não houve importantes diferenças entre as médias dos espectros de autofluorescência. No caso dos dentes incisivos inferiores, o espectro também sofreu uma alteração qualitativa, ou seja, houve uma modificação na estrutura do espectro, sendo mais evidente com a emissão de uma nova banda ao redor de $616 \mathrm{~nm}$ para excitação em $532 \mathrm{~nm}$. O espectro de fluorescência após excitação em $442 \mathrm{~nm}$ apresentou alteração qualitativa em toda a extensão. Essas modificações espectrais são provavelmente decorrentes do manchamento dental que foi observado gradativamente após a primeira leitura. Os dentes passaram de uma coloração branco leitoso para uma coloração amarelo-acastanhado, isso é comum com o envelhecimento da estrutura dental na cavidade oral, que está sujeita a alterações principalmente devido à incorporação de pigmentos da ração.

Esses resultados são importantes para a posterior análise das alterações malignas da lesão uma vez que o envelhecimento e as alterações espectrais envolvidas contribuirão para o espectro de autofluorescência que será coletado do tecido. De uma maneira geral verificou-se que para a mucosa oral e mais especificamente a borda lateral da língua, com a excitação em $532 \mathrm{~nm}$ o envelhecimento natural do tecido não induziu modificações espectrais e com $442 \mathrm{~nm}$, as modificações foram principalmente quantitativas. 


\section{Avaliação dos animais dos grupos induzidos}

A partir do modelo animal utilizado para a indução da carcinogênese foram obtidos diversos tipos de lesão, desde as fases iniciais até o franco carcinoma. Apesar da divisão dos grupos experimentais ter sido em função do tempo de indução química das lesões, a análise dos resultados foi feita em função do resultado histopatológico, considerado o padrão-ouro para o diagnóstico, já que grande variabilidade foi observada entre os indivíduos, considerando tanto a evolução clínica como a histológica. O tempo e o tipo de evolução das lesões foi diferente mesmo entre indivíduos do mesmo grupo experimental. Animais do mesmo grupo, em alguns casos, apresentaram tempos de evolução bem distintos, demonstrando tipos ou intensidades diferentes de resposta frente à mesma dose de estímulo. Além disso, diversos tipos clínicos e histológicos, com variados graus de invasividade e crescimento exofítico, também foram observados. Essa variabilidade de resposta é decorrente das características individuais.

A tendência geral foi o de aparecimento hiperqueratose já nas primeiras semanas e as lesões clínicas a partir da $10^{\mathrm{a}}$ semana de indução.

\subsection{Aspectos clínicos}

As alterações observadas foram identificadas como placas leucoplásicas, lesões exofíticas com aspecto papilomatoso, lesões ulceradas, lesões nodulares e massas nodulares com características neoplásicas. As fotos da figura 23 apresentam alguns exemplos dos quadros clínicos obtidos. As lesões em alguns animais eram únicas, no 
entanto, na maioria dos indivíduos, as lesões eram múltiplas, sendo que podiam apresentar aspectos clínicos variáveis, como placas neoplásicas permeadas por lesões exofíticas e áreas de ulceração (figura 24).

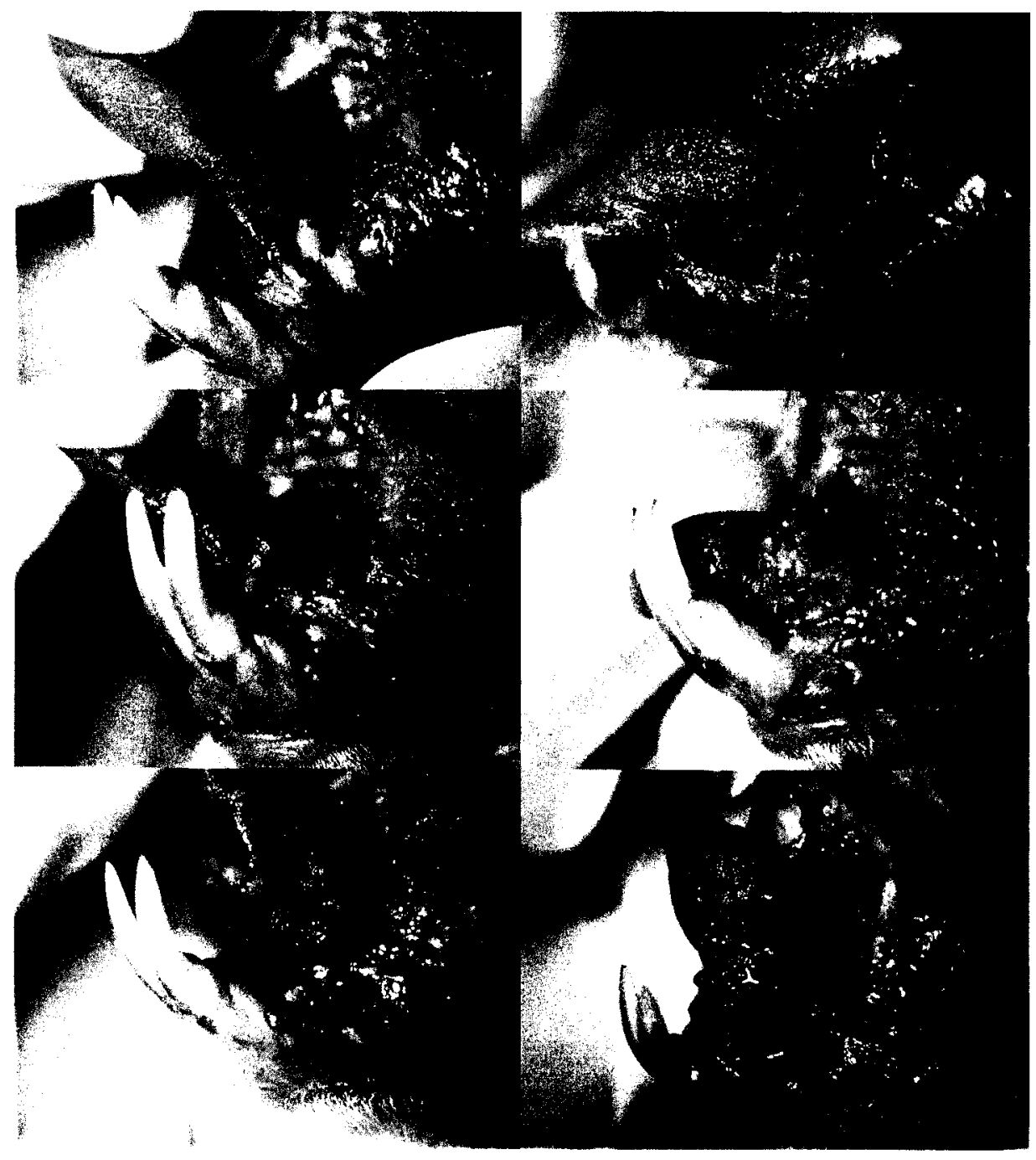

Fig.23 - Exemplos de diferentes tipos clínicos de lesões obtidas nos grupos experimentais. 


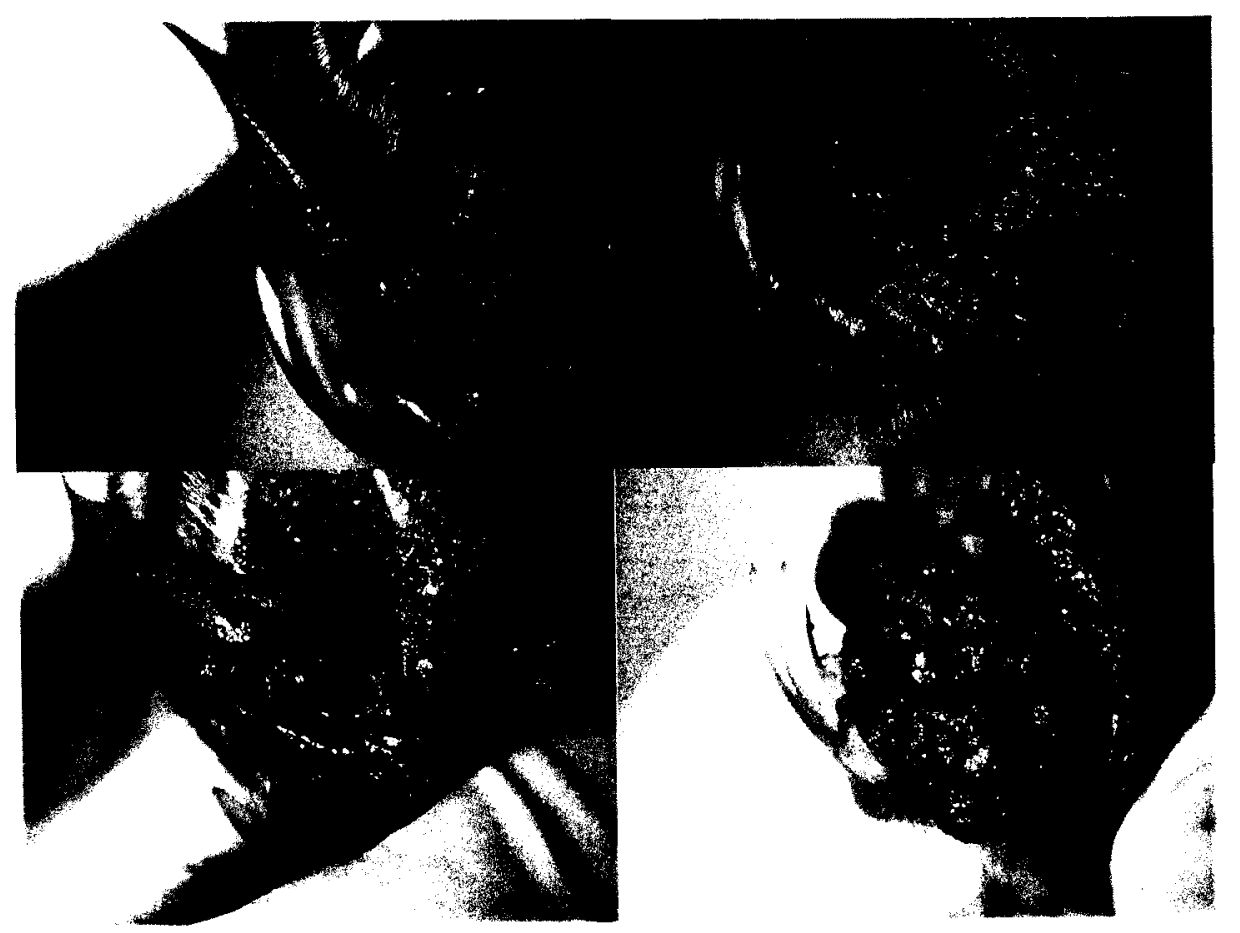

Fig.24 - Exemplos clínicos de lesões múltiplas e de diferentes aspectos clínicos na mesma lesão. 
Apesar da aplicação do agente carcinogênico ter sido realizada topicamente, não é possível assegurar que uma parte da solução não seja espalhada no restante da cavidade oral, principalmente pela ação da saliva. Na tentativa de minimizar esse fator, o DMBA foi diluído em acetona, veículo que evapora rapidamente; a aplicação foi realizada com um pincel somente na área de interesse; e os animais foram mantidos sem oferta de água por um período de seis horas. As lesões também foram observadas em outras áreas além da borda lateral, em freio, dorso e ventre da língua, em regiões do assoalho bucal, mucosa da bolsa jugal e comissura labial (figura 25).

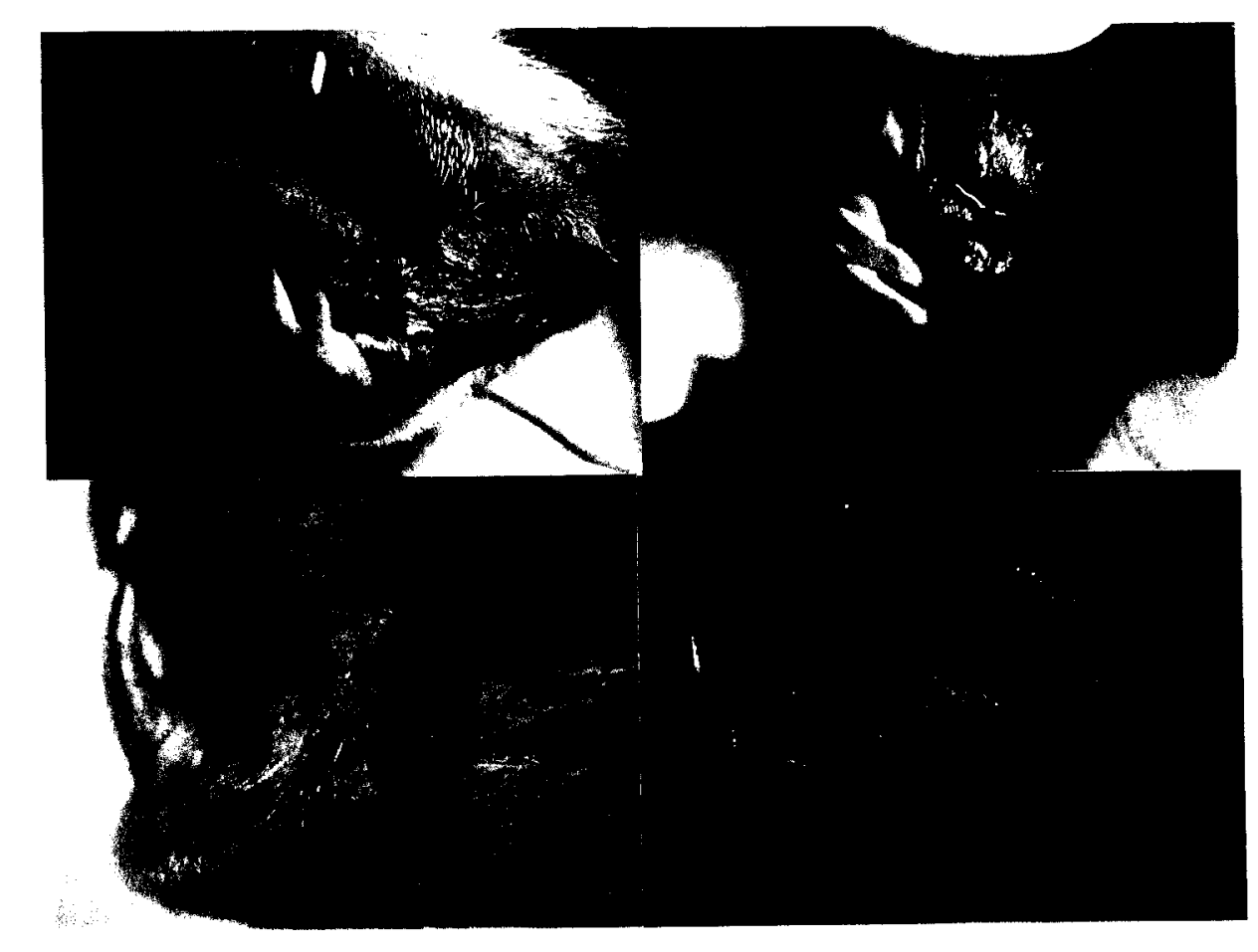

Fig. 25 - Localizações anatômicas fora da área de indução tópica. 
O padrão clínico de desenvolvimento que se observou com maior freqüência iniciava-se com áreas leucoplásicas, que caminhavam para formação de placas papilares. Posteriormente, a maioria das lesões progredia para formas exofíticas, com aspecto papilomatoso, verrucoso ou nodular de base séssil ou pediculada. A partir desse ponto, as lesões tendiam a sofrer necrose central, apresentando ulceração e um crescimento infiltrativo em direção da submucosa. Em outras lesões, com menor freqüência, o caminho observado foi o desenvolvimento direto para lesões ulceradas e infiltrativas, com bordas endurecidas e fixas a planos profundos.

\subsection{Aspectos histopatológicos}

Do total dos 72 animais dos grupos experimentais, oito animais foram a óbito antes do período planejado de investigação pela espectroscopia de fluorescência e sacrifício, sendo que do material avaliado, 17 casos foram classificados como hiperqueratose sem atipia, 9 com atipia epitelial leve, 12 com atipia epitelial moderada, 4 com atipia epitelial intensa, 4 de carcinoma in situ e 18 de carcinoma epidermóide. A tabela II apresenta o diagnóstico para cada animal dos grupos experimentais. 
Tabela II - Diagnóstico das lesões para cada animal. O primeiro algarismo do número dado a cada animal representa o tempo em semanas de indução e o segundo a identificação dentro do grupo.

\begin{tabular}{|c|c|}
\hline Animal & Diagnóstico \\
\hline 41 & hiperqueratose \\
\hline 42. & hiperqueratose \\
\hline 43 & hiperqueratose \\
\hline 44 & hiperqueratose \\
\hline 45 & hiperqueratose \\
\hline 46 & (1) hiperqueratose \\
\hline 61 & atipia epitelial moderada \\
\hline 62 & hiperqueratose \\
\hline 63 & hiperqueratose \\
\hline 64 & carcinoma in situ \\
\hline 65 & hiperqueratose \\
\hline 66 & atipia epitelial leve \\
\hline 81 & hiperqueratose \\
\hline 82 & hiperqueratose \\
\hline 83 & hiperqueratose \\
\hline 84 & hiperqueratose \\
\hline 85 & hiperqueratose \\
\hline 86 & hiperqueratose \\
\hline 101 & atipia epitelial moderada \\
\hline 102 & atipia epitelial leve \\
\hline 103 & atipia epitelial moderada \\
\hline 104 & carcinoma epidermóide \\
\hline 105 & atipia epitelial moderada \\
\hline 106 & óbito \\
\hline 121 & atipia epitelial moderada \\
\hline 122 & hiperqueratose \\
\hline
\end{tabular}




\begin{tabular}{|c|c|}
\hline $\begin{array}{r}123 \\
124 \\
125 \\
126\end{array}$ & $\begin{array}{c}\text { óbito } \\
\text { hiperqueratose } \\
\text { atipia epitelial intensa } \\
\text { óbito }\end{array}$ \\
\hline 141 & carcinoma epidermóide \\
\hline 142 & carcinoma epidermóide \\
\hline 143 & atipia epitelial moderada \\
\hline 144 & carcinoma in situ \\
\hline 145 & atipia epitelial intensa \\
\hline 146 & atipia epitelial leve \\
\hline 161 & atipia epitelial leve \\
\hline 162 & atipia epitelial leve \\
\hline 163 & atipia epitelial leve \\
\hline 164 & óbito \\
\hline 165 & atipia epitelial leve \\
\hline 166 & atipia epitelial intensa \\
\hline 181 & atipia epitelial leve \\
\hline 182 & carcinoma epidermóide \\
\hline 183 & atipia epitelial moderada \\
\hline 184 & atipia epitelial moderada \\
\hline 185 & atipia epitelial moderada \\
\hline 186 & atipia epitelial moderada \\
\hline 201 & carcinoma epidermóide \\
\hline 202 & carcinoma epidermóide \\
\hline 203 & atipia epitelial intensa \\
\hline 204 & carcinoma epidermóide \\
\hline 205 & óbito \\
\hline 206 & atipia epitelial leve \\
\hline 221 & óbito \\
\hline 222 & atipia epitelial moderada \\
\hline
\end{tabular}




\begin{tabular}{|c|c|}
\hline 223 & carcinoma epidermóide \\
224 & carcinoma epidermóide \\
225 & óbito \\
226 & óbito \\
\hline 241 & carcinoma epidermóide \\
242 & carcinoma epidermóide \\
243 & carcinoma epidermóide \\
244 & carcinoma epidermóide \\
\hline 245 & carcinoma epidermóide \\
\hline 246 & carcinoma in situ \\
\hline 261 & carcinoma epidermóide \\
\hline 262 & atipia epitelial moderada \\
\hline 263 & carcinoma epidermóide \\
\hline 264 & carcinoma epidermóide \\
\hline 265 & carcinoma epidermóide \\
\hline 266 & carcinoma in situ \\
\hline
\end{tabular}

A hiperqueratose foi um achado histológico freqüente tanto nos casos sem atipia como em toda a extensão da borda lateral esquerda, ou seja, na região que recebeu a . indução química. Já os casos de atipia epiteliais, independentes do grau, mostraram um revestimento da mucosa hiperparaqueratinizado. O aumento da camada de queratina é comumente encontrado como resposta a agentes traumáticos mecânicos ou químicos, normalmente é o primeiro tipo de resposta observado. Os casos classificados como atipia epitelial apresentaram como achado mais relevante, a duplicação das células da camada basal, e posteriormente, hipercromatismo nuclear e alteração na relação núcleocitoplasma. 
O infiltrado inflamatório observado na maioria dos casos foi do tipo crônico, escasso e localizado preferencialmente ao redor dos vasos. A lâmina própria da borda lateral da língua desses animais estudados apresentou-se com espessura muito estreita, seguida por uma ampla faixa de musculatura estriada esquelética encontrada na submucosa. Em muitos casos, mesmo com atipia celular bastante intensa no epitélio, o tecido conjuntivo adjacente apresentava pequenas alterações das características de normalidade. Essa é uma das diferenças que se pode levantar em comparação com a estrutura anatômica da língua humana, onde o grau do quadro inflamatório pode se apresentar mais intenso.

O carcinoma epidermóide foi encontrado principalmente nas últimas semanas de investigação, no entanto, alguns casos com manifestação precoce já foram observados a partir da $10^{\mathrm{a}}$ semana de indução. A figura 26 apresenta fotomicrografias exemplificando alguns achados histológicos que caracterizam o carcinoma epidermóide. 


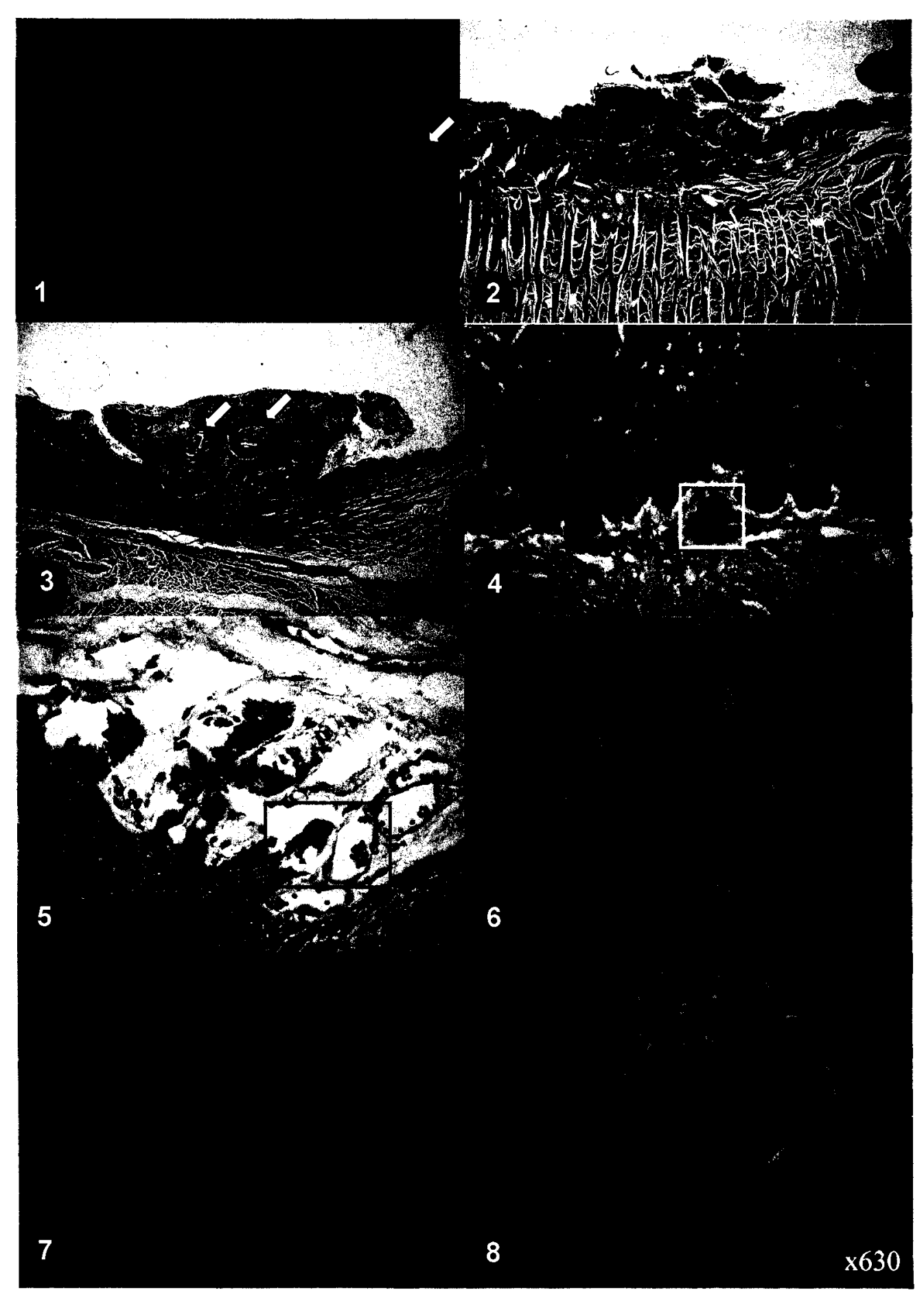

Fig.26 - Foto 1: carcinoma epidermóide com hiperparaqueratose e presença de pérolas córneas (setas). Foto 2: carcinoma epidermóide com crescimento exofitico, hiperparaqueratose e perda da estratificação. Foto 3: carcinoma epidermóide com áreas de ulceração e pérolas córneas (setas), note o escasso infiltrado inflamatório. Foto 4: ilhota neoplásica em proliferação e aparente desprendimento do epitélio (detalhe). Foto 5, 6 e 7: ilhotas neoplásicas. Foto 8: figuras de mitose.

IFSC-USP SERVICO DE PIBLIOTECA

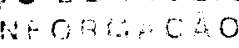




\subsection{Espectros de autofluorescência}

A análise dos espectros de autofluorescência foi realizada em função do tipo de classificação histopatológica de cada caso. A borda lateral direita de cada animal é apresentada como uma região controle individual, porém é importante salientar que não é possível garantir que a área não sofreu a ação do agente carcinogênico. Nesse sentido, esses resultados são apresentados para possibilitar a comparação dos espectros de uma área normal e da região alterada no mesmo indivíduo, na tentativa de minimizar possíveis alterações do comportamento espectral decorrentes das variações entre os animais.

As figuras 27 a 34 apresentam alguns exemplos dos espectros de autofluorescência resultantes da excitação em 442 e $532 \mathrm{~nm}$ para casos com diferentes classificações histopatológicas e características clínicas. Os gráficos mostram a intensidade de luz (em unidades arbitrárias) em função do comprimento de onda de emissão (em nanômetros). Cada curva do gráfico representa um ponto de investigação na área de interesse.

O primeiro caso apresentado (figura 27) é de uma atipia leve, com hiperqueratose. Note a presença de áreas leucoplásicas na borda lateral da língua. $\mathrm{Na}$ região de freio labial pode ser observada uma lesão papular com áreas eritematosas. Nos espectros da hiperqueratose com excitação em $532 \mathrm{~nm}$ há a formação de uma banda de emissão centrada em $636 \mathrm{~nm}$, que não é observada na borda lateral direita. Já em alguns 
pontos investigados da lesão, essa mesma banda de emissão aparece mais evidente, i.e. em maior intensidade.
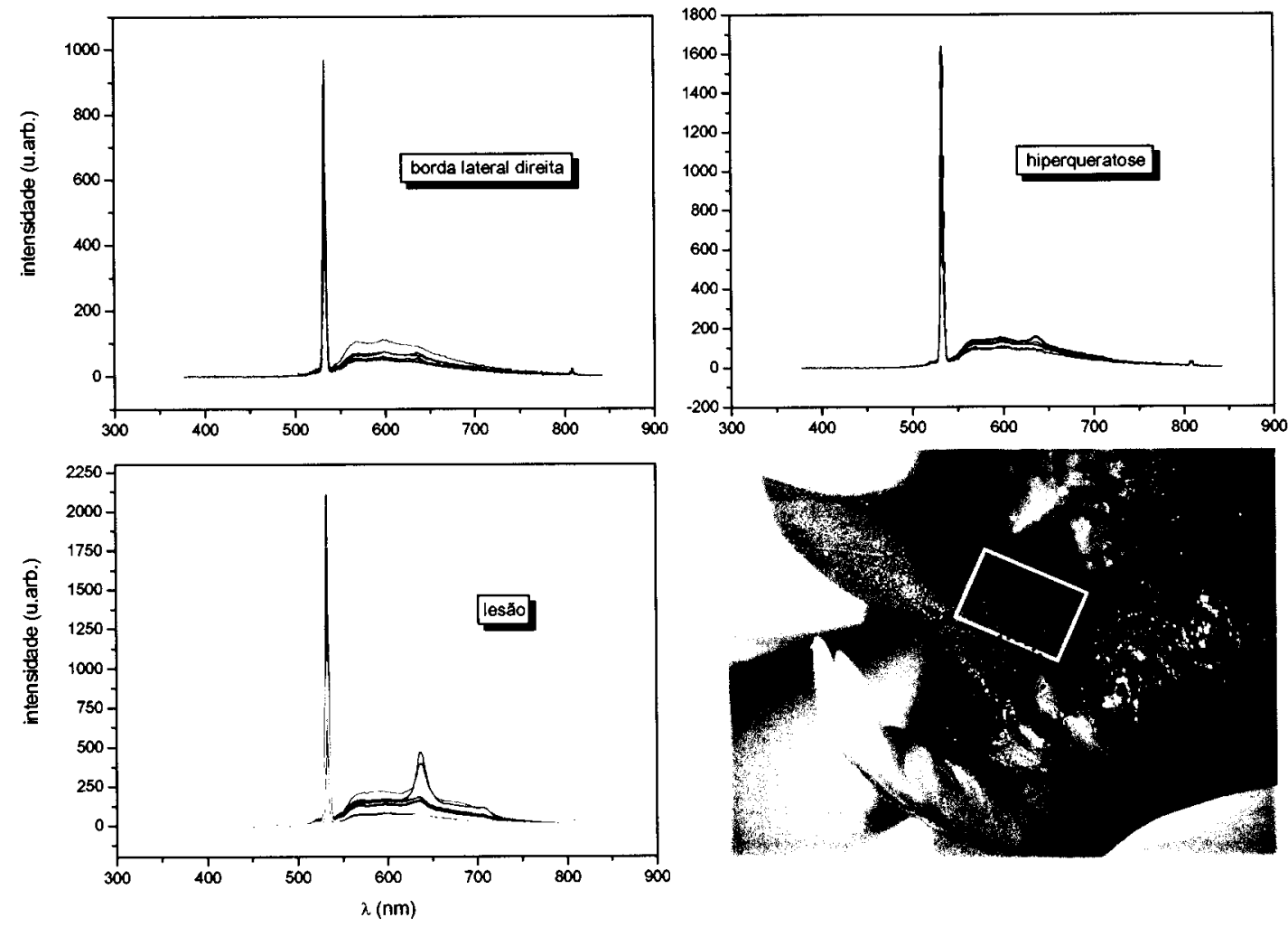

Fig.27A - Espectros de autofluorescência com excitação em $532 \mathrm{~nm}$ para a borda lateral direita (normal), hiperqueratose e lesão hiperplásica. Na fotografia do caso: a região com hiperqueratose (destaque branco) e a lesão (destaque preto). 

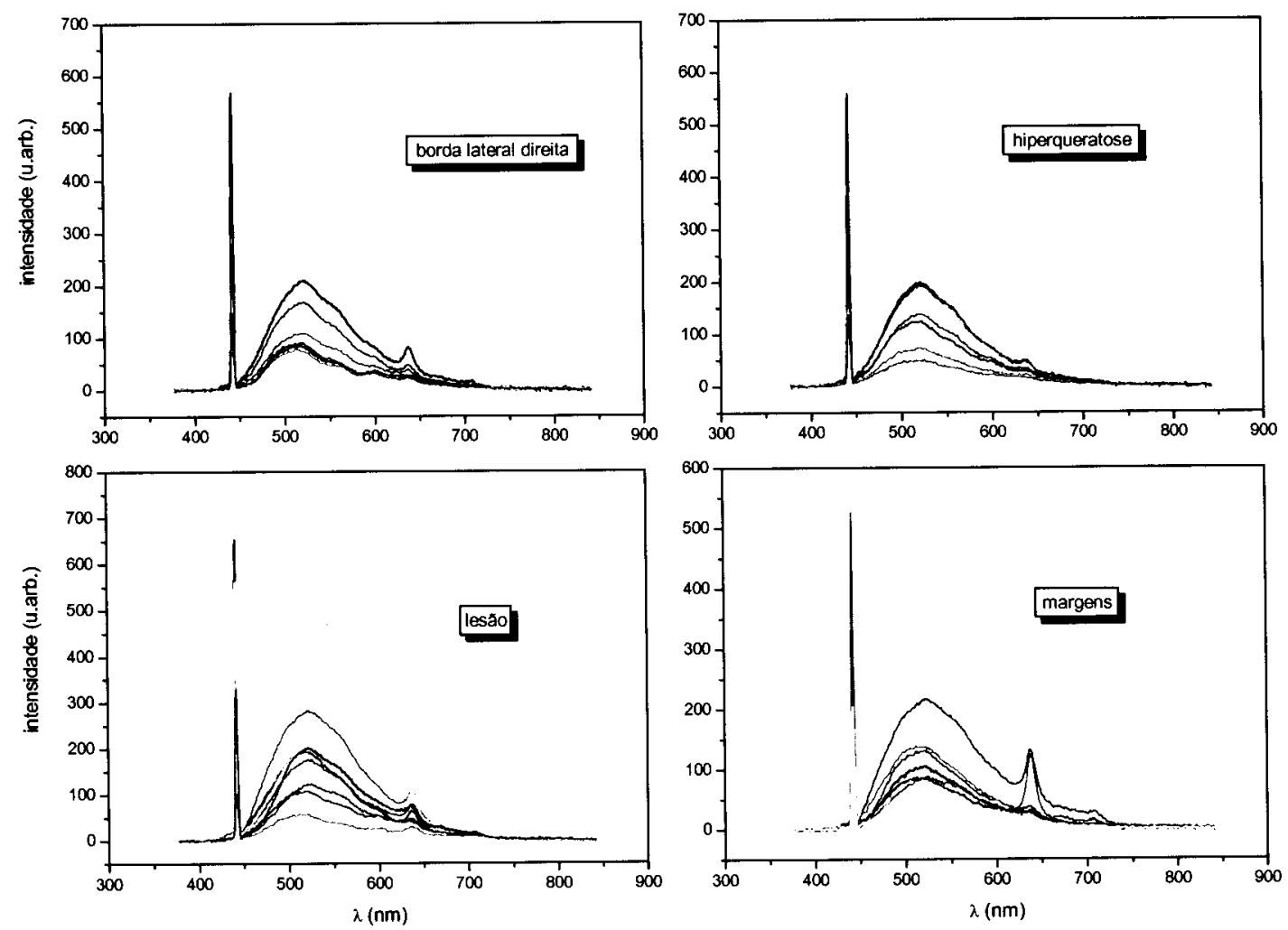

Fig. $27 \mathrm{~B}$ - Espectros de autofluorescência com excitação em $442 \mathrm{~nm}$ para as mesmas regiões da fig. $27 \mathrm{~A}$ e também de pontos investigado nas margens da lesão.

Os espectros para o mesmo caso com excitação em $442 \mathrm{~nm}$ mostraram-se semelhantes quando a borda lateral direita e a hiperqueratose foram comparadas, os resultados de ambas apresentaram a banda de emissão centrada em $636 \mathrm{~nm}$, não foi possível uma diferenciação adequada das regiões investigadas. A lesão apresenta comportamento espectral distinto dependendo do ponto de investigação, em algumas áreas a banda de emissão, com um pequeno deslocamento, centrada em $637 \mathrm{~nm}$, possui 
uma contribuição relativa maior para a fluorescência com o achatamento da banda principal ao redor de $520 \mathrm{~nm}$. Nas margens, esse comportamento foi até mais evidente, como é o caso da curva rosa, com a banda de emissão centrada em $638 \mathrm{~nm}$ sendo a mais importante, correspondendo a uma área ulcerada, que pode ser visualizada como uma região eritematosa.

Com excitação em $442 \mathrm{~nm}$ também puderam ser observados alguns pontos com a mesma banda de emissão na região do vermelho, no entanto, nenhuma lesão clínica e nem um quadro histológico alterado foram detectados, que pudessem justificar esse comportamento espectral.

O segundo caso mostra um animal com uma lesão com classificação de atipia moderada (figura 28). O gráfico da borda lateral esquerda, com excitação em $532 \mathrm{~nm}$, apresentou curvas com comportamento semelhante ao lado direito e outras com comportamento distinto. Isso é resultado do tipo de leitura, sendo que os pontos são investigados no sentido posterior-anterior da borda lateral da língua e, conseqüentemente, os espectros podem corresponder a áreas de normalidade e alteradas. 

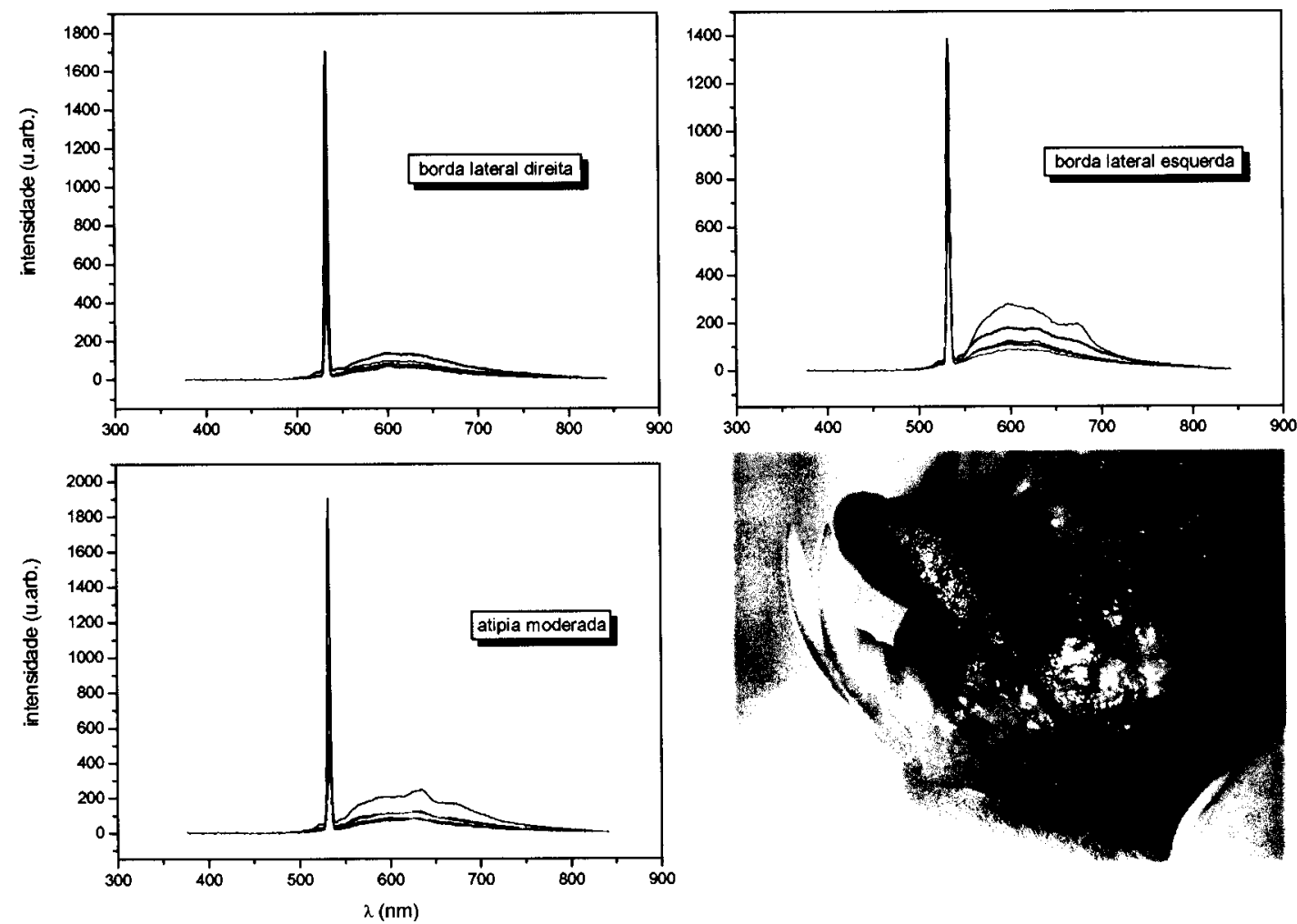

Fig.28A - Espectros de autofluorescência com excitação em $532 \mathrm{~nm}$ comparando as bordas lateral direita e esquerda e a lesão com atipia moderada. Fotografia: lesão com crescimento exofítico. 

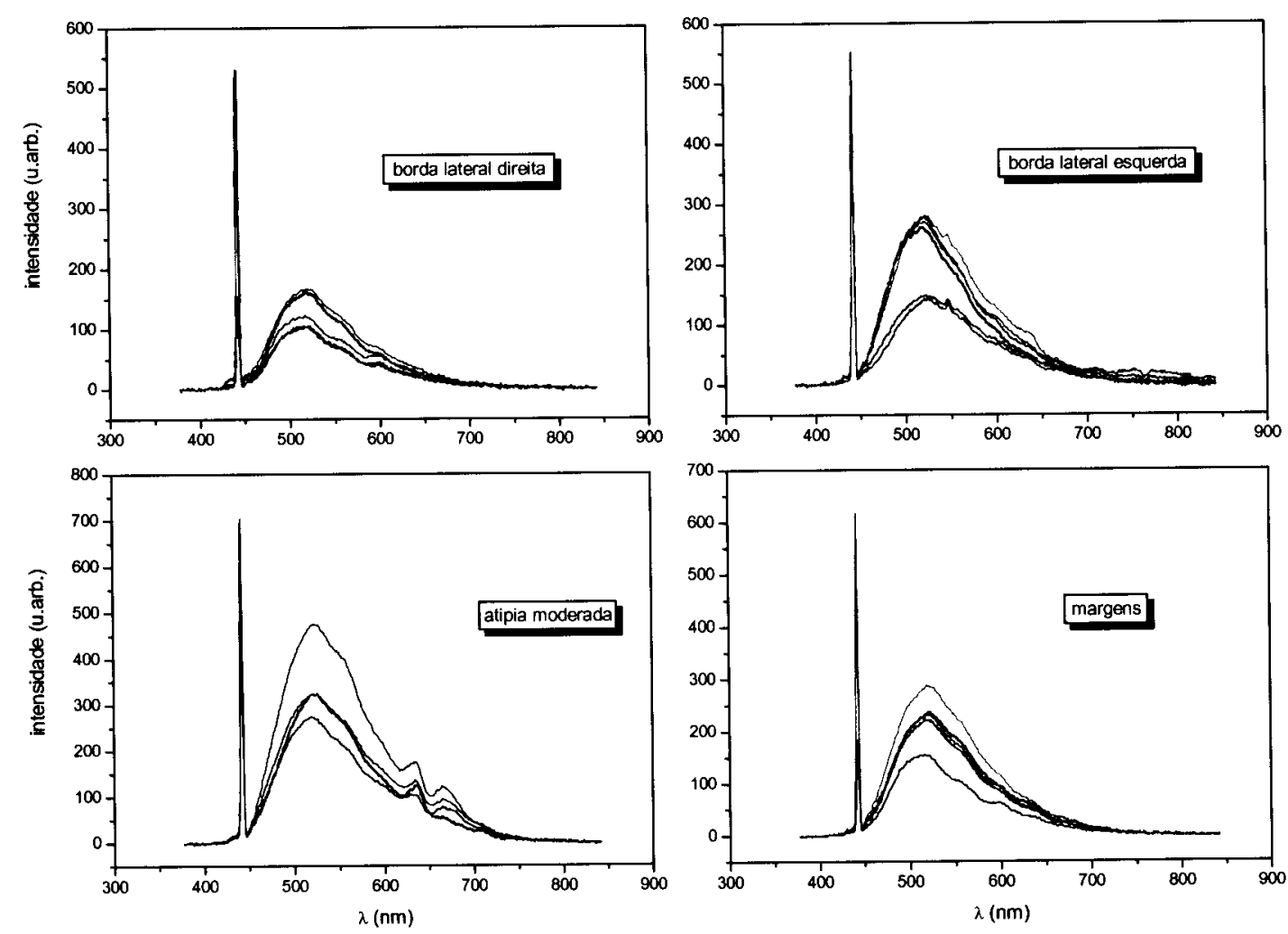

Fig. $28 B$ - Espectros de autofluorescência com excitação em $442 \mathrm{~nm}$ para as mesmas regiões da fig. 28 A e também das margens da lesão.

Isso não foi evidente com excitação em $442 \mathrm{~nm}$, no entanto, a diferenciação da lesão em comparação com a borda lateral direita foi mais clara. A banda de emissão da lesão, após excitação em 532 nm, surgiu centrada em 634 nm e com excitação em 442 $\mathrm{nm}$ duas bandas foram observadas, em 634 e $665 \mathrm{~nm}$. 

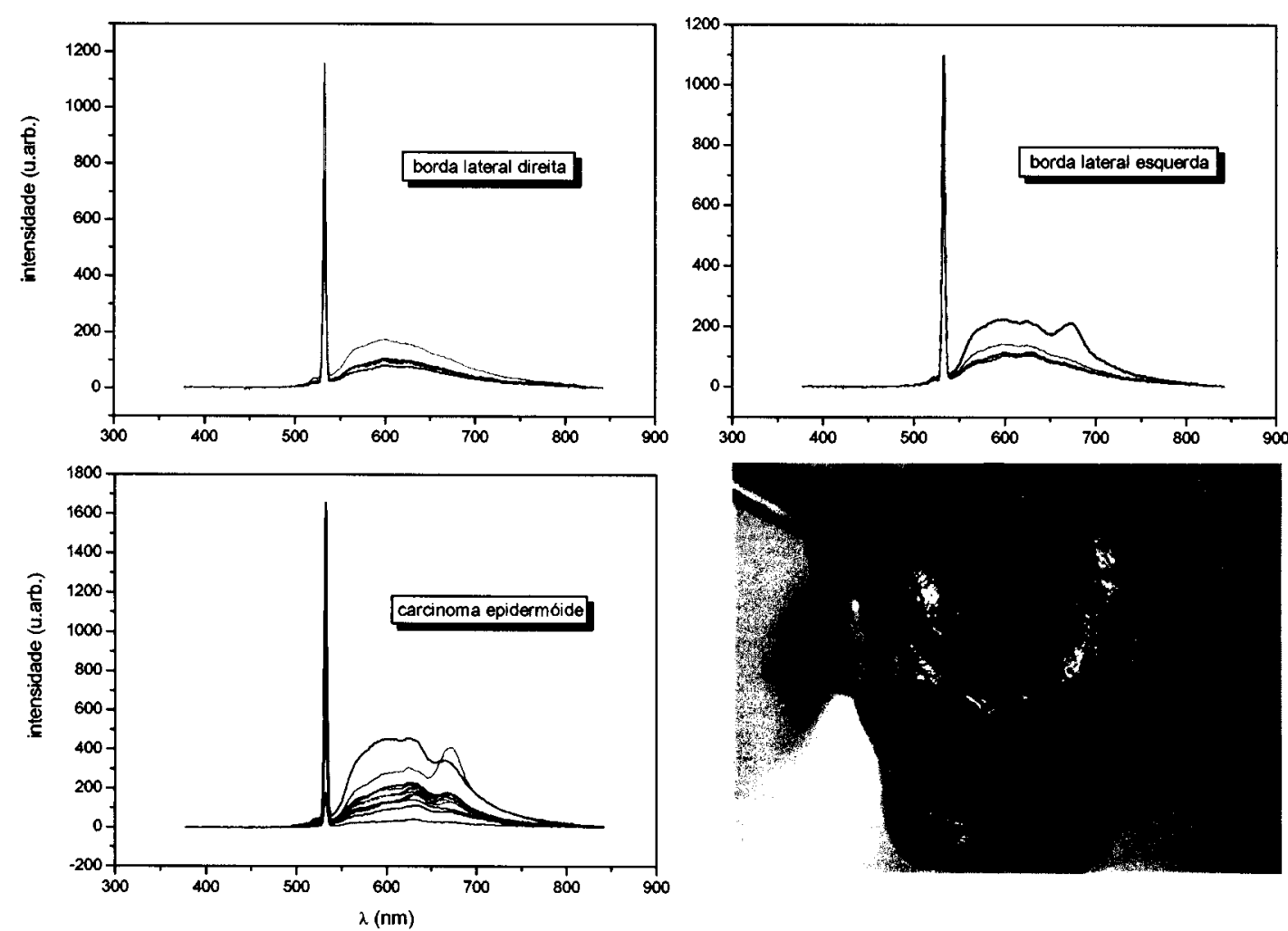

Fig.29A - Espectros de autofluorescência com excitação em $532 \mathrm{~nm}$ comparando as bordas lateral direita e esquerda e a lesão (carcinoma epidermóide). Fotografia: lesão com crescimento exofitico e base pediculada.

O terceiro caso é de um carcinoma epidermóide (figura 29). Da mesma forma que no caso anterior, a excitação violeta mostrou-se mais eficiente na distinção dos espectros de autofluorescência da lesão e do normal. Uma banda de emissão bastante importante aparece centrada em $672 \mathrm{~nm}$ para as duas excitações empregadas mostrando 
um deslocamento ao redor de $7 \mathrm{~nm}$ para a região do infravermelho da segunda banda da atipia moderada.
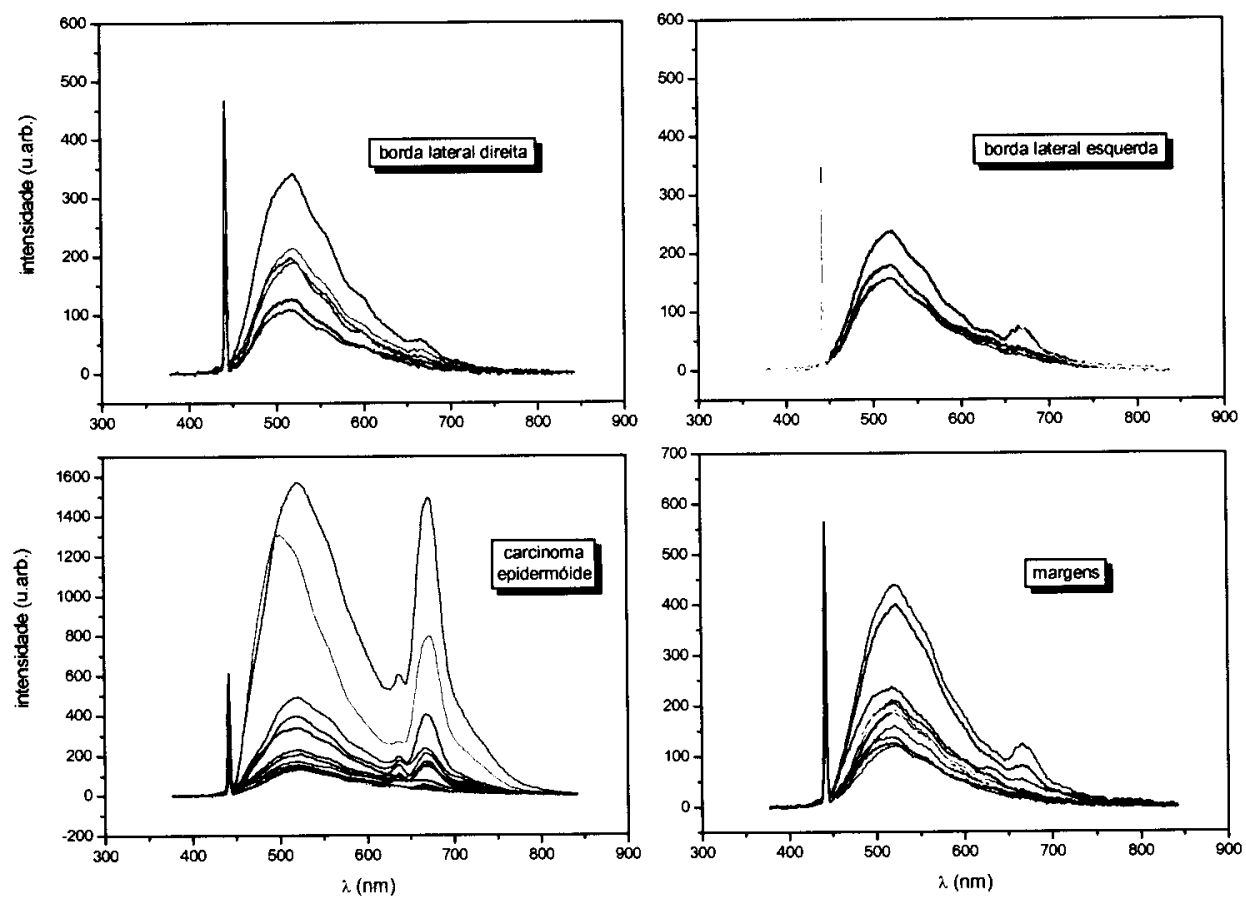

Fig.29B - Espectros de autofluorescência com excitação em $442 \mathrm{~nm}$ para as mesmas regiões da fig. 29 A e também das margens da lesão. 
Os casos apresentados a seguir também são de carcinoma epidermóide, no entanto, as características clínicas, assim como as histológicas, são variáveis, podendo também ser verificado em comportamentos distintos da autofluorescência.
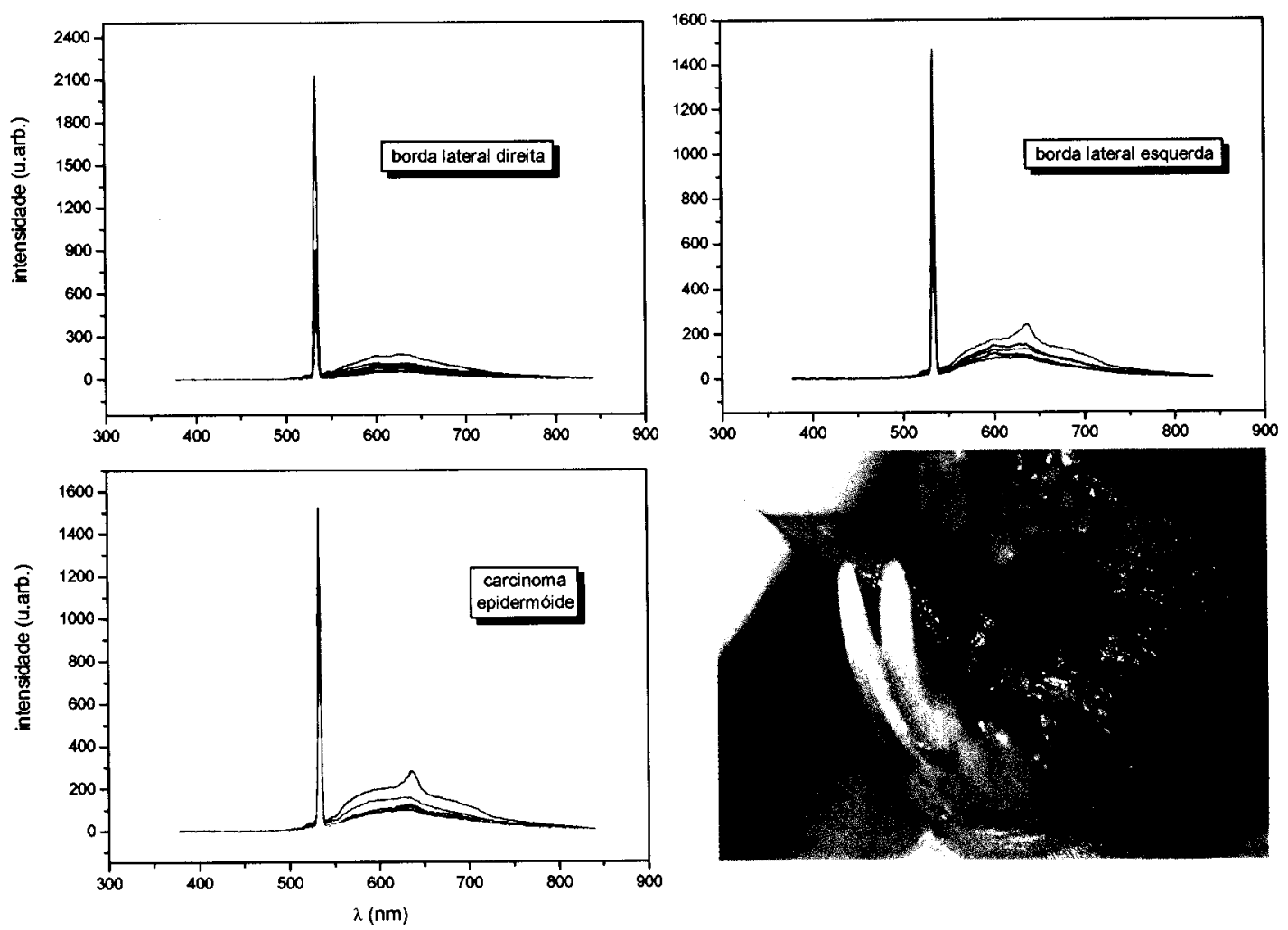

Fig.30A - Espectros de autofluorescência com excitação em $532 \mathrm{~nm}$ comparando as bordas lateral direita e esquerda e a lesão (carcinoma epidermóide). Fotografia: lesão com crescimento exofitico e base pediculada. IFSC-USP SERVICOODE BIBLIOTECA
INFORIMAOAO 

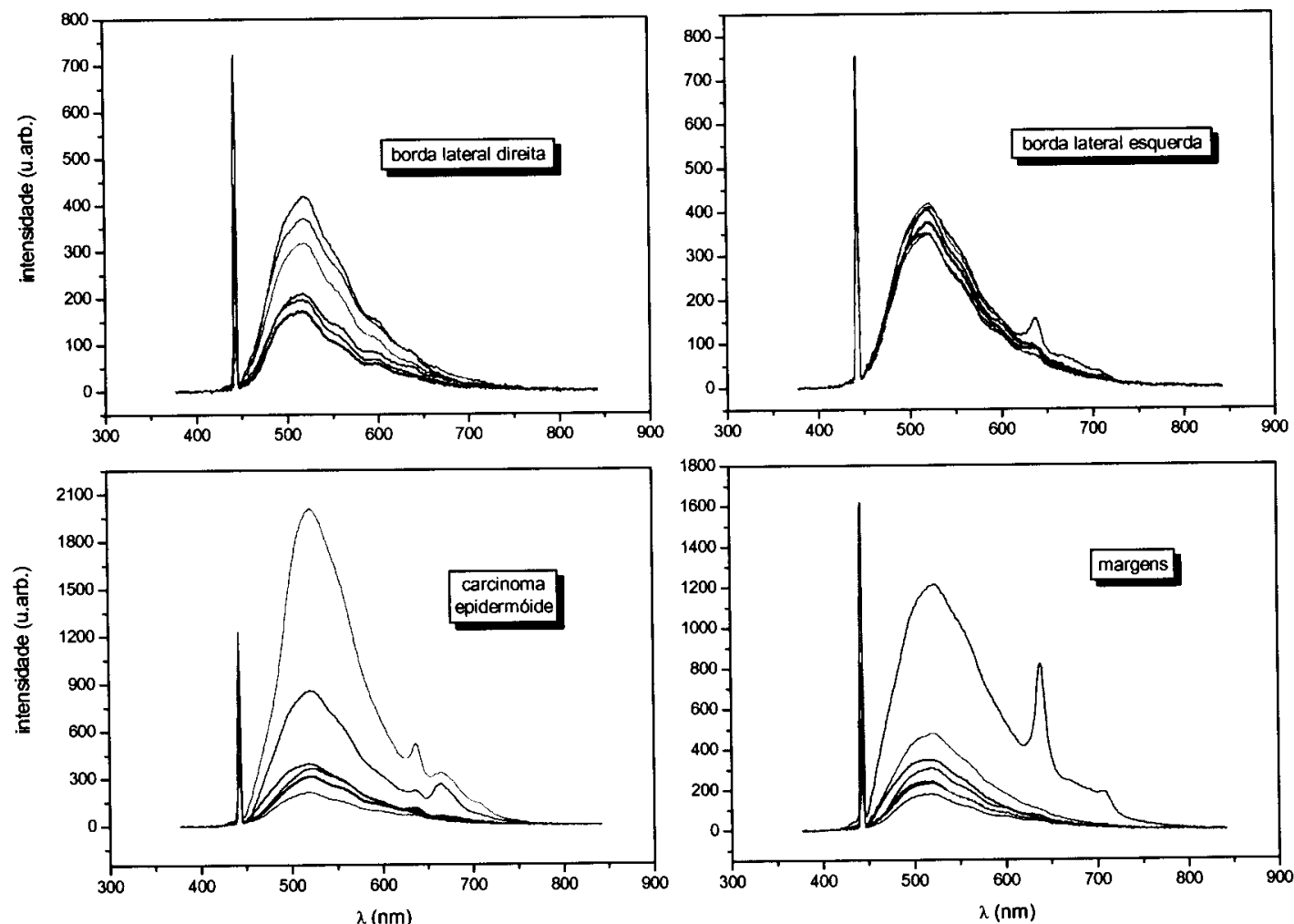

Fig.30B - Espectros de autofluorescência com excitação em $442 \mathrm{~nm}$ para as mesmas regiões da fig.30A e também das margens da lesão.

Em comparação ao carcinoma epidermóide do caso da figura 29 , a lesão da figura 30 clinicamente mostra-se com um tecido menos vascularizado e uma superfície mais leucoplásica. Nesse último, a excitação em $532 \mathrm{~nm}$ induziu a emissão de uma banda centrada em $636 \mathrm{~nm}$, para $442 \mathrm{~nm}$, as bandas foram em 636 e $665 \mathrm{~nm}$ para lesão e nas margens alguns pontos apresentaram uma banda bastante evidente em $638 \mathrm{~nm}$ e um achatamento ao redor de $705 \mathrm{~nm}$. 
O carcinoma epidermóide da figura 31 apresenta um crescimento exofítico de base séssil e uma mucosa de superfície lisa e coloração sem grandes alterações em comparação à da mucosa do tecido normal. Mesmo assim, os espectros resultantes em ambas excitações evidenciaram diferenças tanto em intensidades emitidas, como é claro em alguns pontos investigados com $532 \mathrm{~nm}$, como com a emissão de novas bandas em 636 e $675 \mathrm{~nm}$ e em 636 e $666 \mathrm{~nm}$ para excitação com $442 \mathrm{~nm}$.
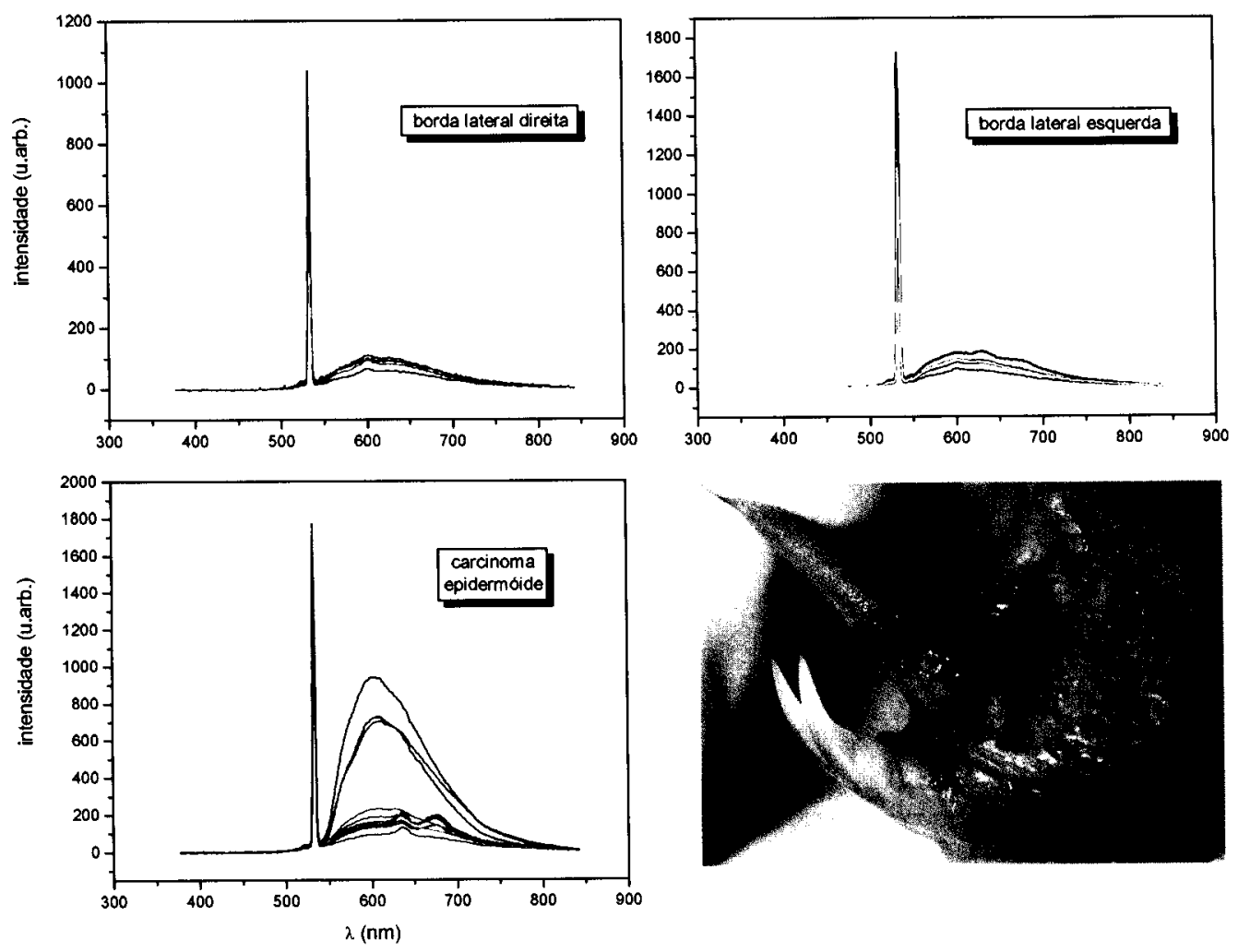

Fig.31A - Espectros de autofluorescência com excitação em $532 \mathrm{~nm}$ comparando as bordas lateral direita e esquerda e a lesão (carcinoma epidermóide). Fotografia: lesão com crescimento exofitico e base séssil. 

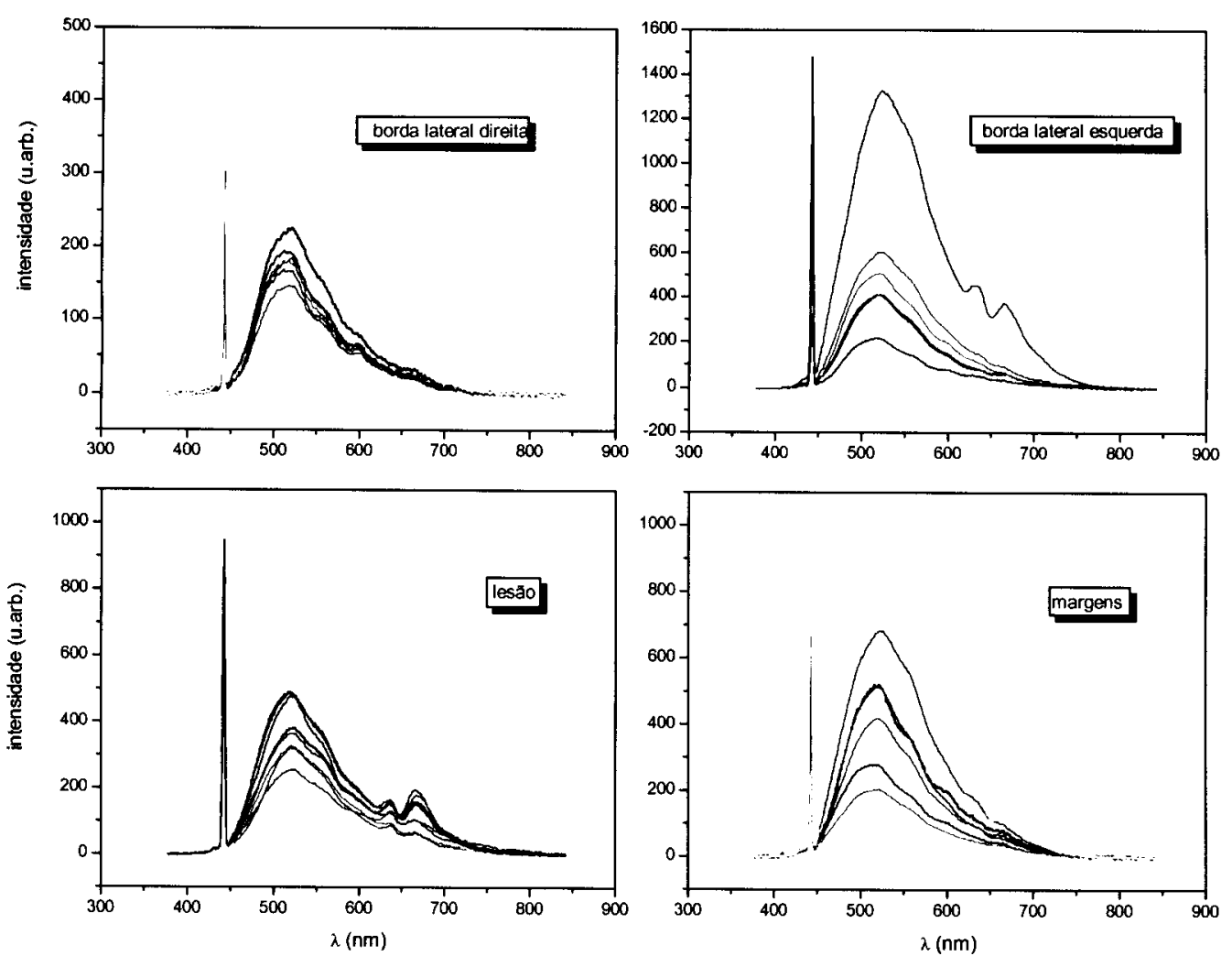

Fig.31B - Espectros de autofluorescência com excitação em $442 \mathrm{~nm}$ para as mesmas regiões da fig. $31 \mathrm{~A}$ e também das margens da lesão.

Os casos apresentados nas figuras 32 e 33, apesar de ambos mostrarem áreas leucoplásicas e eritematosas, tanto as características clínicas dessas regiões como os espectros de fluorescência obtidos são diferentes. De qualquer forma, nas duas lesões, a diferenciação foi mais evidente para as áreas leucoplásicas. No primeiro caso (figura 32), a região leucoplásica é facilmente diferenciada da área eritematosa, constituindo-se 
de uma camada espessa de queratina (células mortas), fator que contribuiu para a maior intensidade de luz espalhada observada. Já no outro caso (figura 33), as áreas leucoplásicas se encontram entremeadas pelas áreas eritematosas, a lesão apresenta uma superfície irregular e papilomatosa. A camada de queratina é menos espessa e em áreas com diâmetros inferiores ao da sonda, a investigação isolada das regiões leucoplásicas e eritematosas não foi possível, assim, alguns pontos de leitura estavam presentes em áreas mistas.
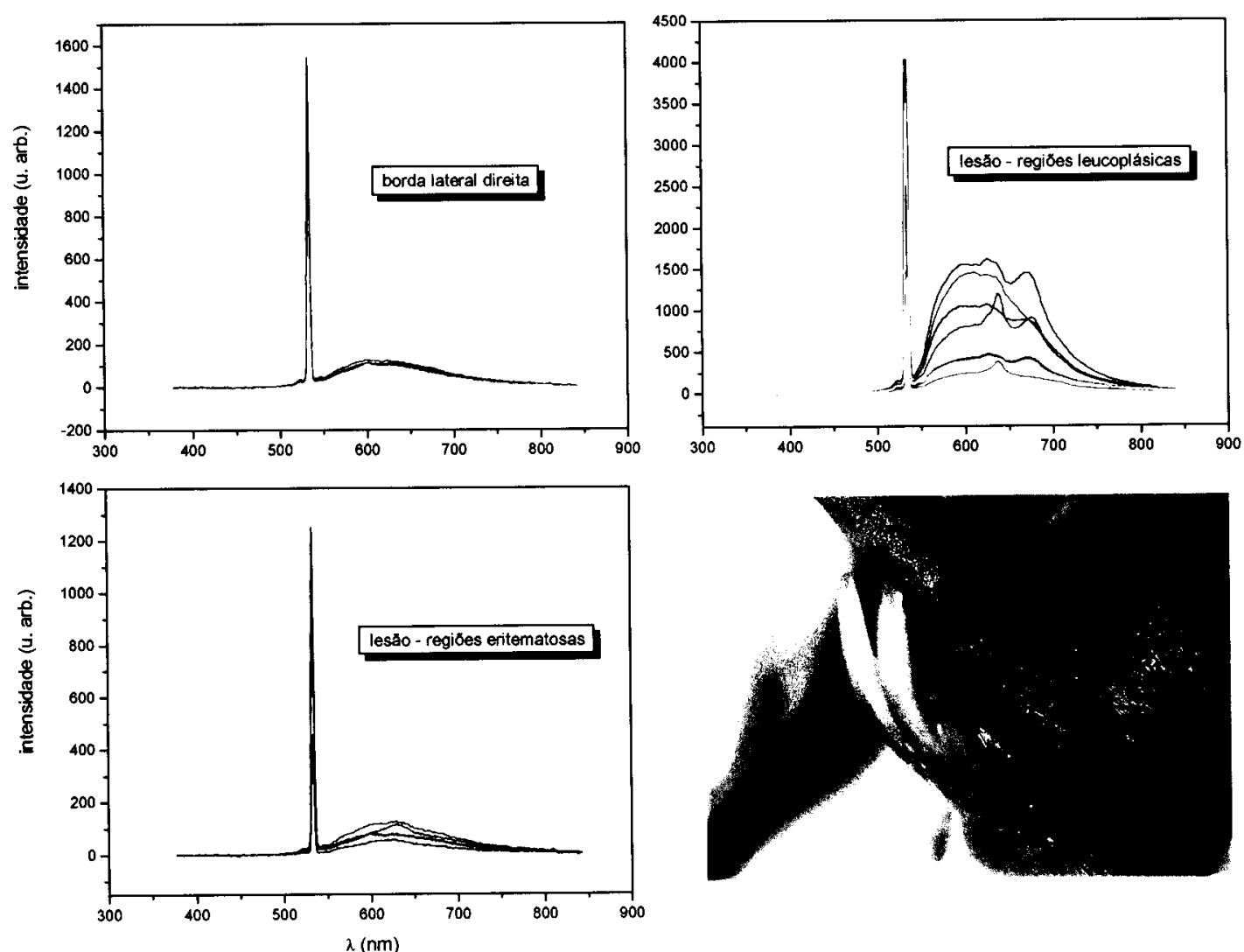

Fig. $32 \mathrm{~A}$ - Espectros de autofluorescência com excitação em $532 \mathrm{~nm}$ comparando as bordas lateral direita e esquerda e a lesão (carcinoma epidermóide). Fotografia: lesão com crescimento exofitico e áreas leucoplásicas e eritematosas. 
Para excitação no verde e no violeta, as bandas de emissão nas áreas leucoplásicas do caso da figura 32 foram centradas em 636 e ao redor de $670 \mathrm{~nm}$. As regiões eritematosas da lesão não foram adequadamente discriminadas do tecido normal por nenhum dos comprimentos de onda empregados.
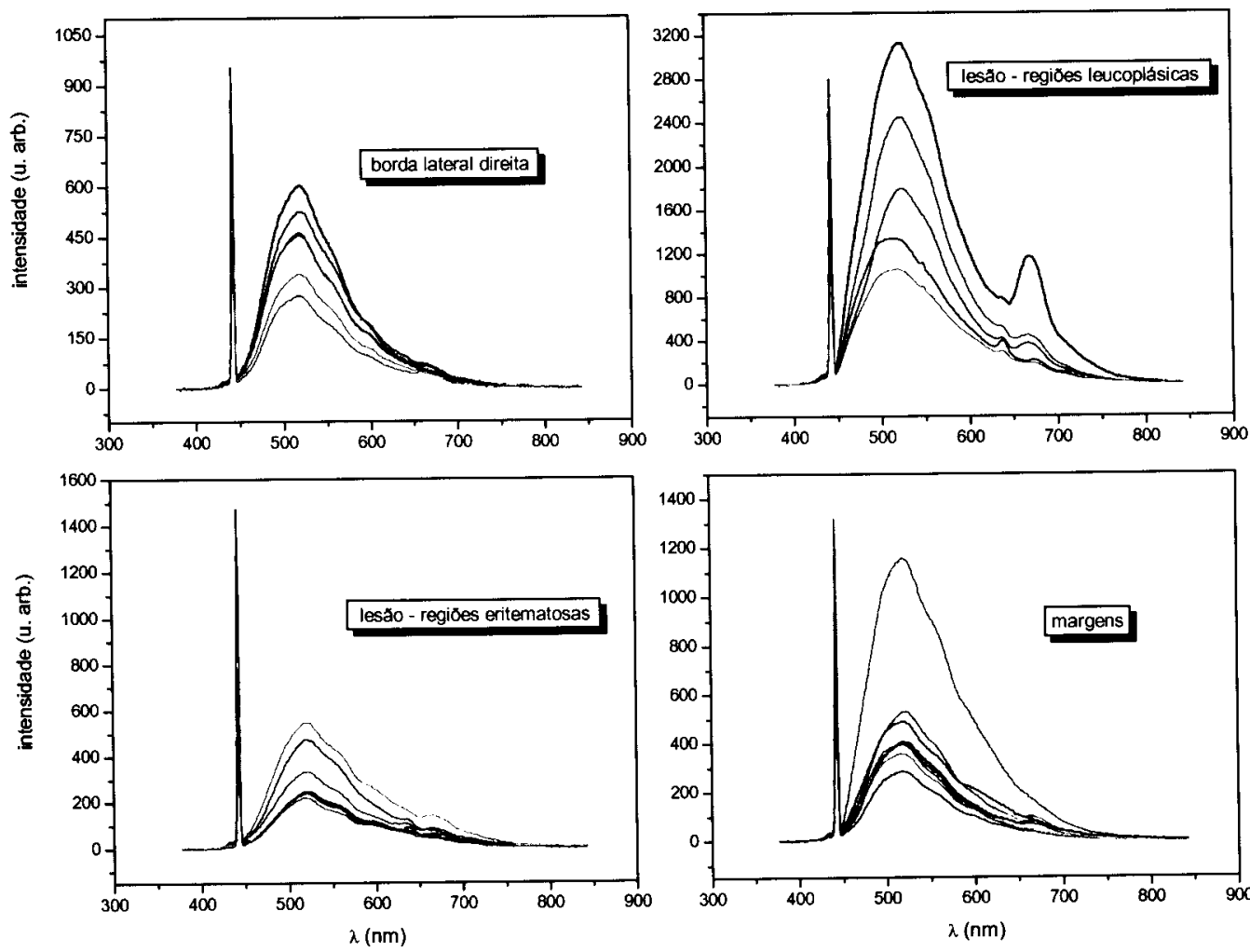

Fig.32B - Espectros de autofluorescência com excitação em $442 \mathrm{~nm}$ para as mesmas regiões da fig. $32 \mathrm{~A}$ e também das margens da lesão. 
As áreas leucoplásicas da figura 33 mostraram bandas de emissão em 636 e 675 nm e as eritematosas em 635 e $676 \mathrm{~nm}$ com excitação em $532 \mathrm{~nm}$. Como a resolução espectral do sistema é de $5 \mathrm{~nm}$, essa variação não é relevante.
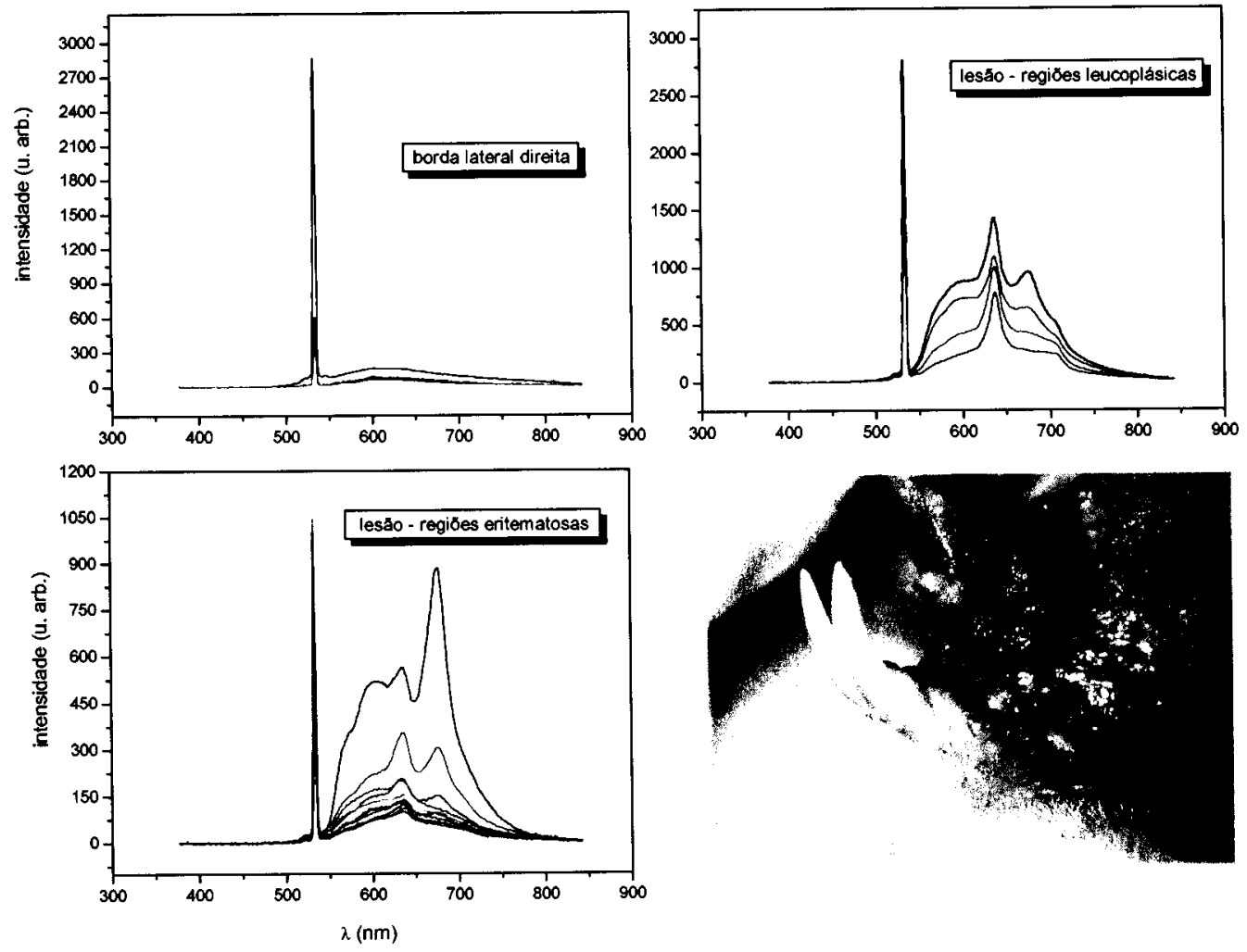

Fig. 33A - Espectros de autofluorescência com excitação em $532 \mathrm{~nm}$ comparando as bordas lateral direita e esquerda e a lesão (carcinoma epidermóide). Fotografia: lesão com crescimento exofitico e áreas leucoplásicas e eritematosas.

Com excitação violeta, a diferenciação pode ser realizada com a identificação de uma banda em $637 \mathrm{~nm}$, que foi mais importante nas áreas leucoplásicas e outra em 664 nm que não é evidente em todos os pontos de leitura. 

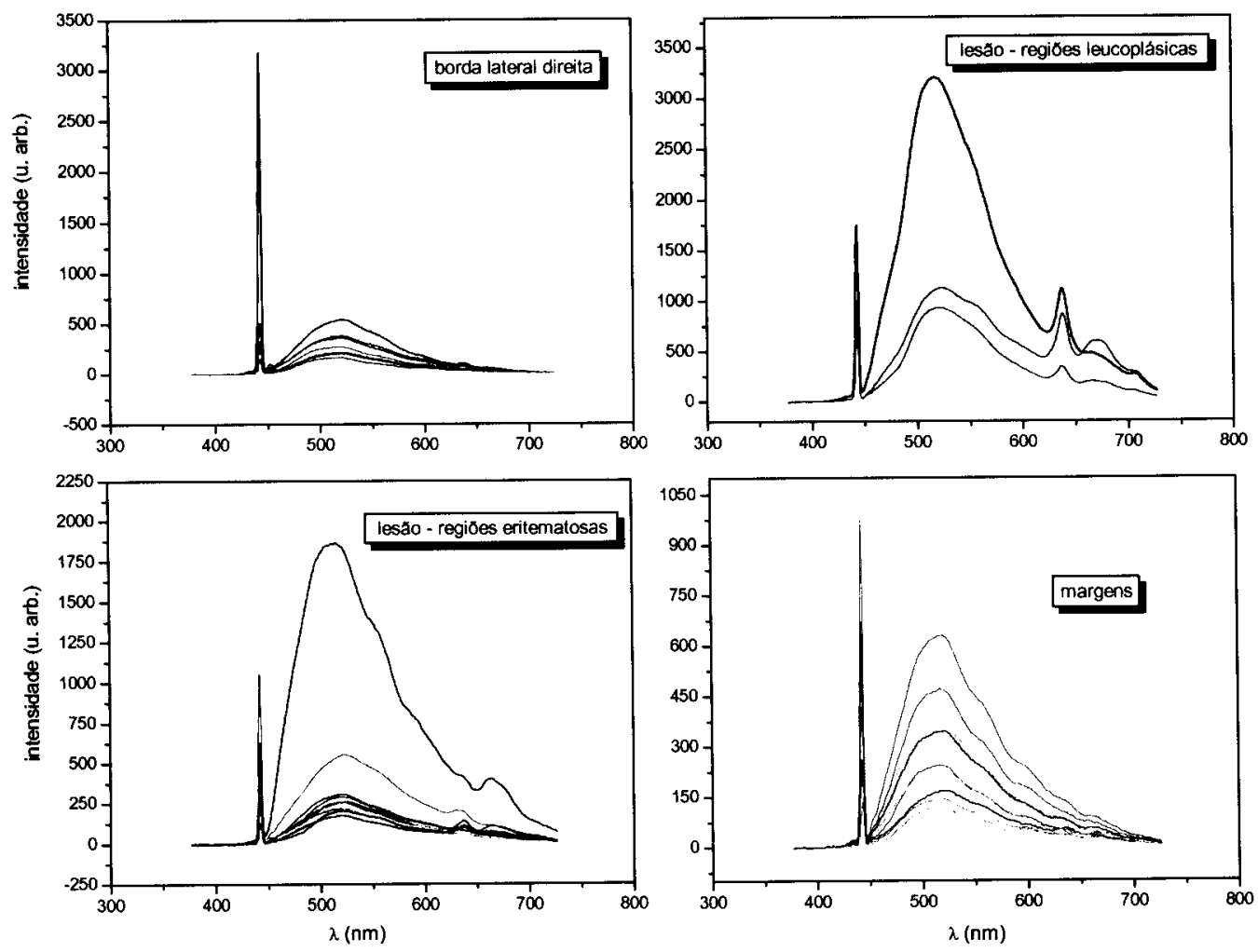

Fig.33B - Espectros de autofluorescência com excitação em $442 \mathrm{~nm}$ para as mesmas regiões da fig. 33 A e também das margens da lesão.

O último caso apresentado é de uma lesão com desenvolvimento distinto dos carcinomas anteriores. A evolução clínica resultou em uma lesão ulcerada com alto grau de invasividade nos tecidos subjacentes à mucosa com bordas elevadas e endurecidas (figura 34). Essa lesão é a que clinicamente teria um pior prognóstico considerando as chances de sucesso do tratamento. Outra característica clínica importante para a interação luz/tecido biológico é a presença de tecido necrótico no centro da lesão. A região foi cuidadosamente limpa antes da leitura da fluorescência, no entanto a porção 
aderida à lesão não foi completamente removida para evitar um quadro hemorrágico. As lesões ulceradas também apresentam um maior grau de contaminação por microrganismos orais, sendo que de maior importância para os resultados espectrais é a contaminação bacteriana, já que algumas espécies produzem porfirina, podendo mascarar o resultado da fluorescência intrínseca do tecido.
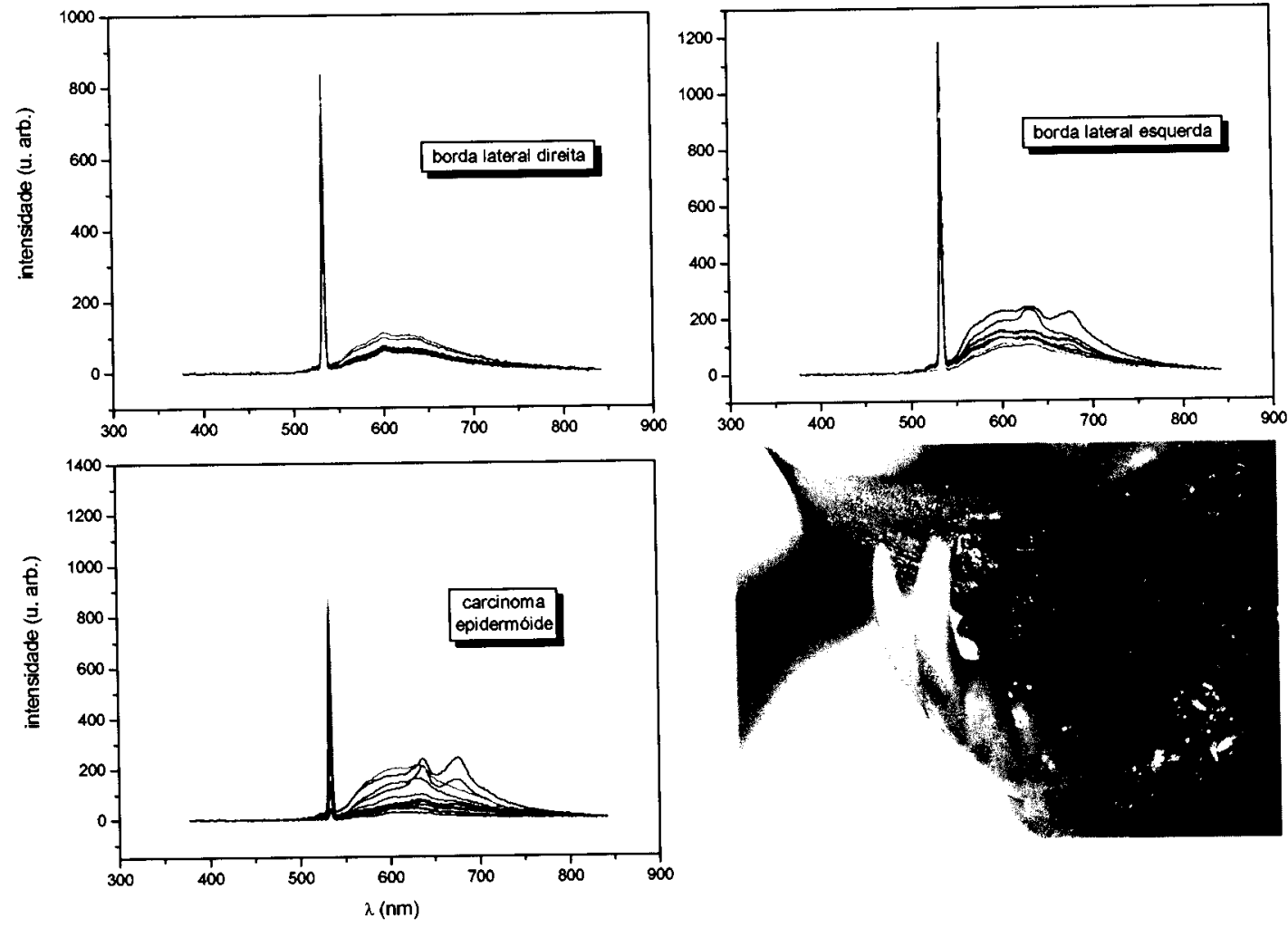

Fig. 34A - Espectros de autofluorescência com excitação em $532 \mathrm{~nm}$ comparando as bordas lateral direita e esquerda e a lesão (carcinoma epidermóide). Fotografia: lesão ulcerada e com alto grau de invasividade. 
As bandas de emissão para essa lesão foram evidentes em 636 e $676 \mathrm{~nm}$ com excitação verde e em 637 e 666 nm para excitação violeta. Além disso, irregularidades na fluorescência entre 515 e $615 \mathrm{~nm}$ se tornam mais evidentes.
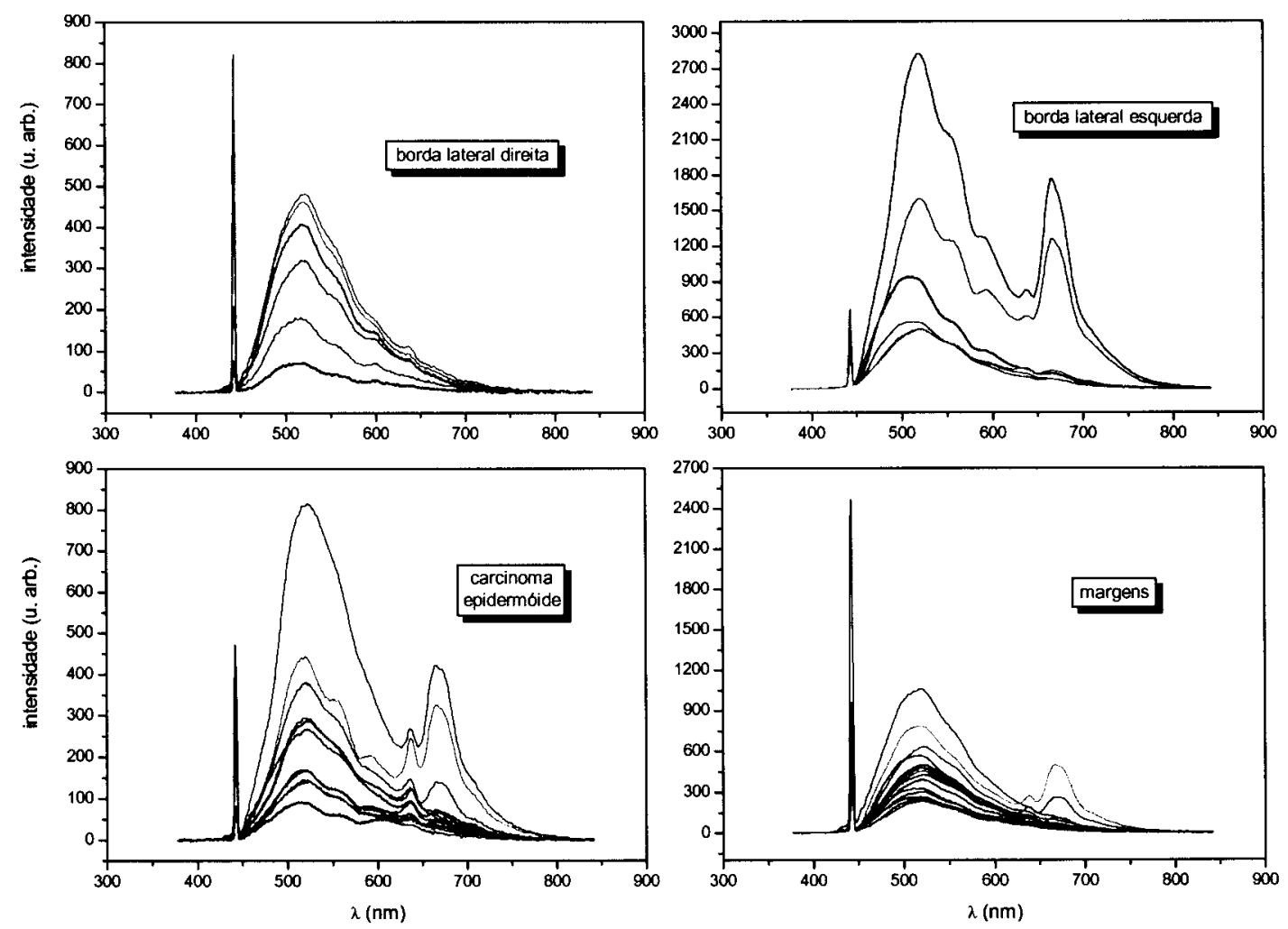

Fig.34B - Espectros de autofluorescência com excitação em $442 \mathrm{~nm}$ para as mesmas regiões da fig. $34 \mathrm{~A}$ e também das margens da lesão.

Considerando de uma forma geral os espectros de autofluorescência obtidos dos tecidos alterados (displasias e carcinoma) diferiram dos espectros do tecido normal pela emissão de novas bandas, principalmente ao redor de 635 e $670 \mathrm{~nm}$, apesar da grande variabilidade clínica e histológica das lesões. As regiões eritematosas presentes na lesão 
apresentaram uma menor intensidade de fluorescência, em comparação às regiões leucoplásicas, decorrente provavelmente pela maior presença de hemoglobina, cromóforo endógeno que absorve tanto a luz de excitação nessa região espectral (violeta-verde), como a fluorescência que está sendo emitida pelo tecido. A queratina parece exercer um importante papel nos fenômenos espalhamento/absorção e conseqüentemente na fluorescência, mas mesmo na presença de camadas mais espessas, a fluorescência proveniente dos tecidos subjacentes ainda pôde ser evidenciada.

Um importante fator a ser ressaltado é o de que a avaliação utilizando essa técnica de espectroscopia pontual investiga apenas uma pequena área do tecido alvo, i.e., o volume de tecido interagindo com a luz de excitação é pequeno. Essa situação ocorre devido: volume de interação laser/tecido biológico na região espectral utilizada é pequeno, a profundidade de penetração do laser na região violeta/verde se restringe a camadas superficiais do tecido; a intensidade de fluorescência emitida pelo tecido é bastante inferior ao fenômeno de espalhamento dificultando a sua coleta; a região espectral da fluorescência intrínseca induzida é também absorvida pela hemoglobina e por outros cromóforos endógenos minimizando ainda mais a quantidade de luz que consegue emergir da superfície tecidual.

Para estimar o volume de tecido investigado usando o sistema empregado, um experimento foi montado para detectar a sensibilidade de leitura em função da distância radial e linear entre a superfície de excitação e a coleta da fluorescência. A figura 35 mostra um desenho esquemático da leitura, onde foram utilizadas duas sondas, uma conectada ao laser de excitação e outra ao espectrômetro. As extremidades não conectadas foram cobertas evitando a influência da luz ambiente. 


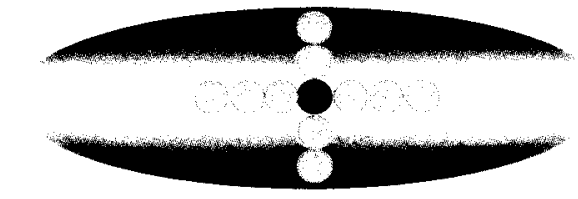

A

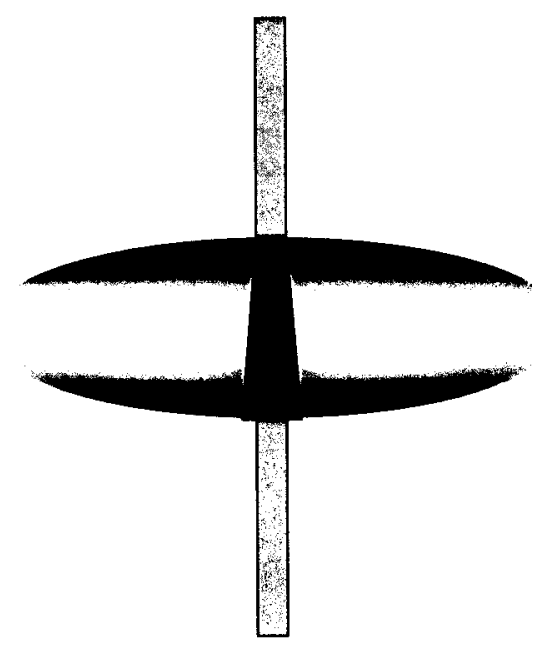

B

Fig. 35 - Desenho esquemático da leitura com variação da distância radial (A) e da distância linear $(B)$, em uma visão lateral da língua. $O$ círculo central (verde) em $A$ representa a sonda conduzindo o laser de excitação e os circulos periféricos (cinza) correspondem aos pontos de coleta com distribuição radial. $\mathrm{Em} B$, a sonda de excitação e coleta posicionadas na mesma orientação vertical.

O resultado em função da distância radial mostrou ausência de coleta de fluorescência, mesmo na menor distância analisada que foi a do diâmetro da sonda de investigação, tanto para excitação em 442 como em $532 \mathrm{~nm}$. Isso demonstrou que a leitura é realmente pontual e que não existe como avaliar uma lesão que não esteja em íntimo contato com a ponta da sonda, considerando a distância radial. Provavelmente a fluorescência que estaria saindo pela superfície vizinha à excitação está sendo absorvida pelos cromóforos endógenos e a intensidade final é muito baixa para a sensibilidade do sistema. $\mathrm{O}$ desenho da figura 36 mostra esquematicamente a absorção da fluorescência pela hemoglobina. 


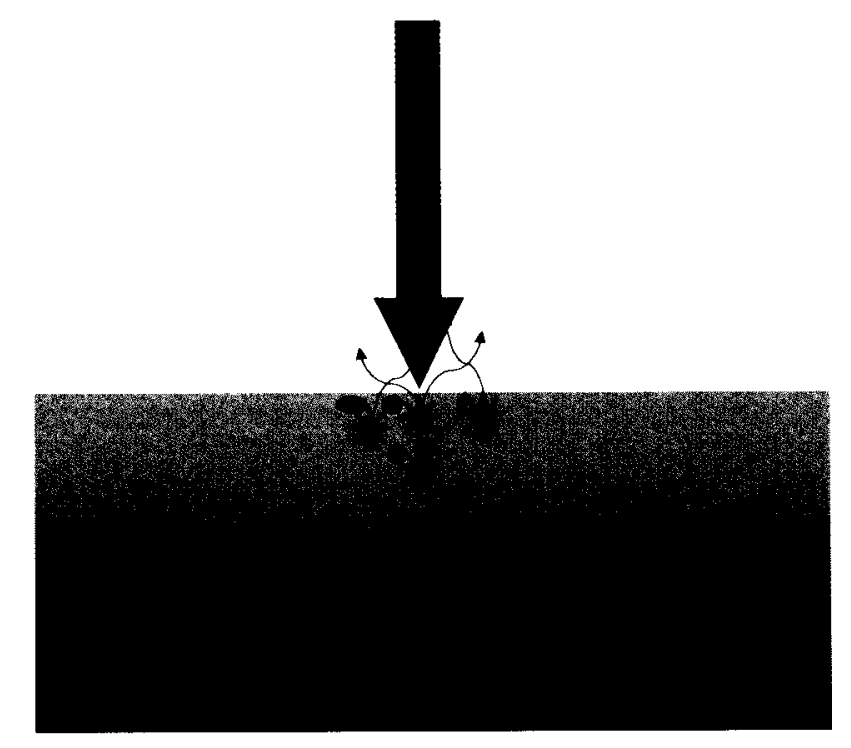

Fig.36 - Desenho esquemático da absorção da fluorescência intrínseca pela hemoglobina tecidual. A seta azul representa a luz de excitação; as figuras em forma de sol, os fluoróforos endógenos emitindo fótons; e os círculos verdes, as hemoglobinas presentes no tecido.

A leitura da distância linear foi realizada somente da espessura total da língua, variações dessa distância somente seriam possíveis caso secções longitudinais do tecido fossem empilhadas. Essa metodologia não foi escolhida uma vez que o corte mecânico da língua resultaria em quadro hemorrágico e posterior coagulação, além de que a estrutura complexa desse órgão, com mucosa especializada, tecido conjuntivo, camada muscular e mucosa do ventre lingual, faz com que a simples sobreposição dos tecidos não seja apenas um aumento da espessura do tecido, as interfaces atuam com grande influência. Desta forma, optou-se pela leitura apenas da distância entre a superfície 
iluminada e a superfície oposta e com variação da distância radial da excitação em uma projeção na face oposta. Apenas a leitura com as duas sondas na mesma orientação vertical mostrou a coleta da luz espalhada e da fluorescência, posição mostrada no desenho B da figura 35, com excitação em $532 \mathrm{~nm}$, nenhuma luz foi coletada com excitação em $442 \mathrm{~nm}$. Ao se distanciar do centro iluminado, nenhuma luz foi coletada.

Esses resultados demonstram que a investigação usando o sistema empregado é realmente pontual, não havendo coleta de informação de estruturas teciduais adjacentes ao ponto de leitura. Com relação à sensibilidade do sistema em detectar a fluorescência intrínseca de estruturas mais profundas, a profundidade de penetração da luz de excitação e a composição e arquitetura do tecido investigado devem ser considerados. A excitação com comprimentos de onda curtos, na região do ultravioleta e azul, a grande atenuação da luz existente restringe a leitura apenas para as camadas superficiais do tecido, a não ser que sejam utilizadas sondas ópticas invasivas [32]. Além disso, as características do microambiente em que os fluoróforos endógenos estão presentes têm grande influência. Comparativamente a excitação em $532 \mathrm{~nm}$ apresenta uma maior profundidade de penetração em relação à em $442 \mathrm{~nm}$, porém deve-se ter em mente que a maioria dos fluoróforos envolvidos no diagnóstico de câncer são mais eficientemente excitados na região do ultravioleta-azul. Desta forma, sempre deve haver um compromisso entre diversos fatores que contribuem para a coleta da fluorescência, muitas vezes ficando restrito a pequenos volumes e a investigação apenas de camadas superficiais do tecido biológico.

Nesse sentido, avaliando os resultados obtidos no modelo animal adotado, a hiperqueratose, o tecido necrótico e a desestruturação epitelial podem ocasionar 
distorções no espectro de fluorescência coletado, mascarando e até impedindo a fotodetecção de alteraç̃es malignas em estruturas mais profundas da lesão. Essa é uma das limitações da técnica e o avaliador deve estar ciente durante sua análise. No entanto, para o estudo de alterações no tecido epitelial, a que este trabalho se propôs, a técnica empregada é suficiente para a coleta de informação.

Apesar da grande variabilidade de evolução clínica e histológica, os espectros coletados de todas as lesões que receberam o diagnóstico histopatológico como carcinoma epidermóide e carcinoma in situ foram considerados como de um único grupo, para avaliar a validade da metodologia empregada na discriminação normal versus neoplasia, independente das variações inerentes dessa entidade patológica. Essa análise possibilitará até a avaliação da discriminação mesmo com a grande diversidade inerente dessa entidade patológica e as "confusões" que isso induz na determinação dos padrões de reconhecimento espectrais de malignidade.

Inicialmente, as novas bandas de emissão presentes na maioria dos espectros coletados nas lesões foram utilizadas como um sinal espectral de malignidade do tecido. Buscando a gradação das lesões em função desse marcador espectral, foram determinados quatro coeficientes para discriminação. Cada coeficiente foi determinado pela razão entre as integrais de dois intervalos da fluorescência. Esses intervalos foram escolhidos após a análise dos espectros de todos os animais investigados e a determinação de regiões de interesse na fluorescência emitida. Apesar do comportamento da fluorescência ser específico para cada tipo clínico da lesão, como observado anteriormente, os intervalos foram escolhidos procurando abranger todos os 
casos. Um exemplo é mostrado na figura 37 , onde os espectros do tecido normal, carcinoma e um ponto da margem da lesão são comparados.

Os coeficientes 1 e $2, A_{1}$ e $A_{2}$ respectivamente, são válidos para a fluorescência obtida com excitação em 532 nm e os coeficientes 3 e 4, $A_{3}$ e A4, para excitação em 442 nm. Os intervalos são apresentados na tabela III, os valores de referência foram determinados para a maior emissão na fluorescência do tecido sadio, centrado na intensidade máxima e a região abrangendo o intervalo com mais e menos $10 \mathrm{~nm}$.

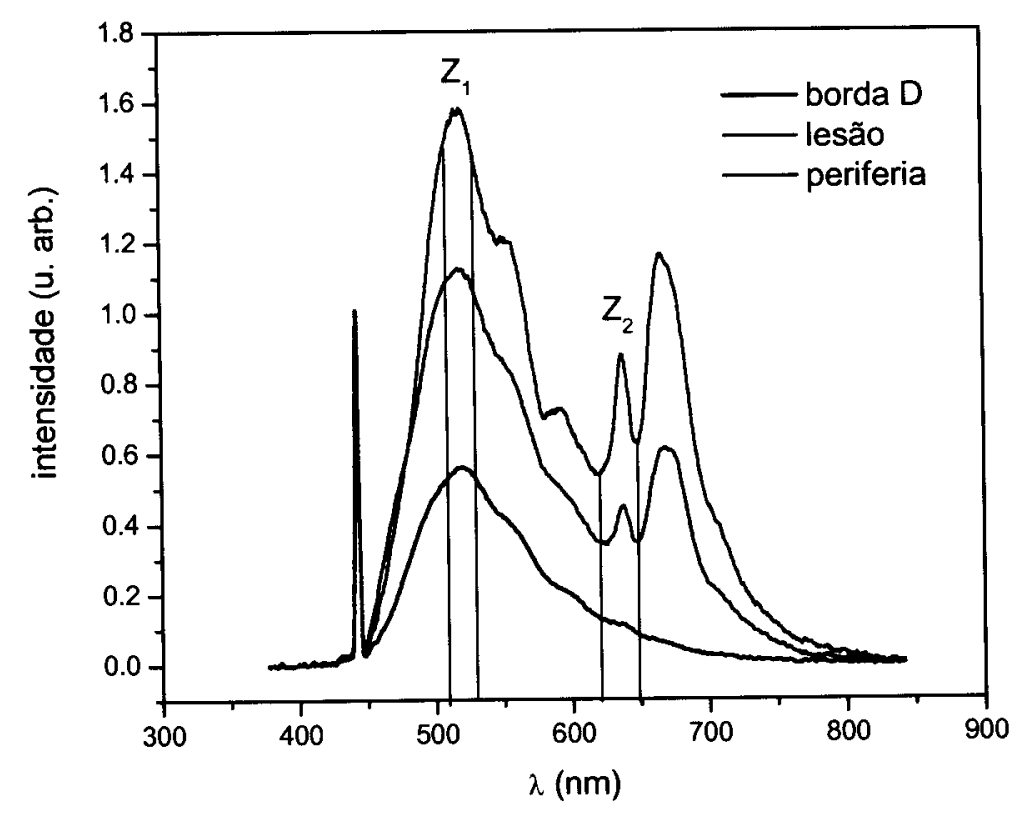

Fig.37 - Os espectros de fluorescência obtidos em tecido normal (borda D), carcinoma (lesão) e um ponto da margem da lesão (periferia) são comparados. Todo o espectro foi normalizado pela amplitude em $442 \mathrm{~nm} . Z_{1}$ e $Z_{2}$ representam as zonas de referência e interesse, respectivamente. 
Tabela III - Valores dos intervalos espectrais das zonas de referência e interesse

\begin{tabular}{|c|c|c|}
\hline Coeficiente & Intervalo referência $\left(Z_{1}\right)$ & Intervalo de interesse $\left(Z_{2}\right)$ \\
\hline $1\left(\mathrm{~A}_{1}\right)$ & $590-610 \mathrm{~nm}$ & $625-645 \mathrm{~nm}$ \\
\hline $2\left(\mathrm{~A}_{2}\right)$ & $590-610 \mathrm{~nm}$ & $650-700 \mathrm{~nm}$ \\
\hline $3\left(\mathrm{~A}_{3}\right)$ & $510-530 \mathrm{~nm}$ & $625-645 \mathrm{~nm}$ \\
\hline $4\left(\mathrm{~A}_{4}\right)$ & $510-530 \mathrm{~nm}$ & $650-700 \mathrm{~nm}$ \\
\hline
\end{tabular}

Os coeficientes são determinados pela razão entre a integral do intervalo de interesse pela integral do intervalo de referência. Sendo assim:

$$
\text { coeficiente }=\frac{\int Z 2}{\int Z 1}
$$

O engenheiro eletrônico do Grupo de Óptica do IFSC, Daniel Varela Magalhães, desenvolveu um programa em plataforma LabView ${ }^{\circledR}$ (National Instruments, EUA) para o cálculo da integral dos intervalos de referência e interesse de cada espectro de fluorescência coletado. Os coeficientes são determinados levando em consideração duas regiões de emissão dentro do mesmo espectro de fluorescência, caracterizando uma análise intra-espectral. 
A comparação dos coeficientes pode ser realizada entre sítios diferentes no mesmo animal, ou então entre os diversos tipos de lesões considerando todos os indivíduos dos grupos experimentais. A análise comparando os resultados do mesmo animal possibilitou uma melhor discriminação do tecido normal versus alterado, provavelmente por não existir a influência da variação da autofluorescência individual, a comparação é feita da lesão e um tecido normal contralateral. Um exemplo da análise no mesmo animal é apresentado na figura 38, onde é possível a avaliação da lesão tendo como base uma região controle (normal) no mesmo animal, minimizando o erro que pode ocorrer devido à variação individual.
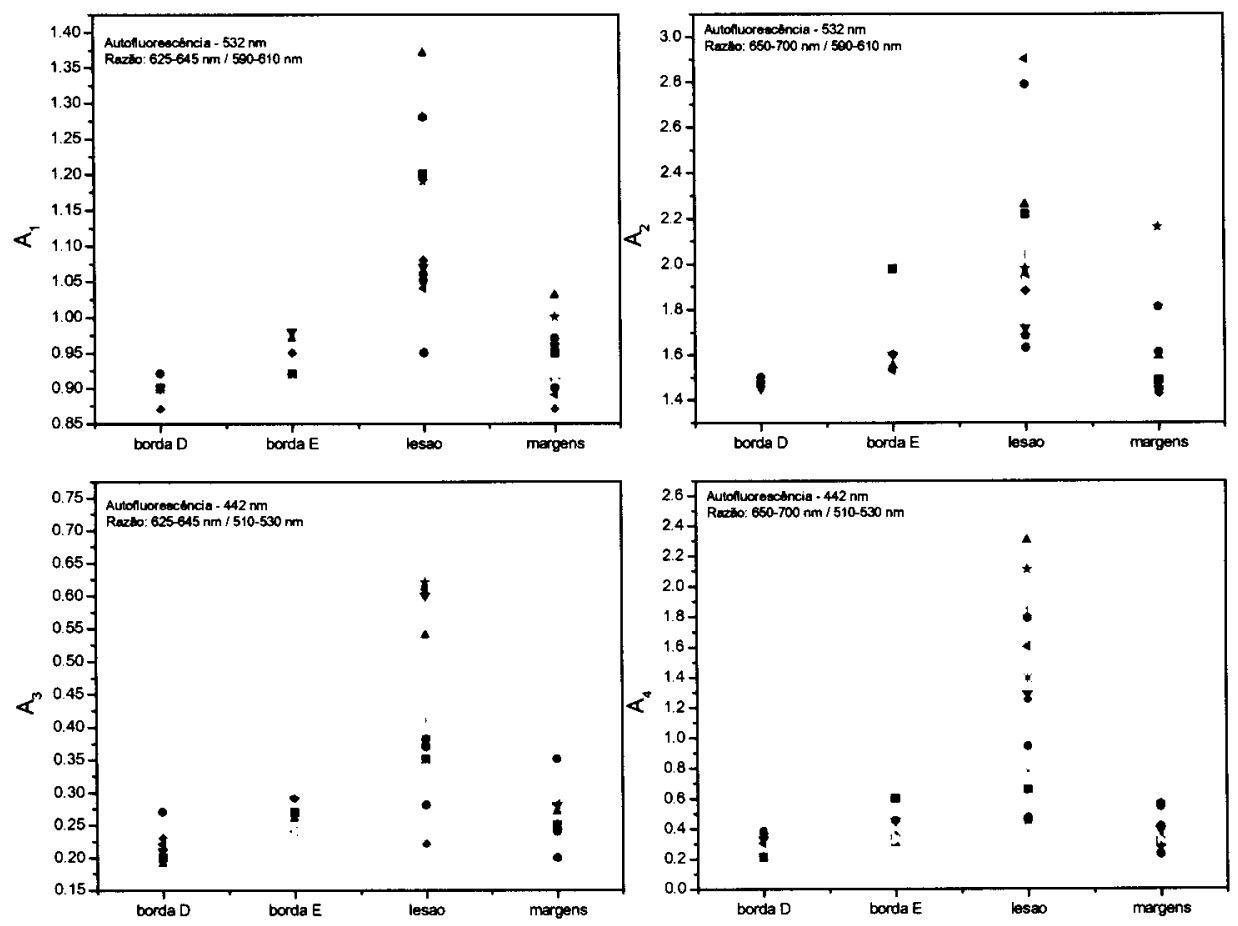

Fig. 38 - Os gráficos apresentam as quatro figuras determinadas para um animal. Note a comparação entre os diferentes sítios de investigação.

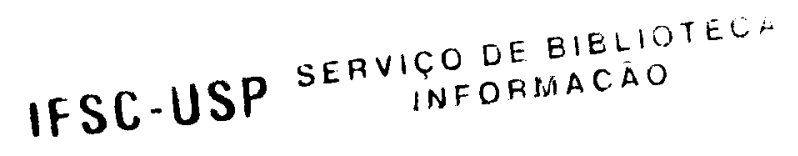


Cada ponto mostra a razão correspondente para uma leitura da investigação óptica realizada. Os pontos da lesão são os que mostram maior espalhamento, comportamento que se repetiu nos outros animais, refletindo as características heterogêneas nas diversas áreas da mesma lesão. Os mesmos resultados são mostrados como gráficos Box-chart para avaliar a distribuição dos pontos (figura 39).
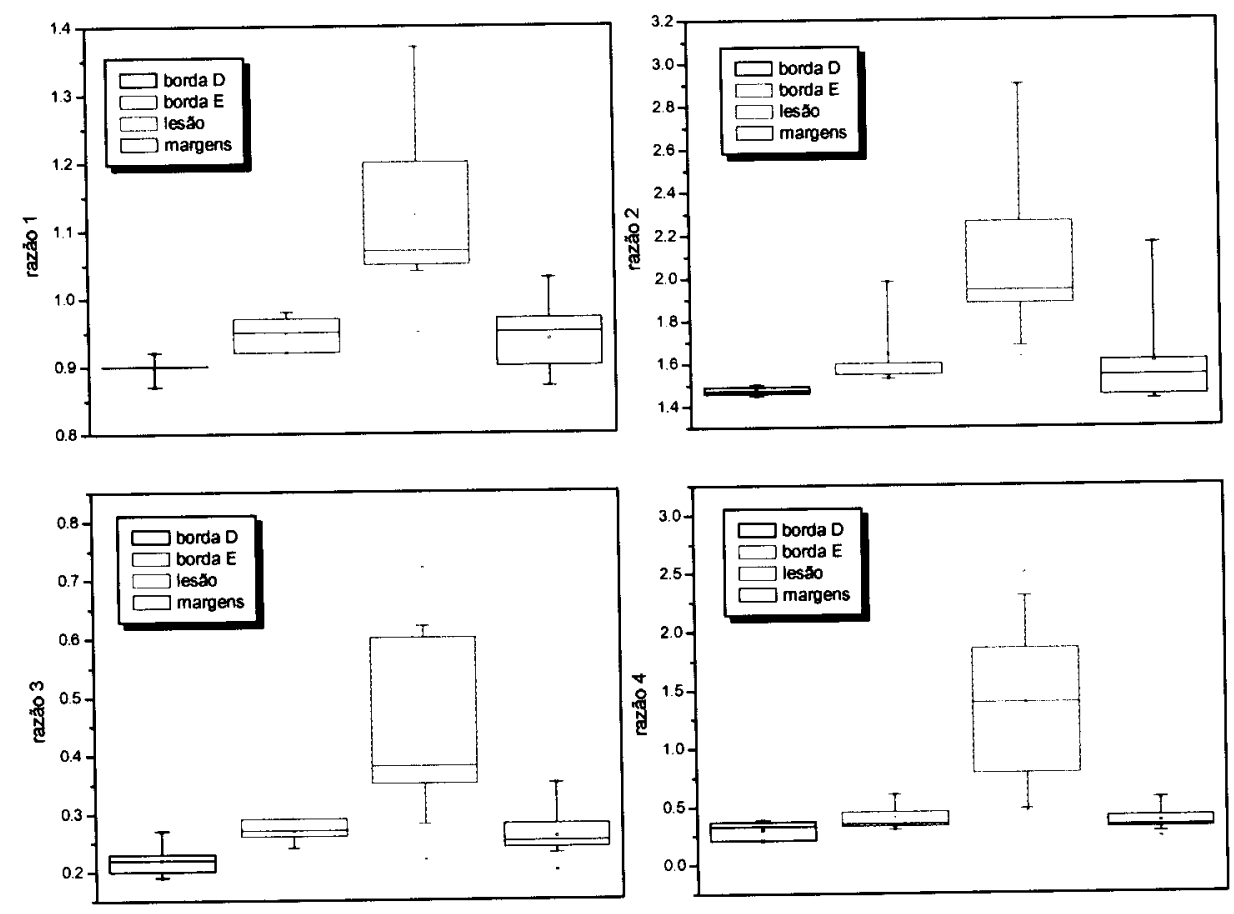

Fig.39- Gráficos Box-chart para o mesmo caso da figura 37.

Outros exemplos de animais com carcinoma epidermóide são apresentados nas figuras 40 e 41. Em algumas lesões, a diferenciação é mais evidente em comparação com outras, sendo que o coeficiente que se mostrou mais eficiente foi $\mathrm{A}_{3}$. 

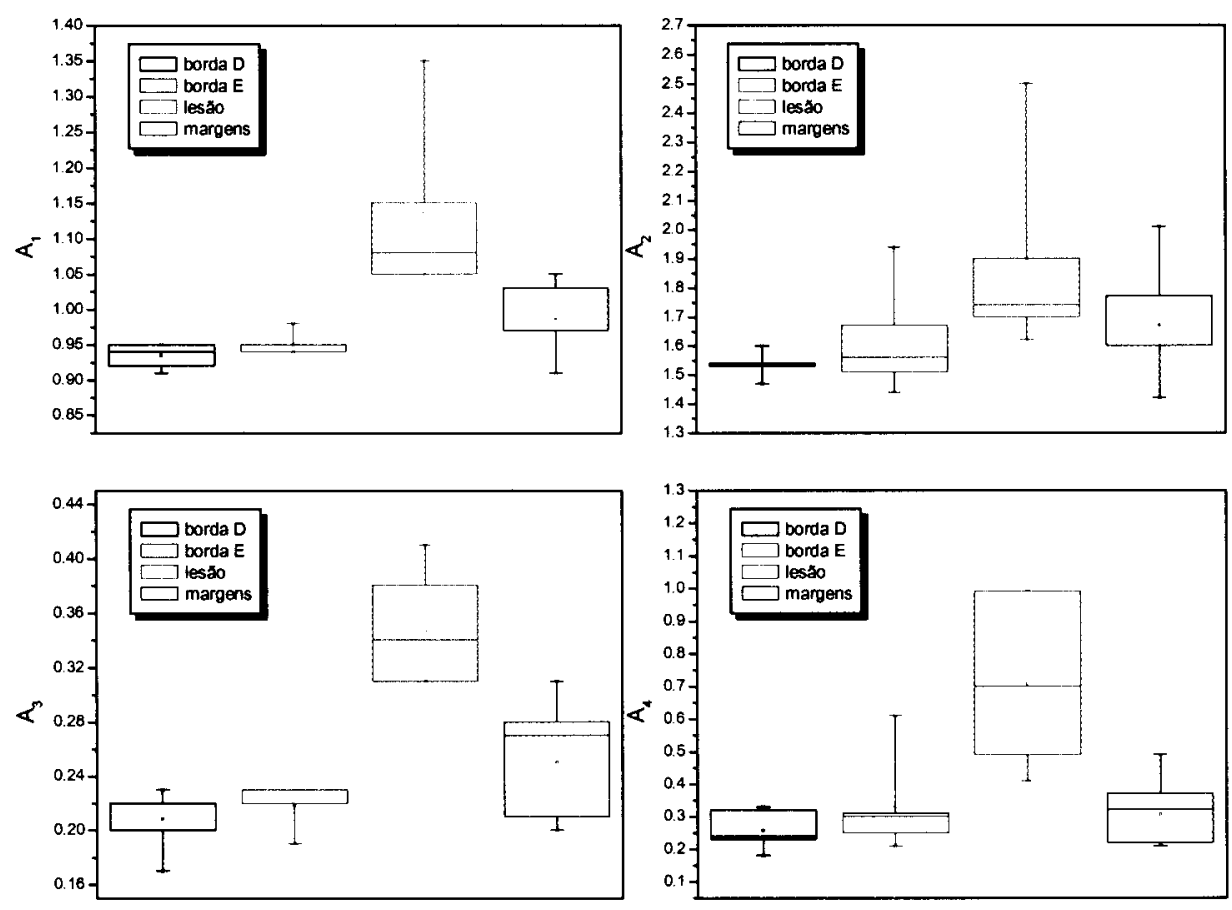

Fig. 40 - Gráficos Box-chart para excitação em 442 e $532 \mathrm{~nm}$ de um animal com carcinoma epidermóide. 

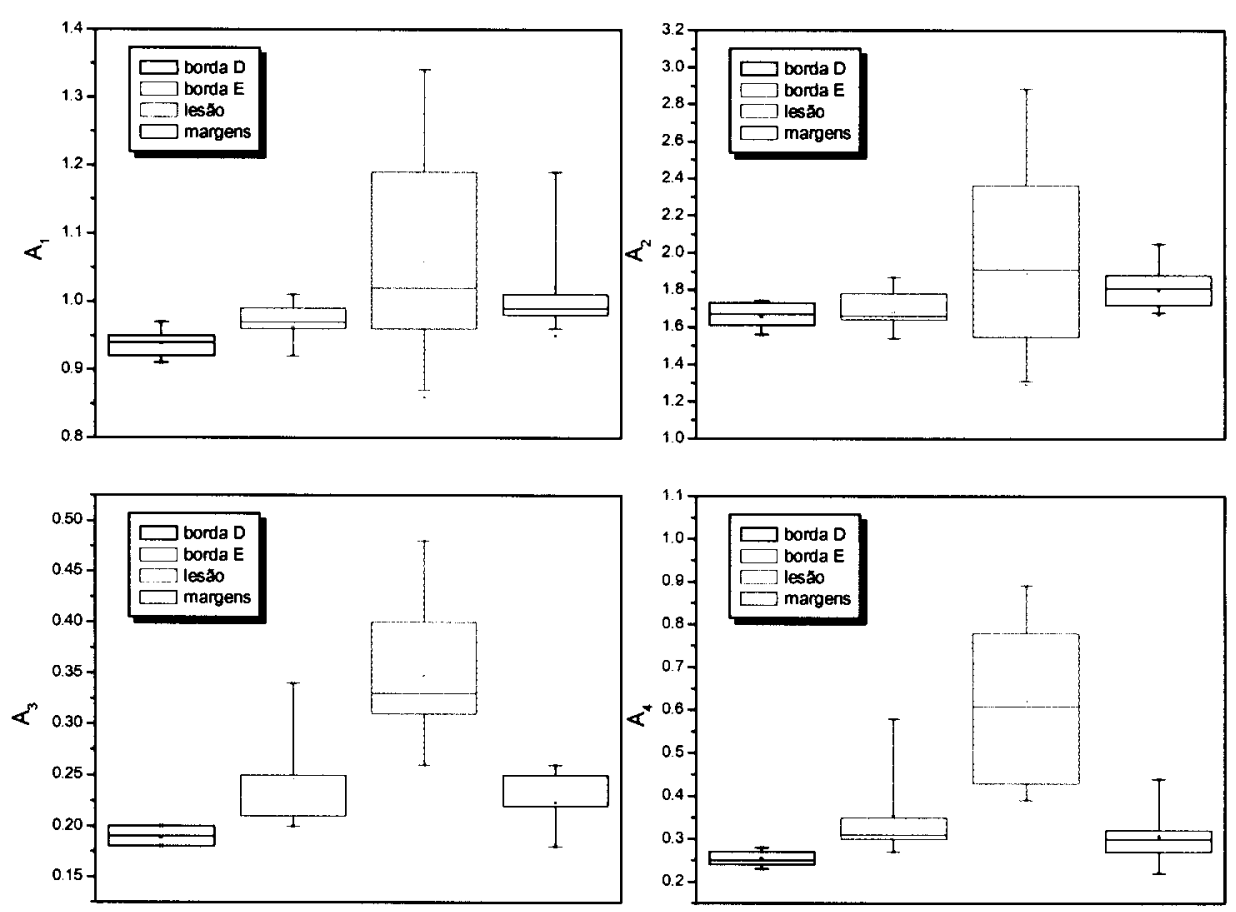

Fig. 41 - Gráficos Box-chart para excitação em 442 e 532 nm de um animal com carcinoma epidermóide.

Os casos das figuras 42 e 43 são lesões de carcinoma epidermóide nas quais foi possível a identificação clínica de duas áreas distintas, uma leucoplásica e outra eritematosa. A diferenciação também pode ser realizada quando os coeficientes determinados são comparados. 

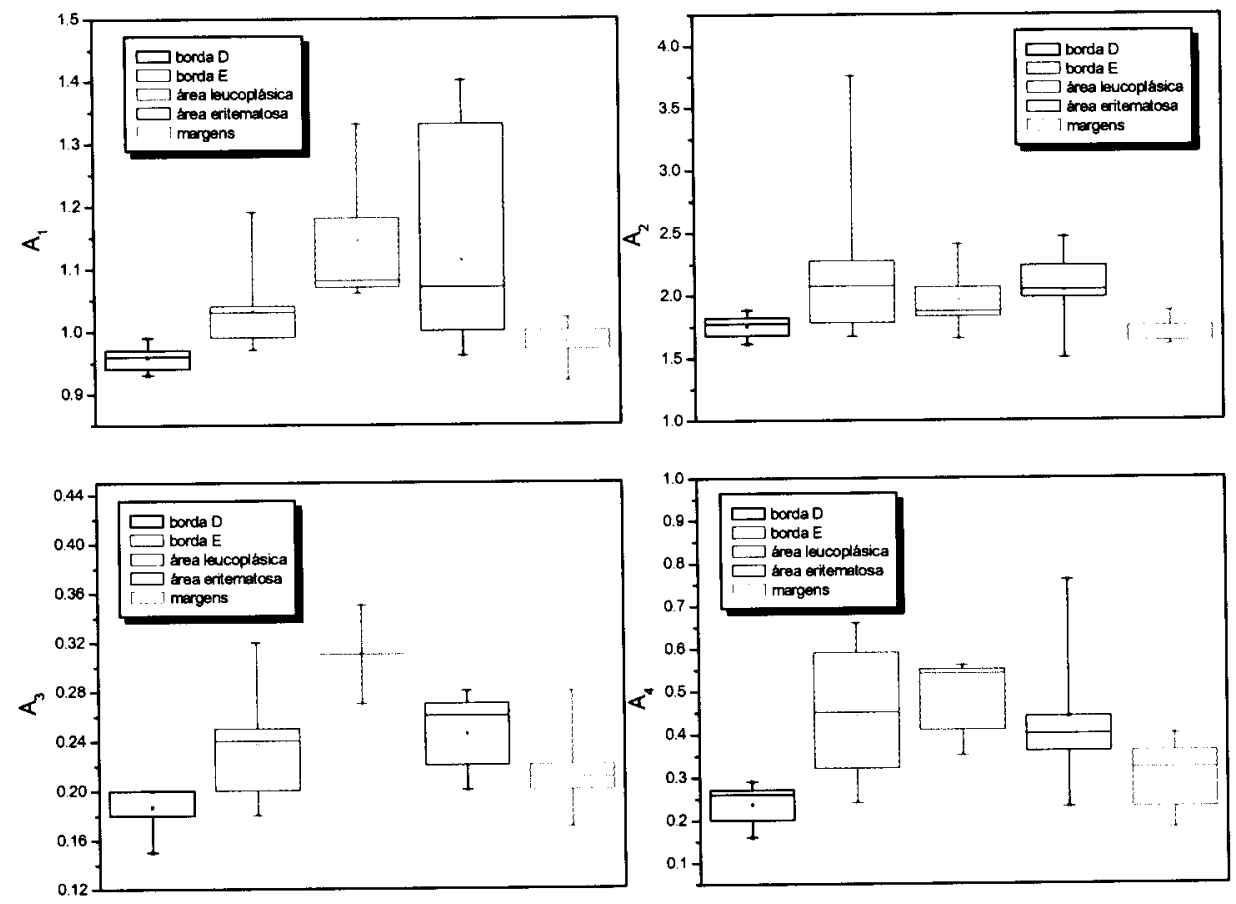

Fig. 42 - Gráficos Box chart para excitação em 442 e $532 \mathrm{~nm}$ de um animal com carcinoma epidermóide.

Os gráficos da figura 42 são do mesmo animal da figura 32, para esse caso, a excitação violeta foi a que proporcionou a melhor diferenciação entre as áreas leucoplásica e eritematosa. Já para o animal da figura 33 a melhor excitação para a distinção dessas áreas foi em $532 \mathrm{~nm}$ (figura 43). 

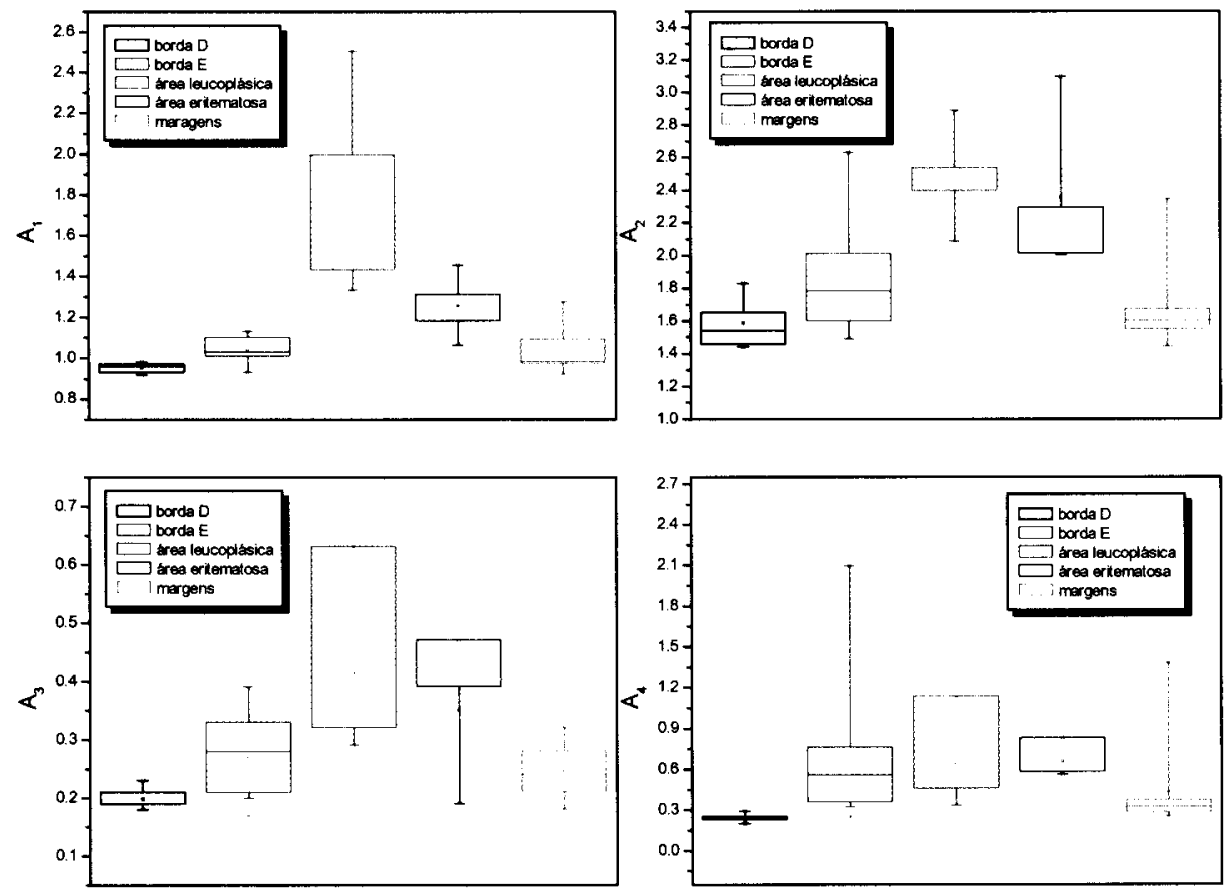

Fig. 43 - Gráficos Box-chart para excitação em 442 e $532 \mathrm{~nm}$ de um animal com carcinoma epidermóide.

Os gráficos apresentados na figura 44 trazem os coeficientes determinados para o " animal da figura 34 também mostrando uma satisfatória discriminação neoplasia versus tecido normal. 

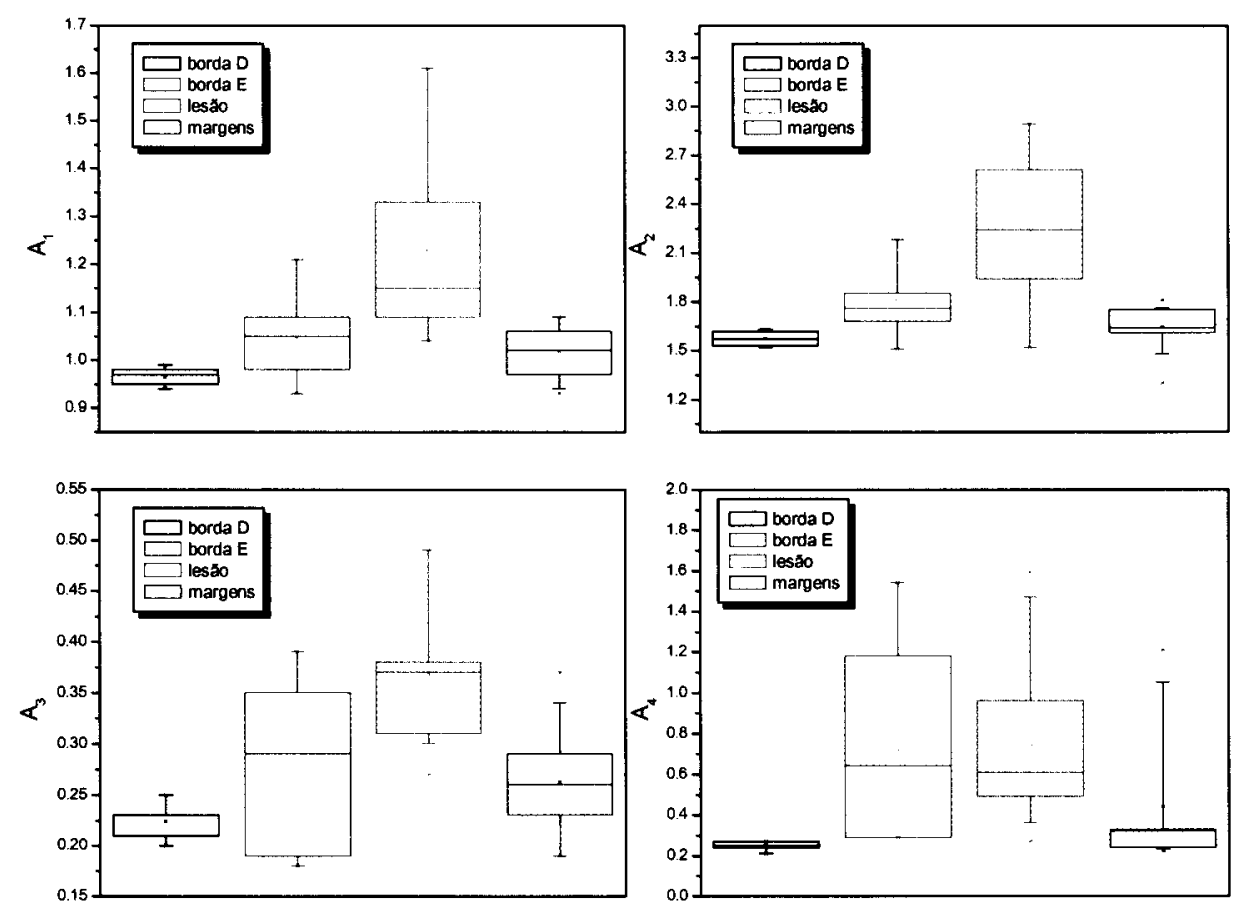

Fig. 44 - Gráficos Box-chart para excitação em 442 e $532 \mathrm{~nm}$ de um animal com carcinoma epidermóide.

Esse tipo de análise já demonstra que os espectros obtidos para o tecido normal apresentam um comportamento que é mais reprodutível entre os indivíduos, podendo ser constatado nos espectros apresentados em função do sítio anatômico e, conseqüentemente na distribuição dos coeficientes determinados. Por outro lado, os espectros e os coeficientes das lesões possuem uma distribuição bem mais espalhada. Os resultados da borda lateral esquerda apresentaram também grande variação, comportamento esperado uma vez que a leitura podia ser em um ponto de lesão ou de tecido normal. 
Quando se realiza a análise geral, agrupando todos os animais dos grupos experimentais, o resultado é um ainda maior espalhamento dos dados, principalmente das lesões (figura 45).
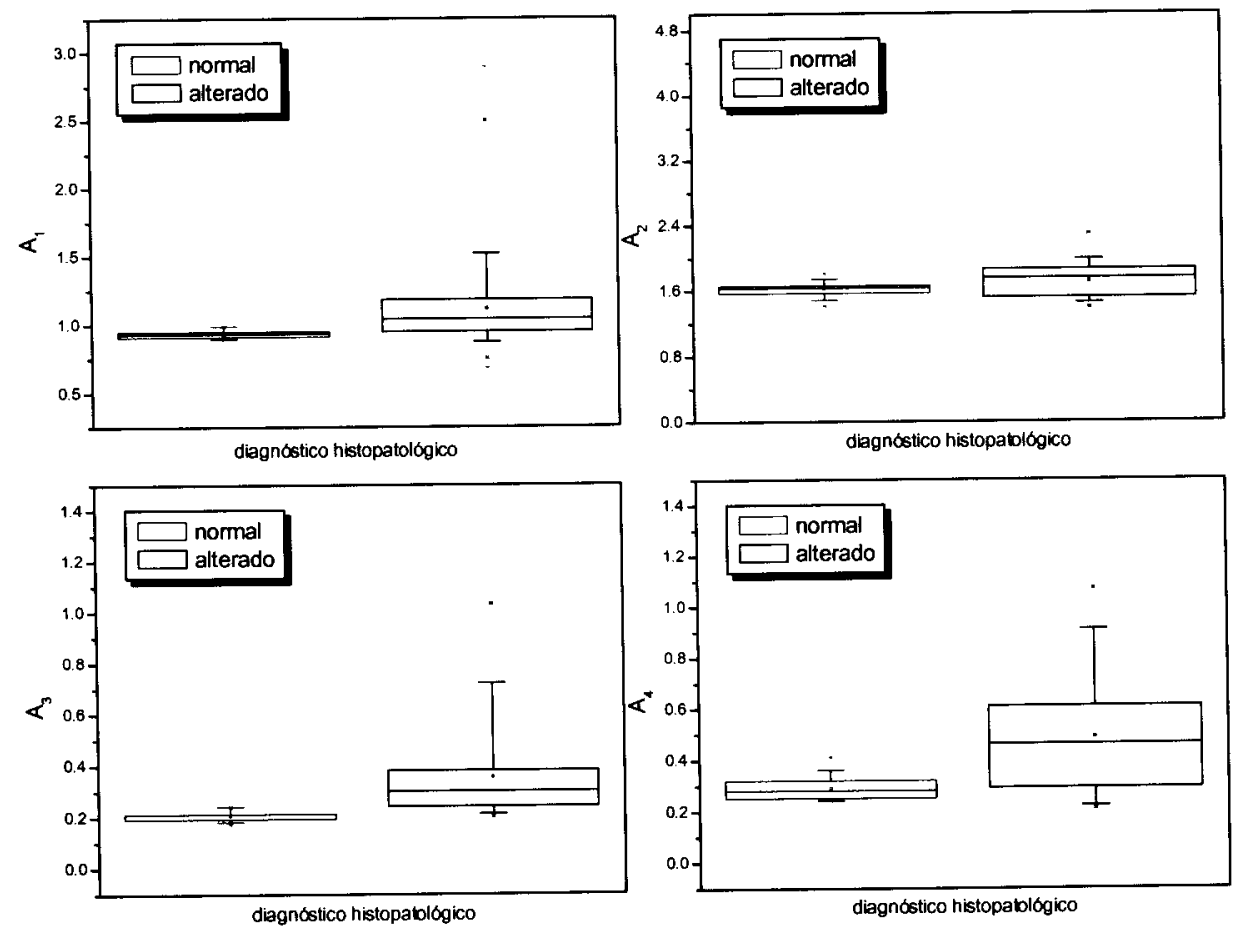

Fig. 45 - Coeficientes $A_{1}, A_{2}, A_{3}$, e $A_{4}$ determinados para a discriminação do tecido normal (azul) versus alterado (preto), que inclui as lesões com diagnóstico de atipias, carcinoma in situ e carcinoma epidermóide. Os resultados mostram a distribuição obtida em todos os animais dos grupos experimentais. 

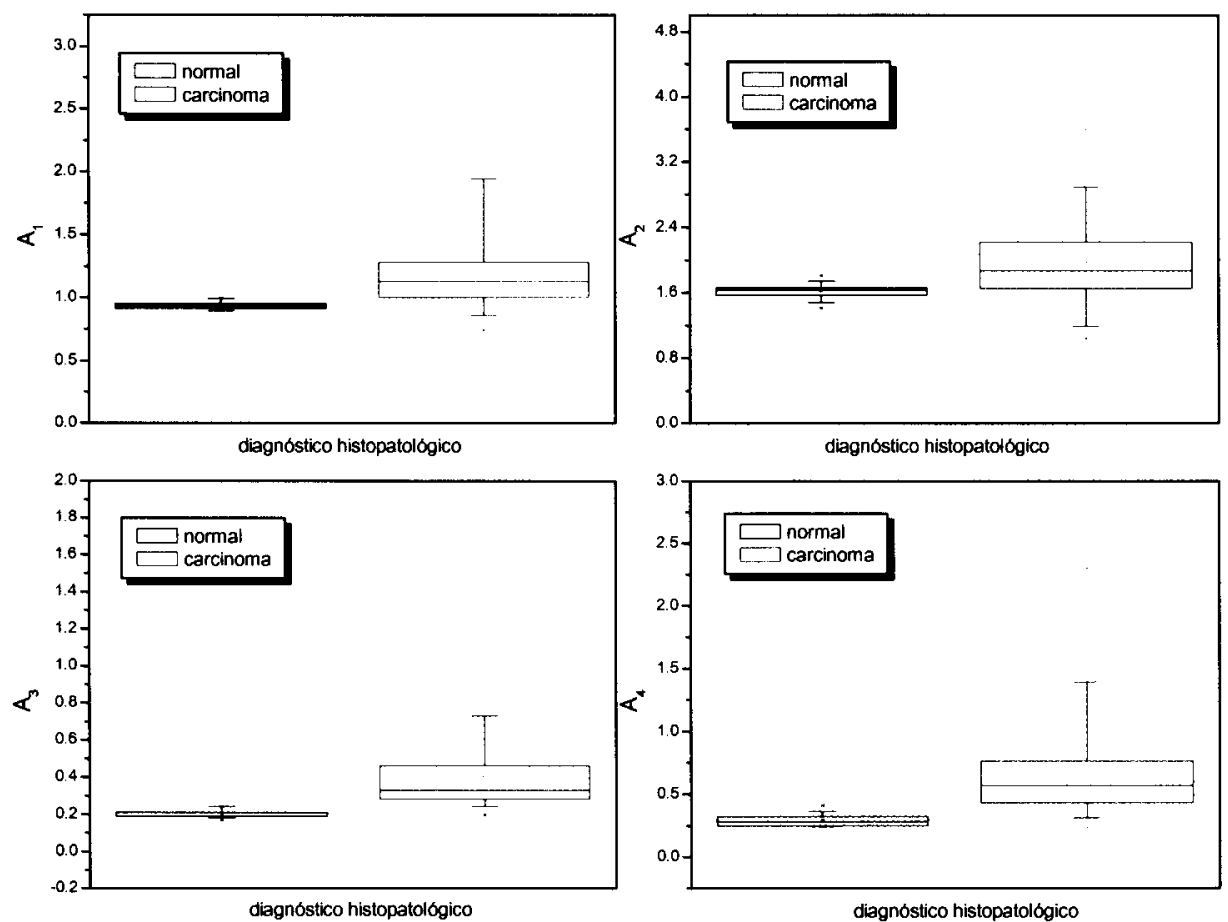

diagnóstico histopatológico

Fig.46 - Coeficientes $A_{1}, A_{2}, A_{3}$, e $A_{4}$ determinados para a discriminação do tecido normal (azul) versus carcinoma (vermelho). Os resultados mostram a distribuição obtida em todos os animais dos grupos experimentais.

A figura 46 apresenta os resultados distribuídos apenas comparando o tecido - normal e o carcinoma. Os gráficos das figuras 45 e 46 mostram que o coeficiente $\mathrm{A}_{3}$ parece ser o melhor para a discriminação entre o tecido normal e as lesões com alterações malignas ou benignas.

No entanto, a discriminação entre os diversos tipos de atipia (leve, moderada e intensa) e o carcinoma (in situ e epidermóide) não foi satisfatória empregando essa metodologia (figura 47). A hiperqueratose não foi incluída, pois constitui um grupo em que não foram detectados sinais de atipia. Essa situação também foi encontrada em 
outros trabalhos, onde a discriminação entre o tecido normal e o alterado é bastante evidente, porém entre os tipos de alterações teciduais investigados os índices de sensibilidade e especificidade da técnica foram inferiores $[27,55]$.
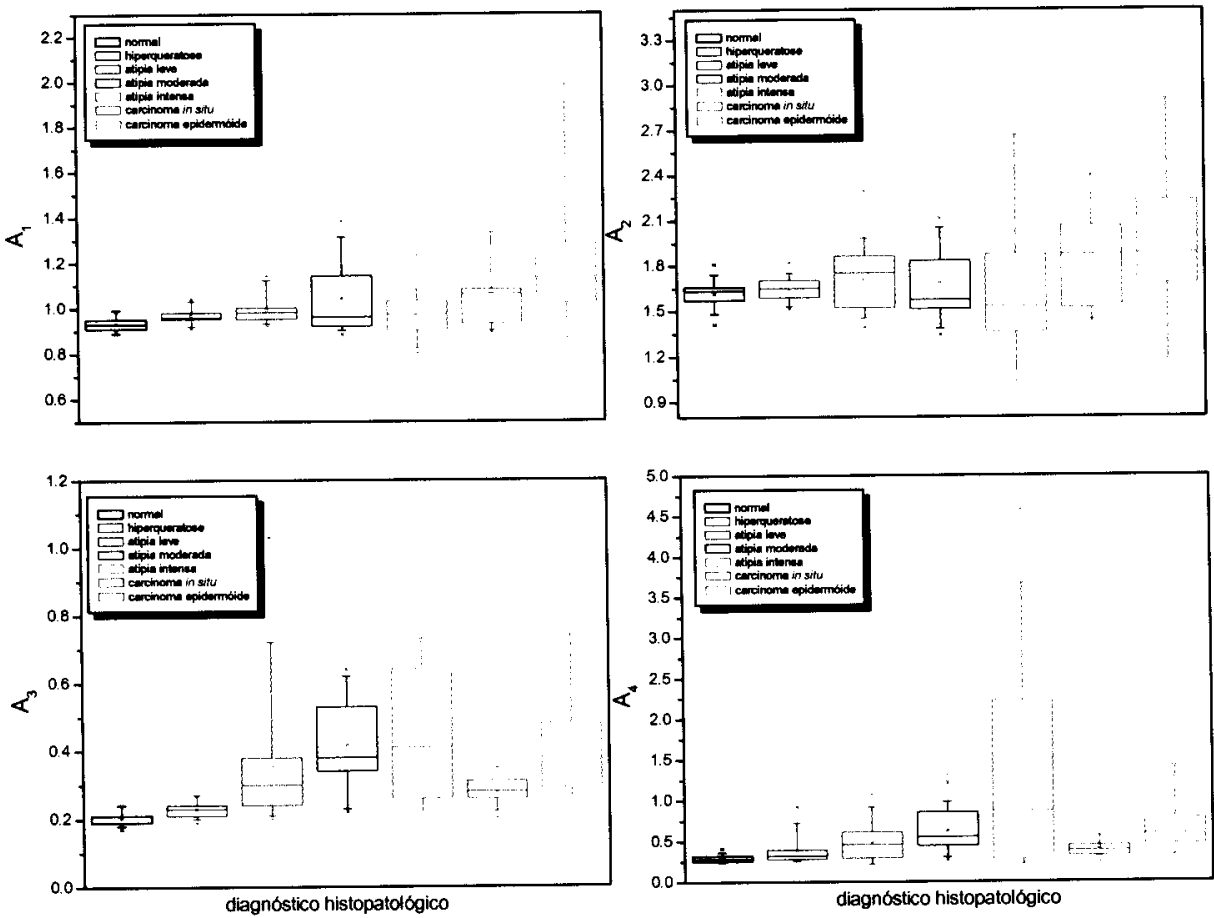

Fig. 47 - Comparação dos coeficientes $A_{1}, A_{2}, A_{2}$ e $A_{4}$ determinados para cada tipo de tecido investigado: normal, hiperqueratose sem atipia, atipia leve, atipia moderada, atipia intensa, carcinoma in situ e carcinoma epidermóide.

A hiperqueratose sem atipia produziu espectros de fluorescência bastante semelhantes aos do tecido normal, no entanto um maior retroespalhamento pôde ser observado. As atipias apresentaram um comportamento espectral variado não havendo discriminação utilizando a metodologia desse estudo. O carcinoma também mostrou um 
comportamento variado, porém quando comparado apenas com o tecido normal a discriminação foi melhor (figura 46).

Para identificar o melhor coeficiente de discriminação normal versus carcinoma os índices de sensibilidade, especificidade e acurácia foram estabelecidos, fatores que são usualmente empregados para determinar a validade de instrumentos de diagnóstico $[65-67]$.

Os resultados fornecidos pela espectroscopia de fluorescência podem ser agrupados e comparados com o padrão-ouro como mostrado na tabela IV.

Tabela IV-Desempenho do diagnóstico pela espectroscopia de fluorescência (teste) em relação ao padrão ouro.

\begin{tabular}{|c|c|c|c|}
\hline \multirow[t]{2}{*}{$\begin{array}{c}\text { Resultados } \\
\text { do teste }\end{array}$} & \multicolumn{2}{|c|}{$\begin{array}{l}\text { Histopatologia } \\
\text { (padrão ouro) }\end{array}$} & \multirow[t]{2}{*}{ Total } \\
\hline & carcinoma & normal & \\
\hline Positivo & $\begin{array}{l}\text { Verdadeiro } \\
\text { positivo }(A)\end{array}$ & $\begin{array}{l}\text { Falso positivo } \\
\text { (B) }\end{array}$ & $\begin{array}{l}\text { Total de testes } \\
\text { positivos }(A+B)\end{array}$ \\
\hline Negativo & $\begin{array}{l}\text { Falso negativo } \\
\text { (C) }\end{array}$ & $\begin{array}{c}\text { Verdadeiro } \\
\text { negativo (D) }\end{array}$ & $\begin{array}{c}\text { Total de testes } \\
\text { negativos }(C+D)\end{array}$ \\
\hline TOTAL & $\begin{array}{l}\text { Total de testes } \\
\text { positivos }(A+C)\end{array}$ & \begin{tabular}{|c|} 
Total de testes \\
negativos $(B+D)$
\end{tabular} & $\begin{array}{c}\text { Total } \\
(A+B+C+D)\end{array}$ \\
\hline
\end{tabular}

Usando a metodologia empregada de determinação dos coeficientes, os números de verdadeiro-positivo, verdadeiro-negativo, falso-positivo e falso-negativo dependerão da posição do limite estabelecido para discriminar a leitura normal versus carcinoma para cada coeficiente. O número de amostras, seguindo o diagnóstico histopatológico, 
para cada coeficiente distribuídas em função do limite estabelecido é apresentado na figura 48.
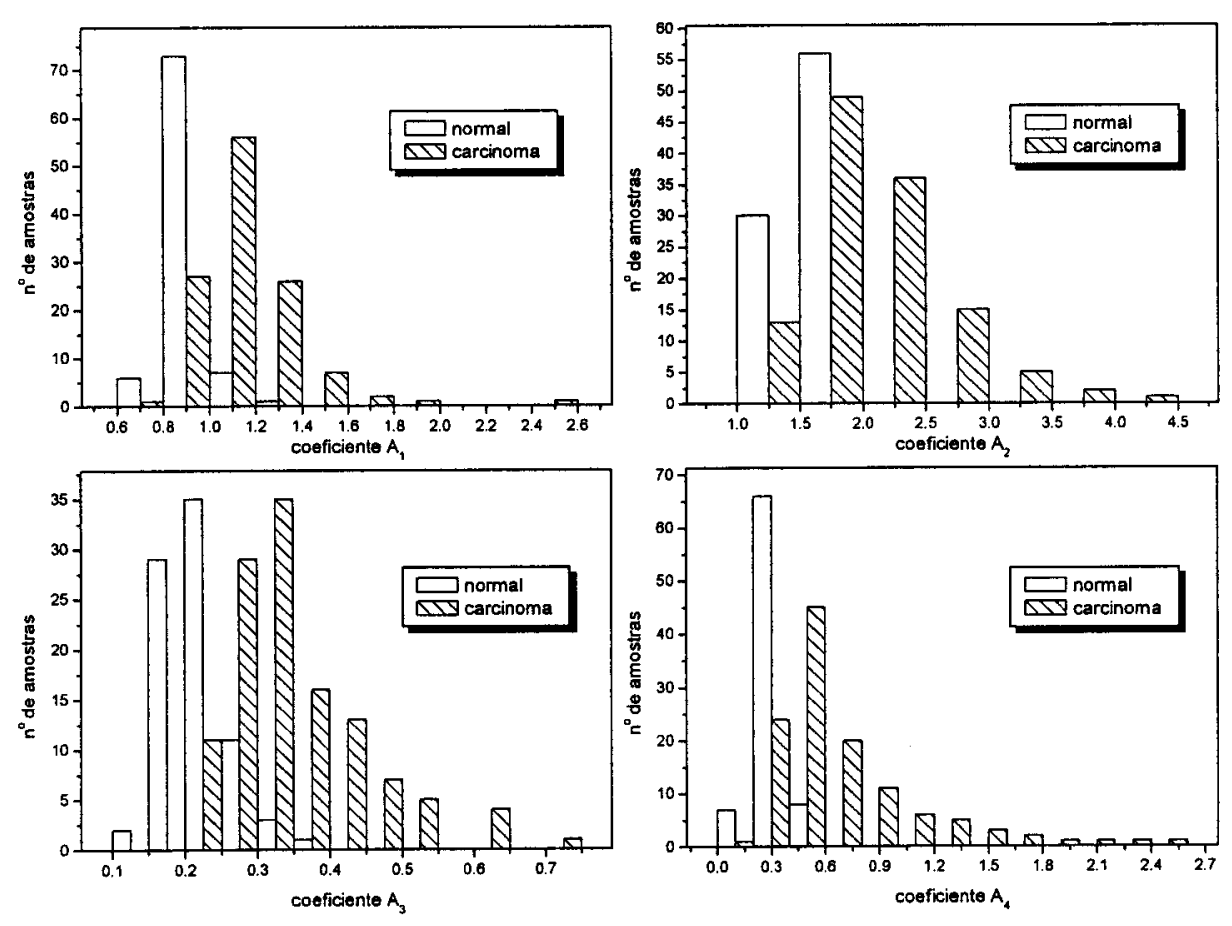

Fig.48 - Distribuição do número de amostras em função do limite normal versus carcinoma estabelecido para cada coeficiente.

Os conceitos dos índices sensibilidade, especificidade, valor preditivo positivo, valor preditivo negativo e acurácia são apresentados no anexo 2. Os índices calculados para todos os coeficientes é mostrado na tabela $\mathrm{V}$. 


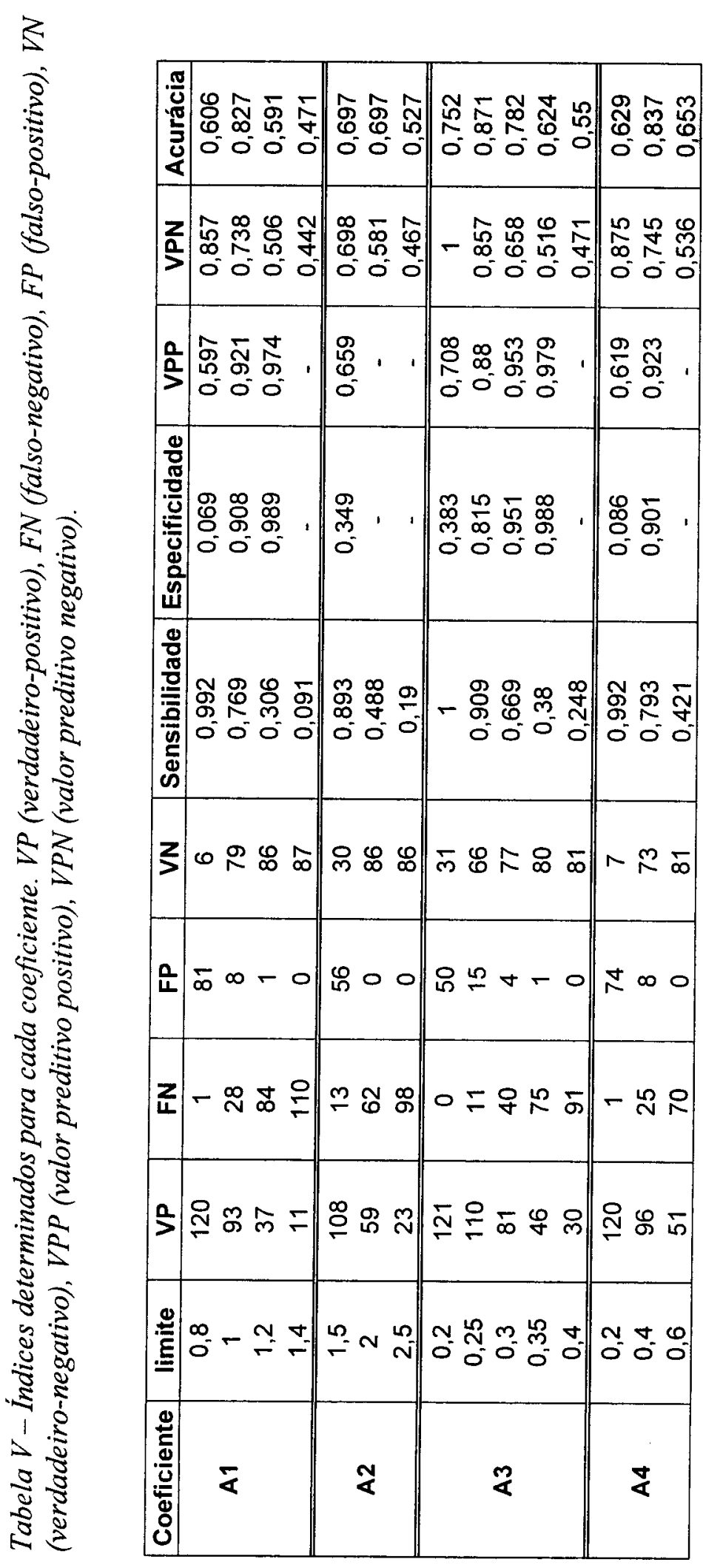


A partir desses índices a curva ROC (Receiver Operating Characteristic) pode ser determinada para coeficiente, possibilitando a determinação do melhor limite, com os melhores índices de sensibilidade e especificidade (figura 49).
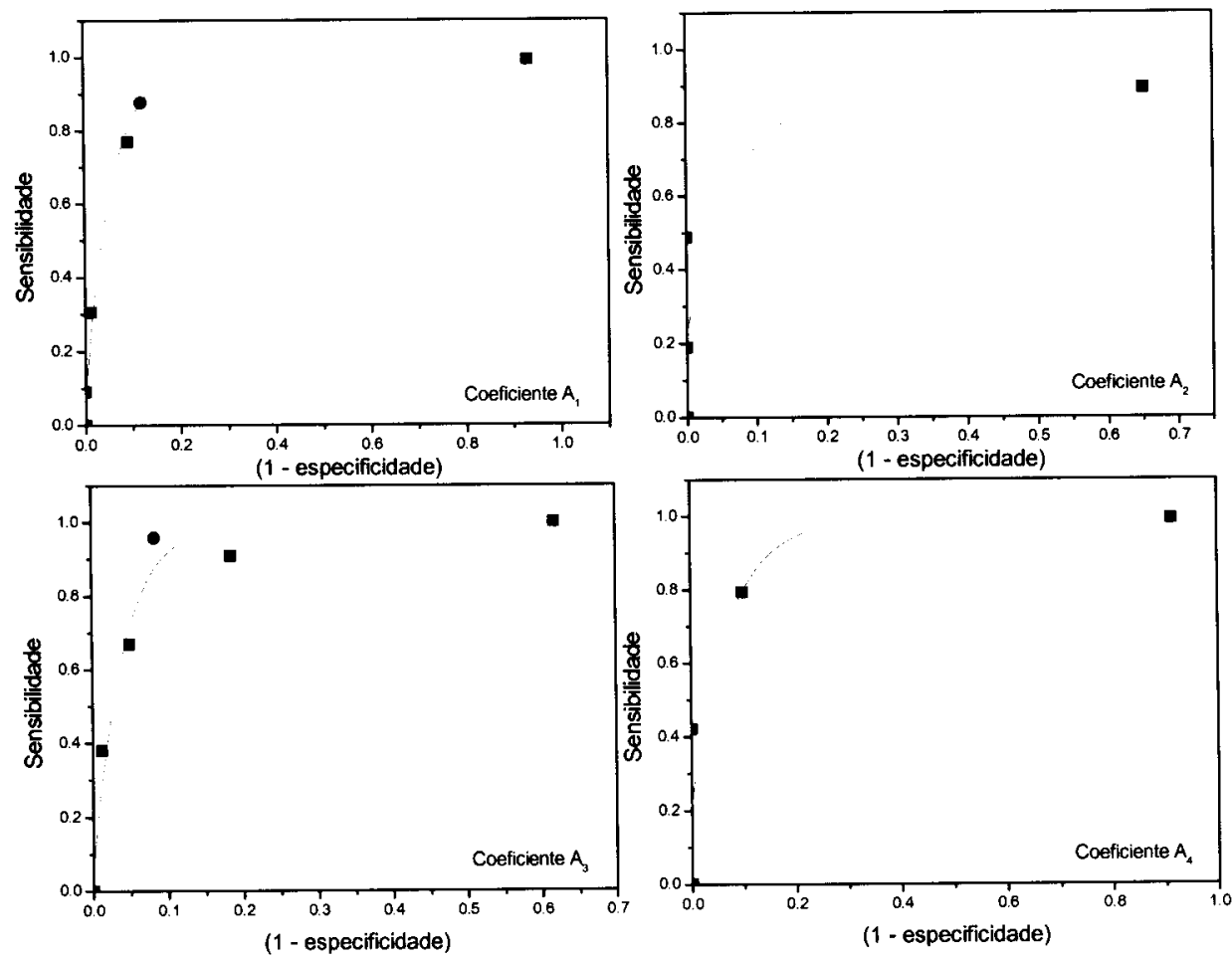

Fig.49-Curvas ROC para os quatro coeficientes estabelecidos

Uma curva ROC pode ser considerada perfeita quando apresenta uma ascensão o mais paralela possível ao eixo y, com origem onde a sensibilidade é 0 e a especificidade é 1 , e continua em uma linha horizontal no topo do gráfico, ou seja, com 0 de especificidade e 1 de sensibilidade. As curvas abaixo desse nível indicam métodos de 
decisão (diagnóstico) não-perfeitos, mas qualquer curva situada acima da reta diagonal estabelecida pelos pontos $(0,0)$ e $(100,100)$ pode ser considerada boa, i.e., ela corresponde aos testes em que há igualdade entre sensibilidade e especificidade [67].

Os coeficientes $A_{1}$ e $A_{3}$ foram o que apresentaram melhores curvas ROC, mais próximas à curva considerada perfeita, porém todos os coeficientes podem ser considerados bons para a discriminação proposta. A partir dessa análise, o intervalo espectral entre 625 e $645 \mathrm{~nm}$ parece fornecer maior informação de malignidade na detecção por fluorescência. Essa região envolve a principal banda de emissão das porfirinas endógenas, sendo provavelmente esse fluoróforo aquele que mais contribuiu para a discriminação entre normal e carcinoma nesse modelo animal empregado.

Os melhores índices obtidos com o coeficiente $A_{1}$ foram com o limite em 1,0; determinando que valores inferiores identificam um tecido normal e valores superiores um carcinoma. Nesse caso os índices de sensibilidade, especificidade e acurácia foram de $0,769(76,9 \%) ; 0,908(90,8 \%)$ e $0,827(82,7 \%)$, respectivamente. Para o coeficiente $A_{3}$ os resultados para o limite em 0,25 obtiveram valores de $90,9 \%$ de sensibilidade; $81,5 \%$ de especificidade; e $87,1 \%$ de acurácia.

Um segundo tipo de processamento dos espectros de fluorescência empregado foi a análise exploratória de dados multivariados (quimiometria). A quimiometria é uma especialidade da Química relativamente nova, mas que vem ganhando adeptos nas mais diversas áreas do conhecimento. Em linhas gerais, esse tipo de análise utiliza ferramentas matemáticas e estatísticas para o reconhecimento de padrões através das informações coletadas, permitindo a classificação ou quantificação das amostras. No caso da aplicação dessa análise nos nossos dados, a informação coletada das amostras é 
o espectro de fluorescência e o resultado que se deseja é a classificação da amostra em tecido normal ou carcinoma. Para isso, é necessária a obtenção de um grande número de espectros do tecido normal e do carcinoma; esses espectros serão analisados através de vários processamentos matemáticos na busca do reconhecimento de padrões que caracterizam ou identificam as classes pré-estabelecidas. Inicialmente é preciso ter o conhecimento do resultado histopatológico da amostra para fornecer a informação previamente à análise. Esse é um tipo de análise inter-espectral, onde os espectros das amostras são comparados entre si.

Dois tipos de análise foram realizados a Análise de Componentes Principais (Principal Components Analysis - PCA) e a análise do K-ésimo Vizinho Mais Próximo $\left(\mathrm{K}^{\text {th }}\right.$ Nearest Neighbor $\left.-\mathrm{KNN}\right)$. O PCA permite a visualização dos grupos separando as classes pré-determinadas, no caso deste trabalho normal e carcinoma, a distribuição das amostras e a probabilidade de cada amostra em pertencer a um grupo, ao outro, a nenhum ou a ambos. O KNN é um tipo de análise que utiliza a posição da amostra no espaço $\mathrm{N}$-dimensional e através de um sistema de votos, o grupo que receber o maior número de votos "ganha" a amostra. O KNN é um tipo de análise matematicamente mais simples, mas não permite a determinação de um modelo e nem a previsão para futuras investigações.

O software empregado para essas análises foi o Pirouette ${ }^{\circledast}$ (InfoMetrix Inc., Bothel-WA, EUA) gentilmente cedido pela Profa. Márcia M.C. Ferreira do Instituto de Química da UNICAMP. As figuras 50 e 51 apresentam um exemplo de PCA realizado para excitação em $442 \mathrm{~nm}$ e a figura 52 apresenta o melhor resultado com KNN. 


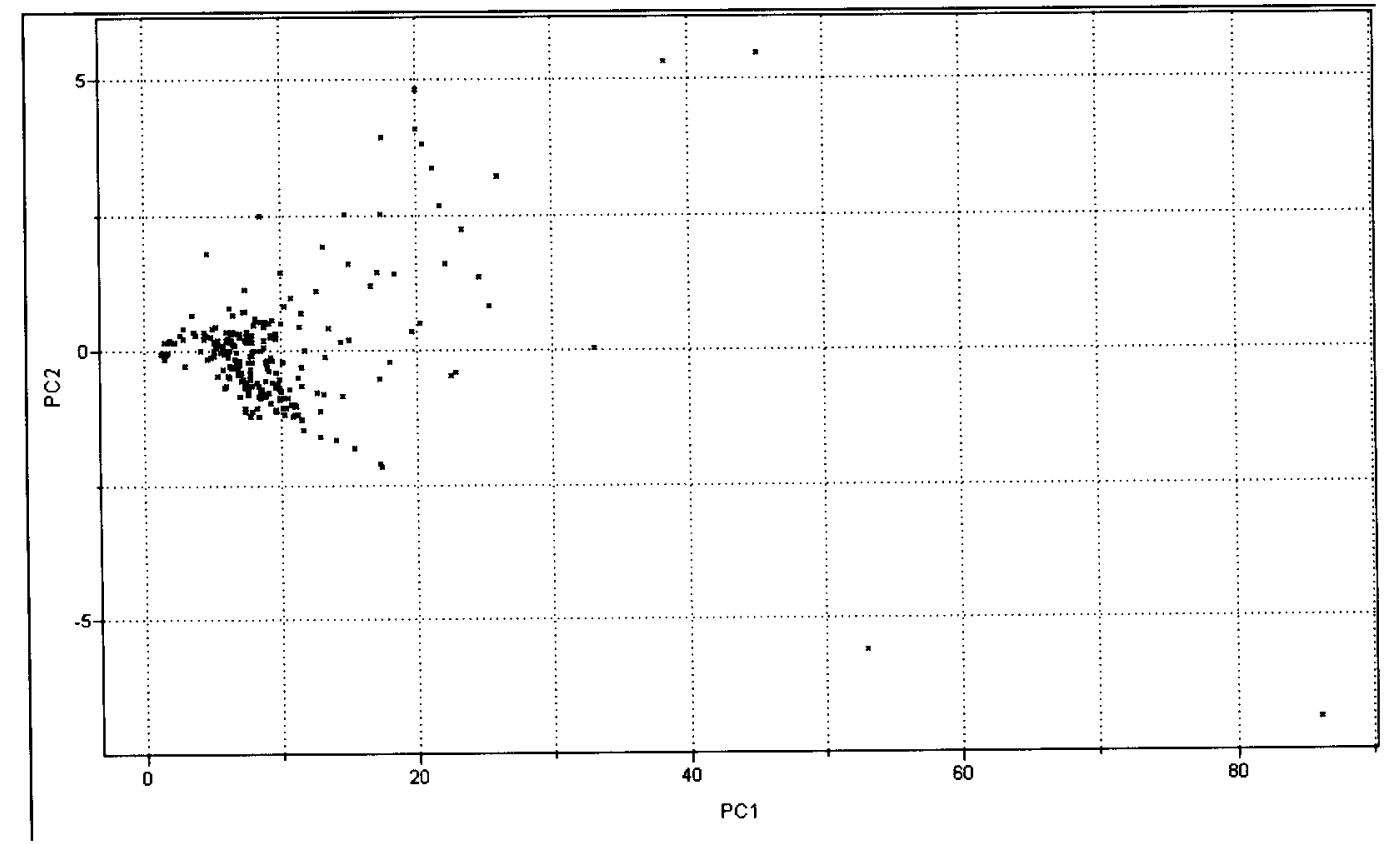

Fig.50 - PCA para a investigação em $442 \mathrm{~nm}$, gráfico de PC1xPC2. As amostras em azul correspondem aos espectros coletados do tecido normal $e$ as amostras em vermelho aos do carcinoma. 


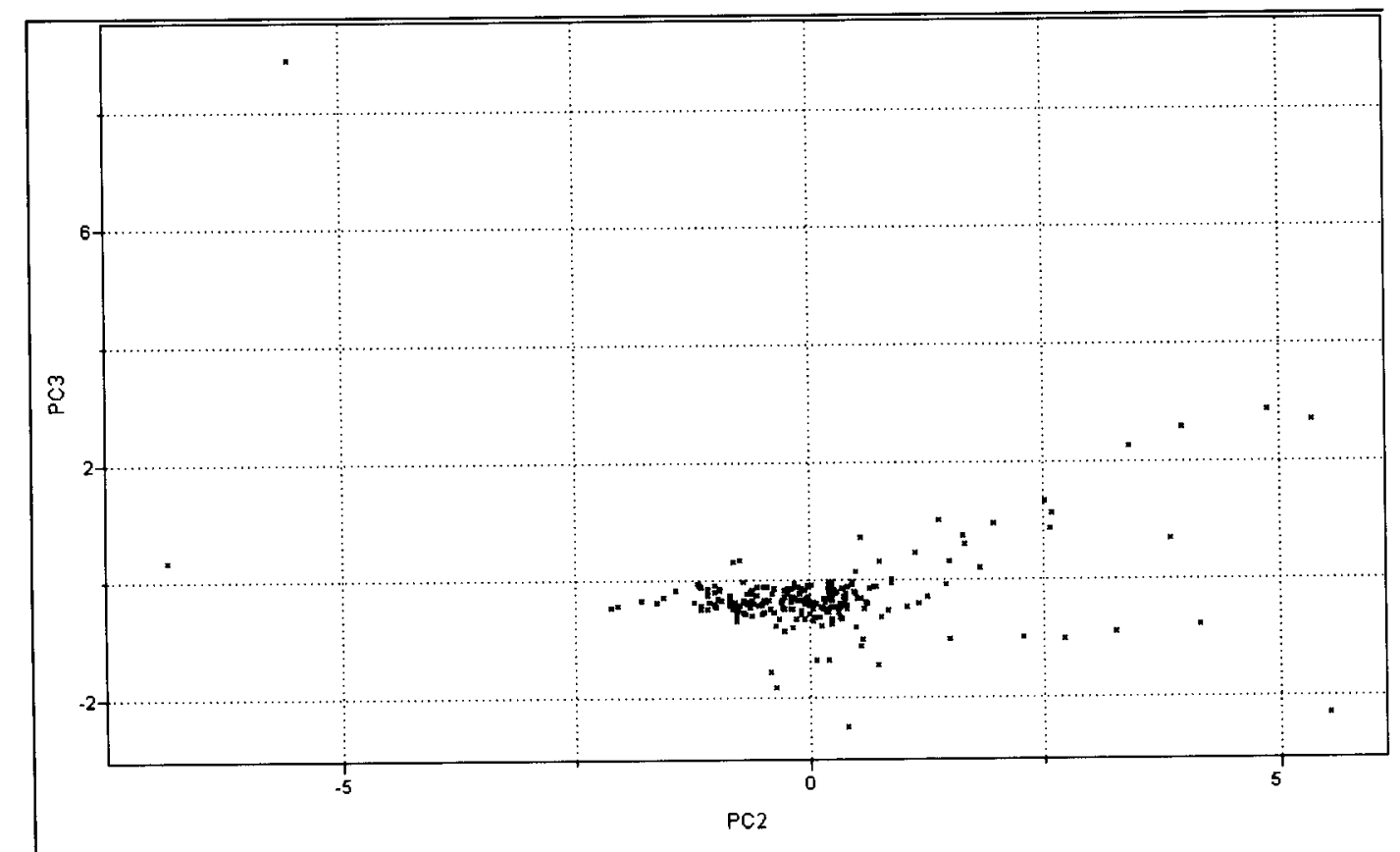

Fig.51 - PCA para a investigação em $442 \mathrm{~nm}$, gráfico de PC2xPC3. As amostras em azul correspondem aos espectros coletados do tecido normal e as amostras em vermelho aos do carcinoma.

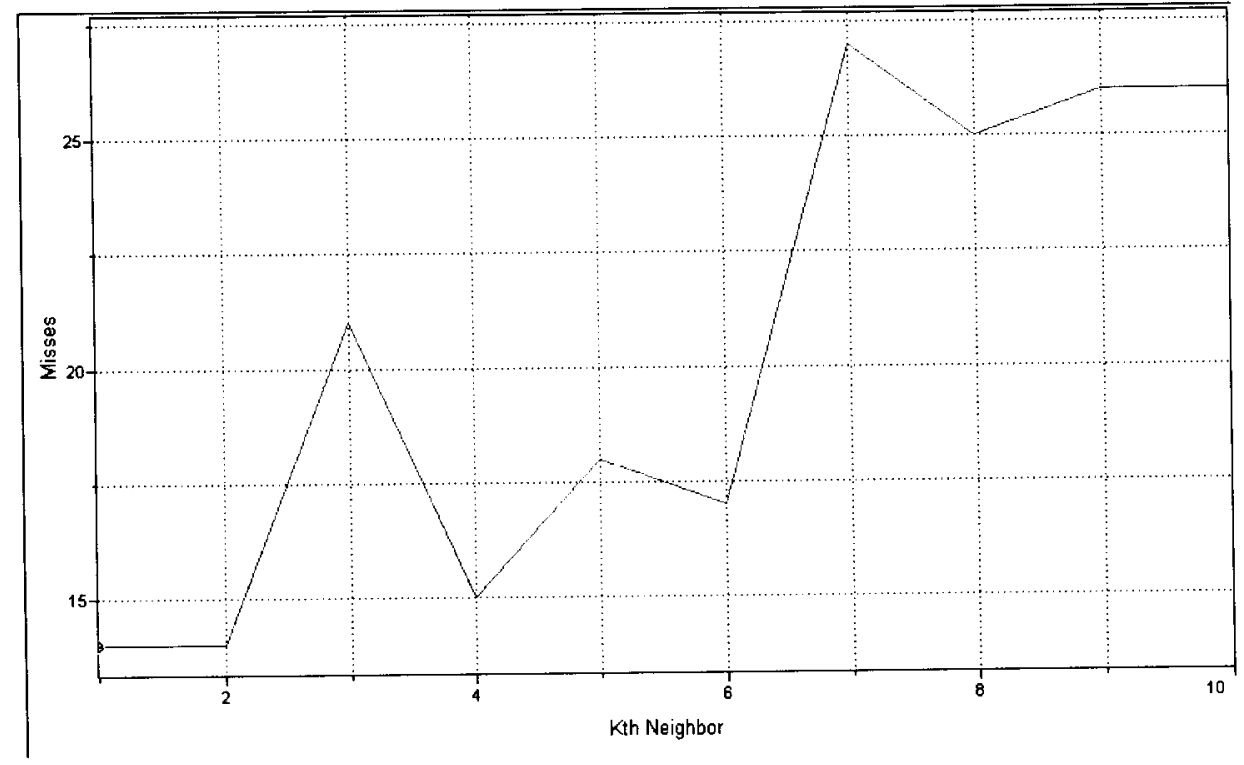

Fig.52 - Resultados do KNN para excitação em $442 \mathrm{~nm}$ com o número de classificações falsas em função do número de vizinhos. 
A análise KNN foi a que apresentou o melhor resultado para separação das amostras. A matriz de erros para excitação em 442 e $532 \mathrm{~nm}$ é apresentada na tabela VI.

Tabela VI - Matriz de erros para a análise KNN para as duas excitações. Entre parênteses está definido o número de vizinhos selecionado para a análise.

\begin{tabular}{|l|c|c|}
\hline \multirow{2}{*}{$\begin{array}{c}\text { KNN (5) - 442nm } \\
\text { Histopatologia }\end{array}$} & \multicolumn{2}{|c|}{ Fluorescência } \\
\cline { 2 - 3 } & normal & carcinoma \\
\hline normal & 87 & 8 \\
\hline carcinoma & 6 & 134 \\
\hline \hline \multirow{2}{*}{$\begin{array}{c}\text { KNN (10) - 532nm } \\
\text { Histopatologia }\end{array}$} & \multicolumn{2}{|c|}{ Fluorescência } \\
\cline { 2 - 3 } & normal & carcinoma \\
\hline normal & 88 & 12 \\
\hline carcinoma & 19 & 133 \\
\hline
\end{tabular}

A matriz de erros apresenta o número de amostras que foram corretamente diagnosticadas pela espectroscopia de fluorescência, ou seja, normal como normal e carcinoma como carcinoma; e o número de erros resultantes da técnica investigada, o número de falso-positivos (histologicamente normal diagnosticado pela fluorescência como carcinoma) e de falso-negativos (histologicamente carcinoma e detectado como normal).

Utilizando o KNN como método de análise, novamente a excitação em $442 \mathrm{~nm}$ se mostrou mais eficaz na discriminação entre o tecido normal e carcinoma. Esse resultado pode ser evidenciado pelos índices mais elevados de sensibilidade, especificidade e acurácia (tabela VII). 
Tabela VII - Índices de sensibilidade, especificidade e acurácia obtidos através da análise KNN para as duas excitações.

\begin{tabular}{|c|c|c|c|}
\hline Excitação & Sensibilidade & Especificidade & Acurácia \\
\hline $442 \mathrm{~nm}$ & 0,957 & 0,916 & 0,94 \\
\hline \hline $532 \mathrm{~nm}$ & 0,875 & 0,88 & 0,877 \\
\hline
\end{tabular}

Os resultados obtidos através da análise exploratória dos dados multivariados, mais especificamente pelo $\mathrm{KNN}$, foram superiores ao primeiro procedimento empregado para análise dos espectros de fluorescência coletados, como pode ser evidente nos gráficos da figura 47. Os pontos azuis colocados nos gráficos das curvas ROC dos coeficientes $A_{1}$ e $A_{3}$ representam os valores determinados para o $\mathrm{KNN}$ dos dados com excitação em 532 e 442 nm respectivamente. A comparação é feita entre os melhores resultados obtidos pela determinação dos coeficientes e o KNN.

Nos dados da excitação em $532 \mathrm{~nm}$, as duas análises apresentaram resultados que podem ser semelhantes uma vez que o ponto pertence à curva ROC determinada para o "coeficiente $A_{1}$. Já para a excitação em 442 nm, a análise $\mathrm{KNN}$ obteve resultados superiores, com maiores índices de sensibilidade, especificidade e acurácia, assim o ponto se localiza acima da curva ROC do coeficiente $\mathrm{A}_{2}$.

O gráfico da figura 53 apresenta os melhores valores de sensibilidade e especificidade para cada fator e KNN obtidos. 


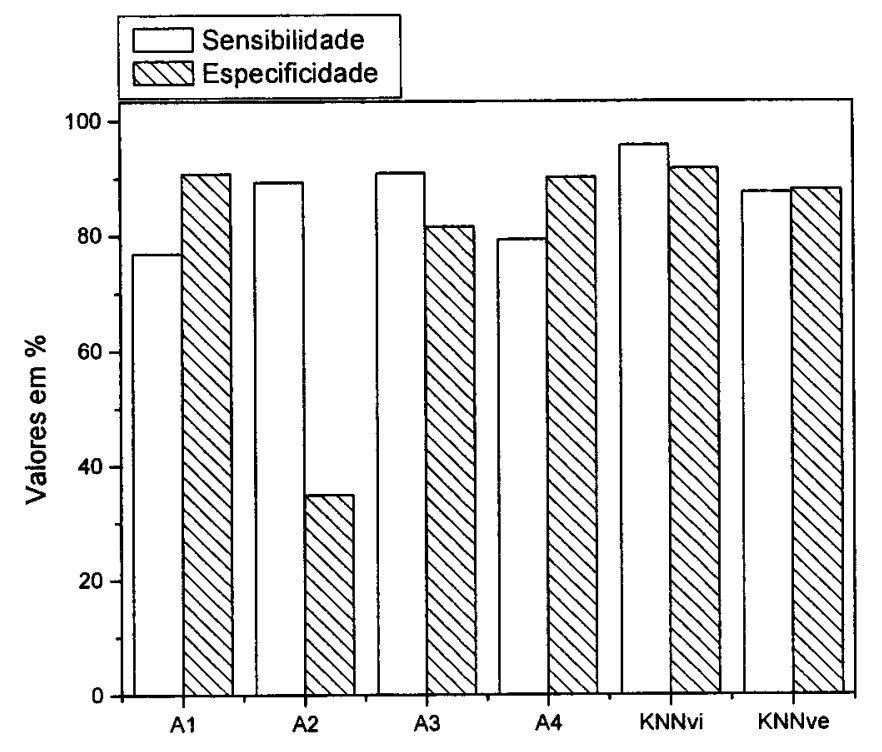

Fig.53 - Comparação entre os índices de sensibilidade e especificidade obtidos para os fatores $A_{1}, A_{2}, A_{3}$ e $A_{4}$, e os melhores resultados para o $K N N$ com excitação em $442 \mathrm{~nm}$ e $532 \mathrm{~nm}$.

O melhor resultado obtido no presente estudo foi utilizando a análise de dados multivariados KNN com índices de 95,7\%; $91,6 \%$ e $94 \%$ de sensibilidade, especificidade e acurácia, respectivamente; para excitação em $442 \mathrm{~nm}$. Com a determinação dos coeficientes, o melhor resultado para $442 \mathrm{~nm}$ foi de 90,9\% de sensibilidade, $81,5 \%$ de especificidade e $87,1 \%$ de acurácia. Isso também é refletido na literatura, sendo que a maioria dos autores trabalha com excitação na região ultravioletaazul.

O processamento utilizando a determinação dos coeficientes permite a variação do limite de discriminação entre o tecido normal e o carcinoma, assim em uma curva 
ajustada através dos valores de sensibilidade e especificidade pode-se chegar a valores semelhantes aos obtidos através do KNN (figuras 54 e 55).
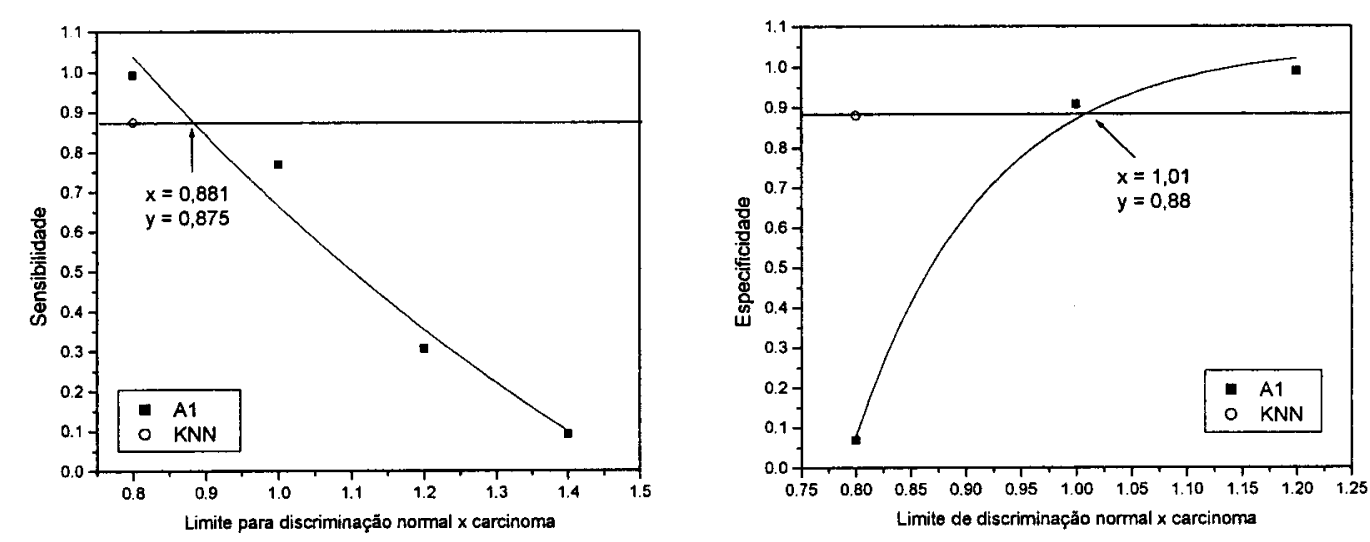

Fig.54-Curvas dos valores de sensibilidade e especificidade em função do limite para o coeficiente $A_{1}$.
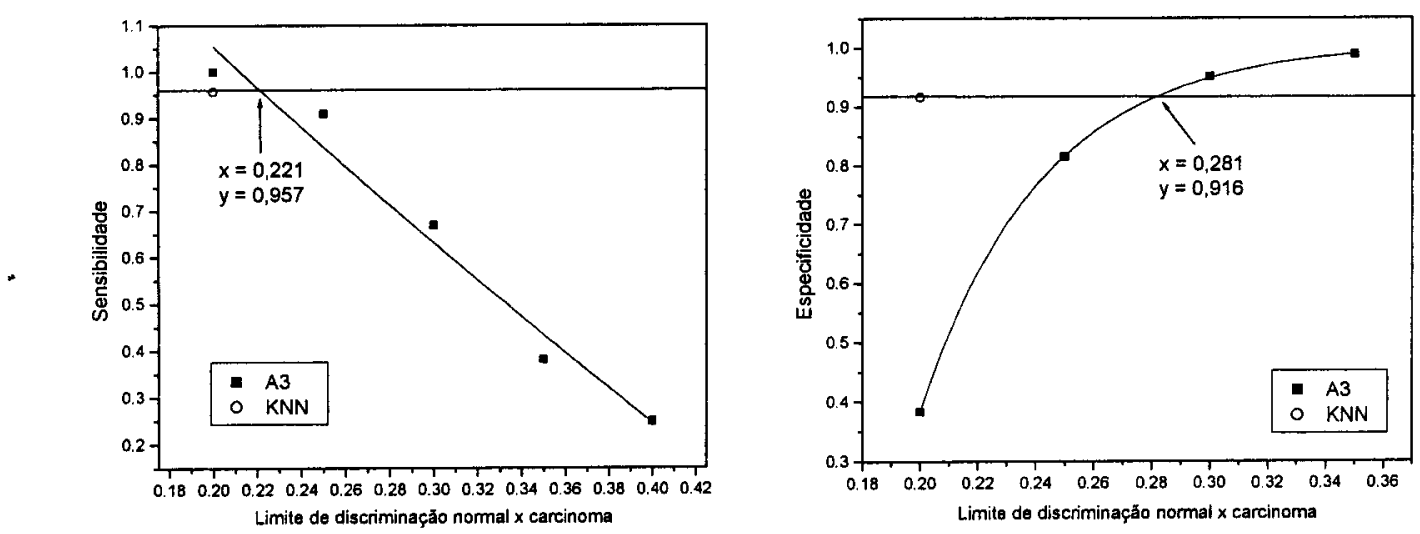

Fig. 55 - Curvas dos valores de sensibilidade e especificidade em função do limite para o coeficiente $\mathrm{A}_{3}$.. 
Através das curvas das figuras 54 e 55 é possível determinar o limite para cada fator que apresenta melhores índices de sensibilidade e especificidade. Nesse sentido, para o fator $\mathrm{A}_{3}$ se o limite for determinado em 0,221 ; a sensibilidade será a mesma do KNN e para valores inferiores a 0,221 de limite a sensibilidade será superior. Isso demonstra que a determinação dos coeficientes empregada foi um processamento espectral matematicamente simples que apresentou resultados semelhantes aos do KNN.

A determinação do melhor valor limite deve levar em consideração ambos índices, porém dependendo da patologia envolvida na discriminação pode ser que, mesmo em detrimento do outro, uma vez que a sensibilidade e a especificidade variam em sentidos opostos, um deles seja mais valorizado. No caso do diagnóstico de neoplasias, a obtenção de um resultado falso-negativo é uma condição bem mais desfavorável do que a de um falso-positivo. Em outras palavras, o diagnóstico de um tecido normal como carcinoma é comparativamente melhor do que o diagnóstico de um carcinoma como tecido normal, pois a neoplasia provavelmente permanecerá sem tratamento adequado comprometendo o prognóstico e a saúde do paciente. Desta forma, consideramos que para o diagnóstico de neoplasias, o índice de sensibilidade da técnica empregada deve ser bastante elevado, mesmo que para isso, a especificidade não seja tão elevada.

Os estudos de outros autores que também avaliaram a validade da espectroscopia de fluorescência no diagnóstico de carcinoma oral apresentam diversos tipos de processamento espectral, além do emprego de diferentes protocolos, variando principalmente a luz de excitação. A comparação dos resultados obtidos por esse estudo 
e os dos outros autores será feita independente da metodologia empregada para obtenção da fluorescência intrínseca e análise dos espectros.

No estudo de Yuanlong e colaboradores [42], utilizando a técnica em material de biópsia coletada de lesões orais de pacientes e excitação em 365 nm, a consistência da avaliação óptica em relação à biópsia tradicional foi de $89 \%$, utilizando picos característicos ao redor de $630 \mathrm{~nm}$ e $690 \mathrm{~nm}$ como critérios para o diagnóstico do câncer. Também em material de biópsia humana, Wang e colaboradores [38] com a determinação de um algoritmo para o diagnóstico do câncer através das fluorescências com dois comprimentos de onda de excitação, obtiveram índices de $81,25 \%$ de sensibilidade, $93,75 \%$ de especificidade e $92,86 \%$ de valor preditivo positivo.

Usando a técnica de espectroscopia trimodal para o diagnóstico do carcinoma em material de biópsia humana, Müller e colaboradores puderam discriminar tecidos alterados (câncer e displasia) do tecido normal com sensibilidade e especificidade de 96\%. No entanto, na discriminação entre câncer e displasia, esses índices caíram para $64 \%$ de sensibilidade e $90 \%$ de especificidade [27].

Em um estudo em bolsa jugal de 20 hamsters usando a associação dos resultados com excitação em 337 nm, $380 \mathrm{~nm}$ e $460 \mathrm{~nm}$, Coghlan e colaboradores obtiveram índices de $95 \%$ e $93 \%$ de sensibilidade e especificidade respectivamente após a obtenção de um algoritmo para discriminação neoplásico versus normal [39].

O trabalho de Heintzelman e colaboradores utilizando a detecção in vivo de neoplasia oral em humanos demonstrou $90 \%$ de sensibilidade e $88 \%$ de especificidade no conjunto de treinamento e $100 \%$ de sensibilidade e $98 \%$ de especificidade no 
conjunto de validação; usando a análise em $472 \mathrm{~nm}$ de emissão, e 350 e $450 \mathrm{~nm}$ de excitação [41].

Utilizando como critério de discriminação a fluorescência semelhante à da porfirina, Inaguma e Hashimoto obtiveram um resultado positivo em $85 \%$ dos carcinomas investigados com excitação em $410 \mathrm{~nm}$ [45].

Comparando os resultados do presente trabalho com esses apresentados, verificase que a metodologia empregada foi eficiente para a discriminação normal versus neoplásico principalmente com excitação em $442 \mathrm{~nm}$. Apesar do resultado superior do KNN, a determinação dos coeficientes pode ser mais bem empregada por ser um procedimento matemático simples e que não necessita da aquisição de um software específico para quimiometria. Além disso, é possível a determinação de um algoritmo para a previsão do resultado em futuras leituras, ou seja, em pontos a serem investigados onde não se sabe o resultado histopatológico, visualizando o emprego clínico de um sistema de diagnóstico por fluorescência. $\mathrm{A}$ análise pelo $\mathrm{KNN}$ não possibilita determinar um modelo de previsão, pois é apenas um método de classificação onde se deve saber prioritariamente a classificação de cada amostra.

A metodologia empregada para o diagnóstico das lesões quimicamente induzidas na borda lateral da língua de hamsters produziu resultados confiáveis, mostrando a validade da técnica como método de diagnóstico para a discriminação do tecido normal versus carcinoma. Os dois comprimentos de onda empregados para excitação, 442 e 532 $\mathrm{nm}$, foram eficazes para esse objetivo, porém o primeiro obteve os melhores índices de sensibilidade, especificidade e acurácia. 
A investigação in vivo, i.e. realizada no tecido biológico, fornece informação mais relevante para o diagnóstico em comparação à investigação in vitro realizada em material de biópsia. Isso é em decorrência da variação do comportamento dos fluoróforos endógenos em função do microambiente em que se encontram e da contribuição da microcirculação local, ausente na leitura in vitro, principalmente da atuação da hemoglobina, grande absorvedora da luz de excitação e da fluorescência emitida. Os cromóforos e as biomoléculas espalhadoras também têm sua atividade modificada em função das condições do ambiente em que se encontram. Dependendo do tipo de conservação e do processamento empregados para a manutenção do tecido biológico, artefatos da técnica podem ser incorporados e conseqüentemente alterar a estrutura do espectro de fluorescência intrínseca.

A grande variabilidade da evolução dos carcinomas induzidos também foi refletida nos espectros de fluorescência coletados e, ainda assim, a técnica se mostrou eficiente na discriminação normal versus carcinoma quando todos os carcinomas foram agrupados para análise. Essas variações na forma e na intensidade espectral provavelmente 'confundiram' os métodos para processamento dos espectros empregados, já que a resposta esperada era a mesma: carcinoma.

As variações no espectro de autofluorescência podem ser notadas mesmo em tecidos normais sem alterações clínicas detectáveis. De Veld e colaboradores estudaram os efeitos das características individuais - consumo de álcool e tabaco, cor da pele, sexo, idade e uso de prótese - nos espectros de autofluorescência em mucosa oral saudável e verificaram que alterações eram observadas. Os autores concluem que as diferenças resultantes das características individuais podem ajudar a explicar a grande variação 
observada nos espectros de autofluorescência coletados dos pacientes sadios, no entanto, as diferenças foram inferiores se comparados ao desvio padrão dentro das categorias [68]. Esses resultados demonstram a complexidade de análise dos espectros, onde muitos fatores contribuem para a informação final, mesmo alterações que não são clinicamente detectáveis e nem são morfológicas, refletem em modificações espectrais.

As novas bandas de emissão observadas na maioria dos espectros coletados dos carcinomas provavelmente são resultantes de uma maior quantidade de porfirinas, biomarcador endógeno utilizado para a discriminação da malignidade, assim como foi descrito por diversos autores $[42,43,45,69]$.

As principais vantagens da técnica de investigação por espectroscopia de fluorescência em relação à técnica de diagnóstico convencional são: (1) resultado rápido, (2) procedimento não-invasivo e não-destrutivo e (3) técnica quantitativa. A fluorescência tem o potencial de conectar as propriedades bioquímicas e morfológicas dos tecidos e o cuidado individual do paciente. O estado metabólico celular, a composição bioquímica e a arquitetura tecidual são informações que podem ser obtidas através da análise dos espectros de fluorescência.

Algumas das tendências atuais no diagnóstico óptico envolvem a determinação das matrizes de excitação-emissão para cada tipo de tecido biológico e lesão investigado; sistemas para a determinação dos tempos de vida da fluorescência utilizando excitação com intensidade modulada a alta freqüência; imagem hiperespectral com associação da espectroscopia e localização/imagem espacial; e avaliação endoscópica empregando técnicas de microscopia confocal, melhorando a validade das técnicas e instrumentos de discriminação e a determinação quantitativa do fluoróforo. 
Além disso, a combinação de mais de uma técnica de investigação espectroscópica vem sendo apontada como uma poderosa ferramenta de diagnóstico. A espectroscopia por luz espalhada, para o estudo da distribuição de tamanho e conteúdo de cromatina do núcleo da célula epitelial; a espectroscopia de fluorescência intrínseca, para o monitoramento de alterações no metabolismo e bioquímica dos tecidos; e a espectroscopia por reflectância difusa, para caracterização do espalhamento e oxigenação tecidual; constituem a espectroscopia trimodal e fornecem informação quantitativa do status tecidual sem a necessidade de remoção cirúrgica [70].

\subsection{Monitoramento da distribuição do Photogem ${ }^{\circledR}$ na cavidade oral}

Após o término das leituras de autofluorescência, os animais foram fotossensibilizados com um derivado de hematoporfirina. $O$ acompanhamento pela espectroscopia de fluorescência foi realizado em diferentes tempos de investigação pósmedicação.

A variação individual, assim como a localização e o tipo de lesão fazem com que a farmacocinética seja diferente para cada animal, apesar da via de administração e a dose aplicada terem sido as mesmas para todos os grupos. Desta forma, os tempos de acúmulo e de eliminação obtidos nas diversas lesões apresentaram algumas variações. O fator mais importante observado foi o quadro clínico sistêmico do animal, principalmente o peso corpóreo. 
A variabilidade entre os indivíduos foi grande, como pode ser verificado nos exemplos apresentados nas figuras 56,57 e 58, com o monitoramento da presença do fotossensibilizador em três tempos de investigação (6, 12 e 24 horas) após a medicação intravenosa. Cada curva representa a média obtida pelos seis pontos de investigação para cada sítio anatômico.

O tempo de maior acúmulo na lesão ficou no intervalo entre 6 e 12 horas após a administração do fotossensibilizador, porém na maioria dos animais esse tempo foi em 6 horas. Os animais que apresentavam o tempo mais tardio eram os que estavam com menores pesos corpóreos, indícios da debilidade sistêmica. No entanto, no tempo de 24 horas, a quantidade de porfirina já se mostrou em declínio.

Variações também foram observadas entre os pontos investigados em cada sítio, principalmente naqueles obtidos para as lesões, i.e., na lesão a quantidade de hematoporfirina indiretamente aferida pela intensidade de fluorescência emitida nas bandas características, variou de uma região para outra. 

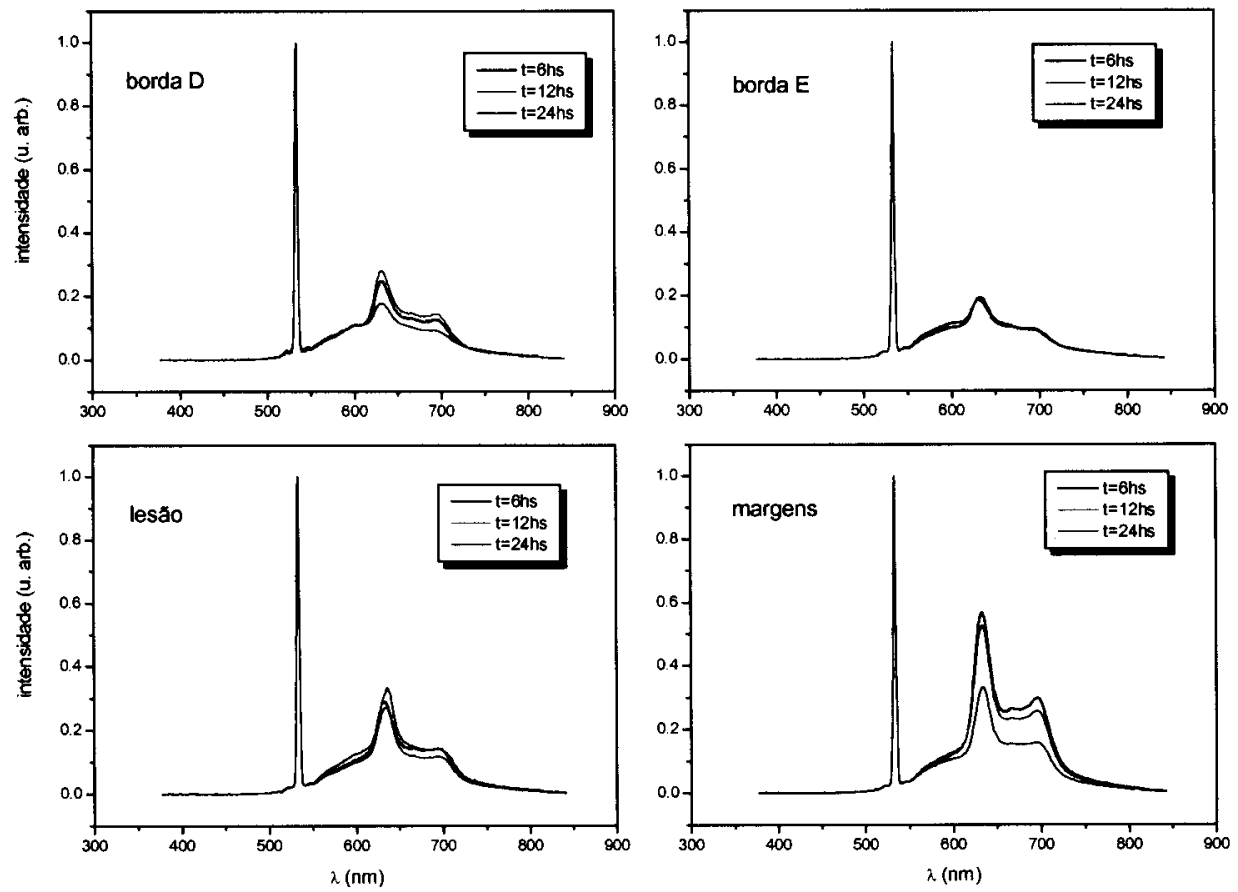

Fig.56 - Espectros de fluorescência para a identificação e monitoramento temporal da porfirina, comparação entre quatro sítios de investigação.

Um protocolo ideal seria o monitoramento temporal individual para cada paciente, assim a determinação do tempo ótimo de iluminação da terapia fotodinâmica seria realizada para a lesão específica e não pelo que é atualmente determinado clinicamente, onde a janela de espera é a mesma independente da localização anatômica da lesão, ou seja, lesões em pele, cavidade oral, esôfago e bexiga são irradiadas no mesmo tempo pós-medicação. 
Nos exemplos mostrados, o tratamento teria maiores chances de sucesso caso a lesão fosse iluminada após 6 horas da medicação no animal da figura 57 e após 12 horas no animal da figura 58.
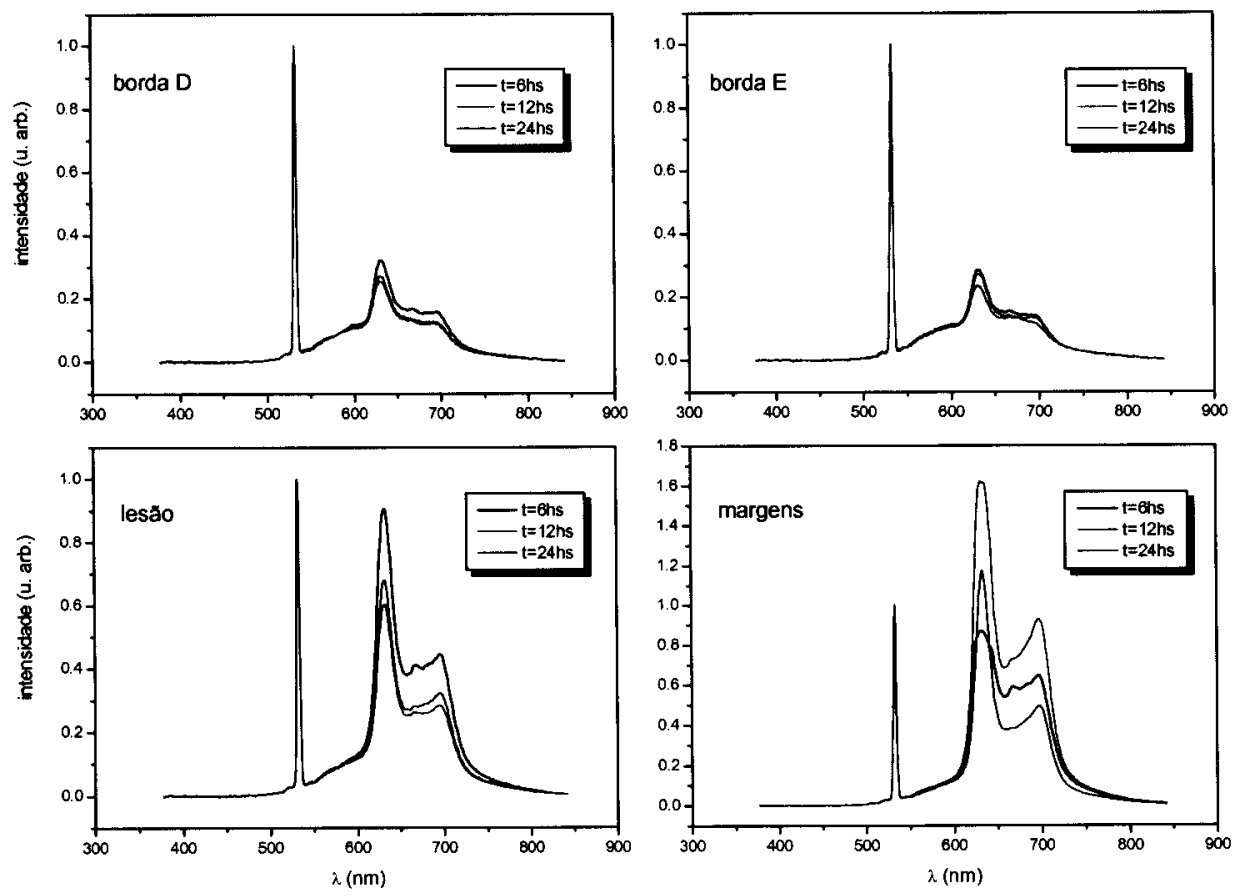

Fig. 57 - Espectros de fluorescência para a identificação e monitoramento temporal da porfirina, comparação entre quatro sítios de investigação.

Os resultados demonstraram uma tendência de maiores intensidades de emissão nas bandas características do Photogem, e assim maiores concentrações na lesão e nas margens em comparação ao tecido normal, no entanto devido à grande variabilidade entre os indivíduos e até entre os pontos do mesmo sítio investigado, não foi possível 
determinar a maior seletividade de retenção da porfirina em tecidos alterados. A tendência para maior concentração da porfirina na lesão e margens provavelmente ocorre devido à maior concentração de vasos sanguíneos presente nessas áreas.
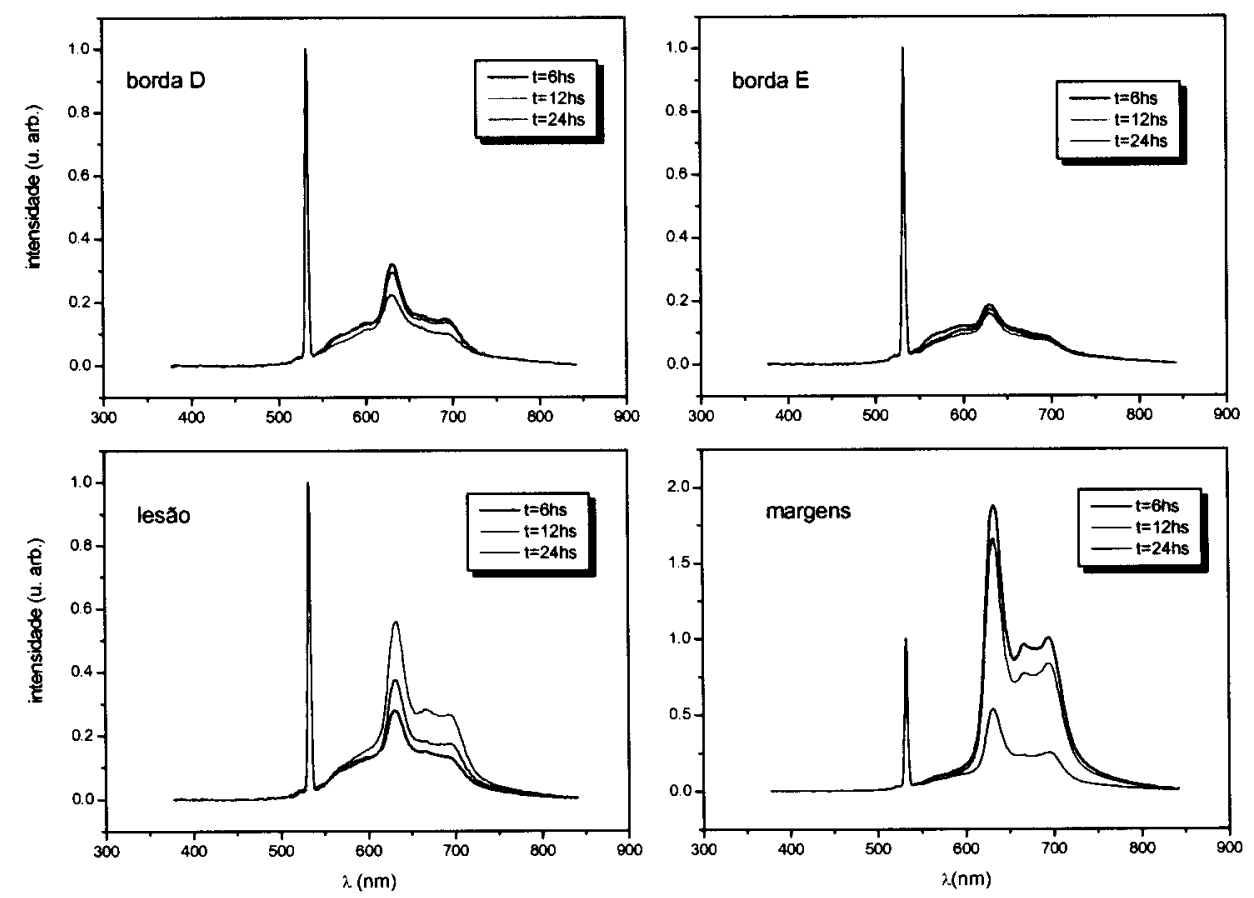

Fig.58 - Espectros de fluorescência para a identificação e monitoramento temporal da - porfirina, comparação entre quatro sitios de investigação.

O monitoramento da farmacocinética do Photogem ${ }^{\circledR}$ em cavidade oral através da espectroscopia de fluorescência possibilitou uma leitura com resultado em tempo real, ou seja, ao posicionar a sonda em contato com a superfície do tecido o espectro já é 
obtido. A técnica para detecção espectral da porfirina se mostra eficaz para o monitoramento da farmacocinética do Photogem ${ }^{\circledR}$.

Para a verificação da maior seletividade do marcador em tecidos alterados, um estudo experimental mais detalhado seria necessário, com um maior número de lesões para cada alteração patológica e uma maior investigação temporal, minimizando os intervalos de leitura e aumentando o período após a medicação.

O resultados, utilizando a porfirina como marcador de malignidade nesse modelo animal empregado, não puderam ser empregados para aumentar o contraste da fluorescência na discriminação normal versus carcinoma. 


\section{CONCLUSÕES}

Os resultados desse estudo mostraram a validade da espectroscopia de fluorescência como técnica para o diagnóstico de lesões quimicamente induzidas na borda lateral de hamsters, tanto com excitação em $442 \mathrm{~nm}$ como com $532 \mathrm{~nm}$, sendo que a excitação no violeta foi a mais eficiente para a discriminação entre o tecido normal e o carcinoma. A partir desse estudo pode-se concluir:

1. A espectroscopia de autofluorescência induzida com excitação em 442 e $532 \mathrm{~nm}$ foi uma técnica sensível às alterações morfológicas decorrentes do processo de carcinogênese no modelo animal empregado. Tanto as lesões iniciais, com variados graus de atipias, como o carcinoma in situ e o carcinoma epidermóide produziram espectros de fluorescência distintos aos do tecido normal. 
2. A discriminação espectral com excitação em $442 \mathrm{~nm}$ apresentou maior contraste entre tecido normal e carcinoma.

3. A análise intra-espectral com a determinação da correlação entre regiões de fluorescência possibilitou uma discriminação quantitativa para classificação da amostra como normal ou carcinoma, através de um processamento matemático simples.

4. A análise inter-espectral através do KNN apresentou índices de sensibilidade, especificidade e acurácia de $95,7 \%, 91,6 \%$ e $94 \%$, respectivamente.

5. A escolha adequada do valor limite de discriminação normal versus carcinoma da análise intra-espectral possibilita a obtenção de índices de sensibilidade e especificidade semelhantes aos obtidos pelo KNN. 


\section{CERTIFICADO}

CERTIFICAMOS, que o protocolo $n^{\circ}$ 007/2003-PACEP, sobre "Avaliação da biópsia óptica na deteç̧ão de lesões quimicamente induzidas em borda lateral de língua - estudo in vivo", sob a responsabilidade de Cristina Kurachi, tendo como colaborador 0 Professor Luiz Eduardo Blumer Rosa, está de acordo com os Princípios Éticos na Experimentação Animal adotado pelo Colégio Brasileiro de Experimentaçăo Animal (COBEA) e foi aprovado pelo Comitê de Ética em Pesquisa.

Săo José dos Campos, 11 de março de 2003.

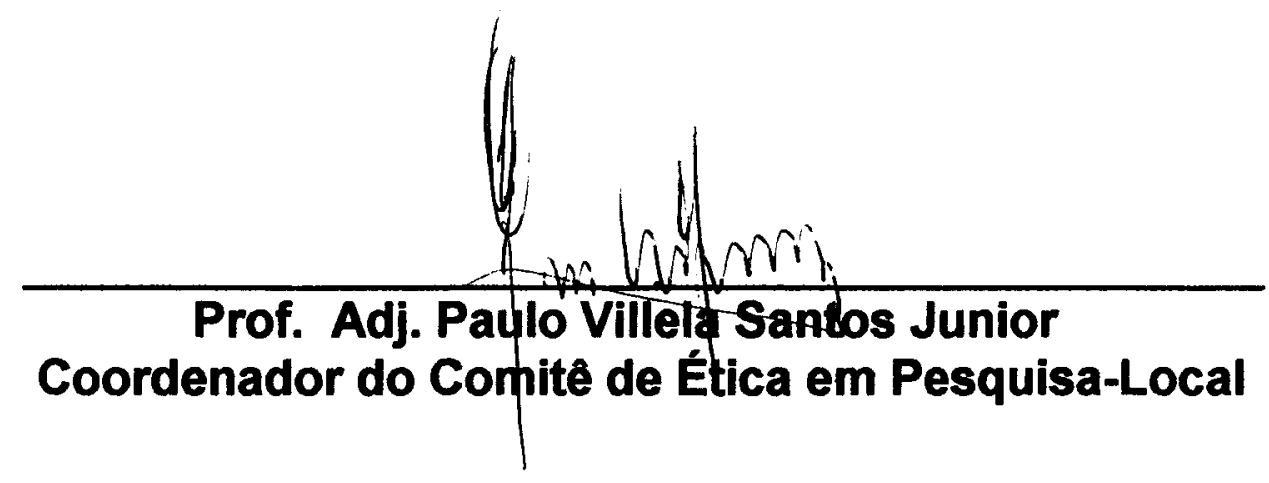




\section{ANEXO 2: Definições para os índices empregados na validadação de instrumentos de diagnóstico médico.}

1. Acurácia: a proporção de predições corretas, ou seja, a soma de resultados verdadeiro-positivos (VP) e verdadeiro-negativos (VN).

$$
\text { Acurácia }=\frac{V P+V N}{V P+V N+F P+F N}
$$

2. Sensibilidade: a proporção de resultados verdadeiro-positivos, i.e. a medida da capacidade do método de decisão de predizer a condição patológica para aqueles casos em que realmente a apresentam, os verdadeiramente positivos.

$$
\text { Sensibilidade }=\frac{V P}{V P+F N}
$$

3. Especificidade: a proporção de resultados verdadeiro-negativos, i.e. a medida da capacidade do método de decisão de apontar ausência da condição para aqueles casos que realmente não a possuem, os verdadeiramente negativos.

$$
\text { Especificidade }=\frac{V N}{V N+F P}
$$

4. Valor preditivo positivo (VPP): a proporção de resultados verdadeiro-positivos em relação a todas as predições positivas.

$$
\mathrm{VPP}=\frac{V P}{V P+F P}
$$


5. Valor preditivo negativo: a proporção de resultados verdadeiro-negativos em relação a todas as predições negativas.

$$
\mathrm{VNN}=\frac{V N}{V N+F N}
$$

Geralmente, para qualquer tarefa de decisão médica, a sensibilidade e a especificidade variam em direções opostas, ou seja, quando o teste é muito sensível a positivos, há a tendência de gerar muitos falso-positivos e, conseqüentemente, a especificidade diminui, pois o número de falso-negativos cai.

Um teste de decisão perfeito é algo raro de ser alcançado, a curva ROC (Receiver Operating Characteristic) é utilizada para análise do balanço entre esses índices e, portanto da validade do método de decisão. Essa curva é determinada através dos índices obtidos em vários pontos de corte estabelecidos tendo como eixo $\mathrm{X}$ o valor de (1-especificidade) e como eixo Y o valor de (sensibilidade). 


\section{ANEXO 3: Biópsia Óptica - Relato de um caso clínico}

O sistema de diagnóstico por espectroscopia de fluorescência foi utilizado em um caso clínico. O paciente do sexo masculino, 68 anos de idade foi indicado para o tratamento de um carcinoma verrucoso empregando a terapia fotodinâmica. A lesão apresentava envolvimento da comissura labial e mucosa jugal esquerda (figura 1). $\mathrm{O}$ paciente tabagista desde os 7 anos de idade, recusava-se ao tratamento pelo procedimento cirúrgico pela possibilidade de mutilação facial.
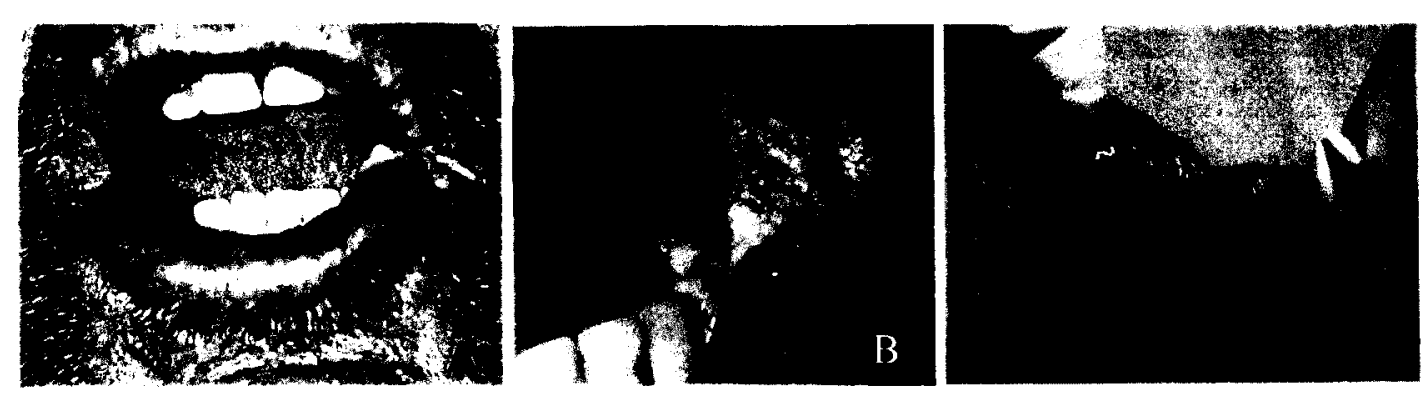

Fig. 1 - As fotos apresentam o caso clínico: aspecto da lesão na comissura labial esquerda em pele (A), aspecto da transição pele/mucosa (C) e aspecto da lesão atingindo mucosa jugal esquerda.

Externamente a lesão mostrava-se como um crescimento exofítico de base séssil com $2,5 \mathrm{~cm}$ de maior diâmetro e de coloração semelhante à da região adjacente. Em mucosa, o aspecto é de cordões leucoplásicos entremeados por área eritematosas, envolvendo uma área de $1,8 \mathrm{~cm}$ X 1,2 cm. O tempo de evolução relatado pelo paciente é de aproximadamente 4 anos. 
A avaliação foi realizada utilizando um laser de hélio-cádmio ( $\mathrm{HeCd}$ ) para excitação em $442 \mathrm{~nm}$. As regiões de investigação foram: região da comissura labial direita (pele controle), mucosa jugal direita (mucosa controle), lesão em comissura labial esquerda, margens da lesão em pele, lesão em mucosa jugal esquerda e margens da lesão em mucosa. A superfície investigada foi previamente limpa com gaze ou haste flexível com algodão nas pontas embebidos em solução de cloreto de sódio a $0,9 \%$. A ponteira de leitura foi posicionada o mais perpendicularmente possível à superfície do tecido alvo em contato (figura 2). Para cada área controle foram coletados 6 pontos e na lesão, pontos suficientes para cobrir toda sua extensão. As regiões avaliadas foram: dorso da mão, face (bochecha), pele adjacente e mucosa da comissura labial direita, lesão em pele, lesão em mucosa (área leucoplásica e eritematosa) e margens da lesão (em pele e em mucosa).

Esse procedimento foi repetido após 22 horas da medicação intravenosa de Photogem $^{\circledR}$ (Photogem, Moscou, Rússia) que o paciente recebeu para tratamento pela terapia fotodinâmica. A excitação foi obtida com um laser de Nd:YAG dobrado que emite em $532 \mathrm{~nm}$, o derivado de hematoporfirina absorve fótons nessa região do . espectro eletromagnético. 


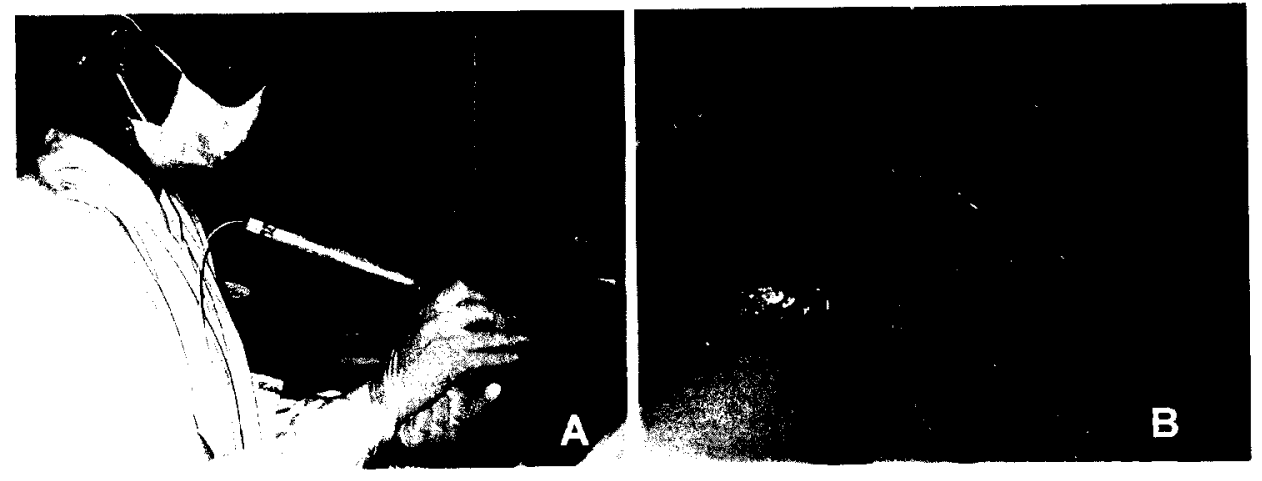

Fig. 2 - As fotos apresentam a biópsia óptica sendo realizada no paciente. Note em $B o$ posicionamento da ponta de aplicação.

Os gráficos são apresentados nas figuras 3 e 4 . Os espectros de autofluorescência resultantes permitem uma diferenciação do controle e da lesão. 


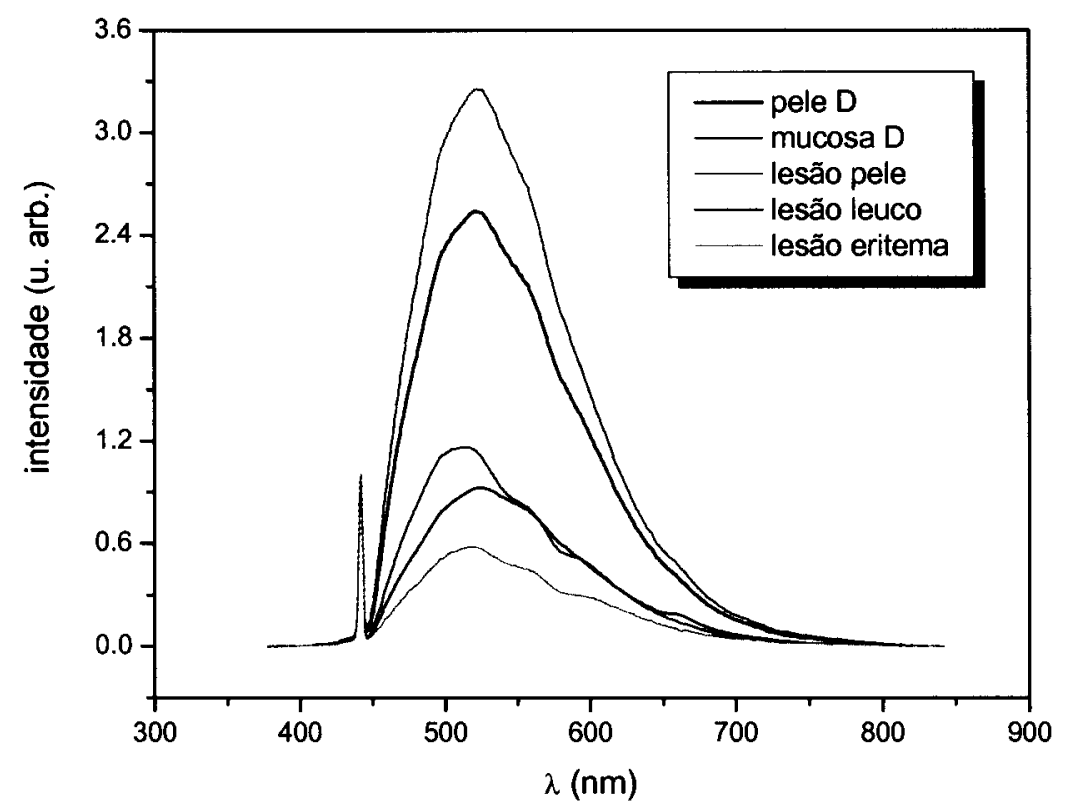

Fig.3 - Comparação dos espectros de autofluorescência das regiões em pele e mucosa do lado direito e da lesão.

Cada curva do gráfico corresponde à média obtida dos vários pontos de leitura de cada sítio investigado. A comissura labial direita foi avaliada para comparação de uma região com características anatômicas similares sem lesão clinicamente aparente, constituindo o controle do paciente.

A autofluorescência obtida da lesão em pele não mostrou diferenças considerando o comportamento da curva, no entanto, a intensidade foi comparativamente superior ao do tecido normal do lado direito. Um comportamento oposto foi observado quando comparada a mucosa controle (lado direito) e a área eritematosa da lesão, i.e., a intensidade da autofluorescência diminui na lesão. O espectro resultante das áreas leucoplásicas apresentou variações quando comparado ao 
da mucosa controle, isso pode ser observado no gráfico da figura 4, a curva apresenta uma banda larga de emissão ao redor de $660 \mathrm{~nm}$, que não é observada na mucosa controle e nem nas áreas eritematosas da lesão.

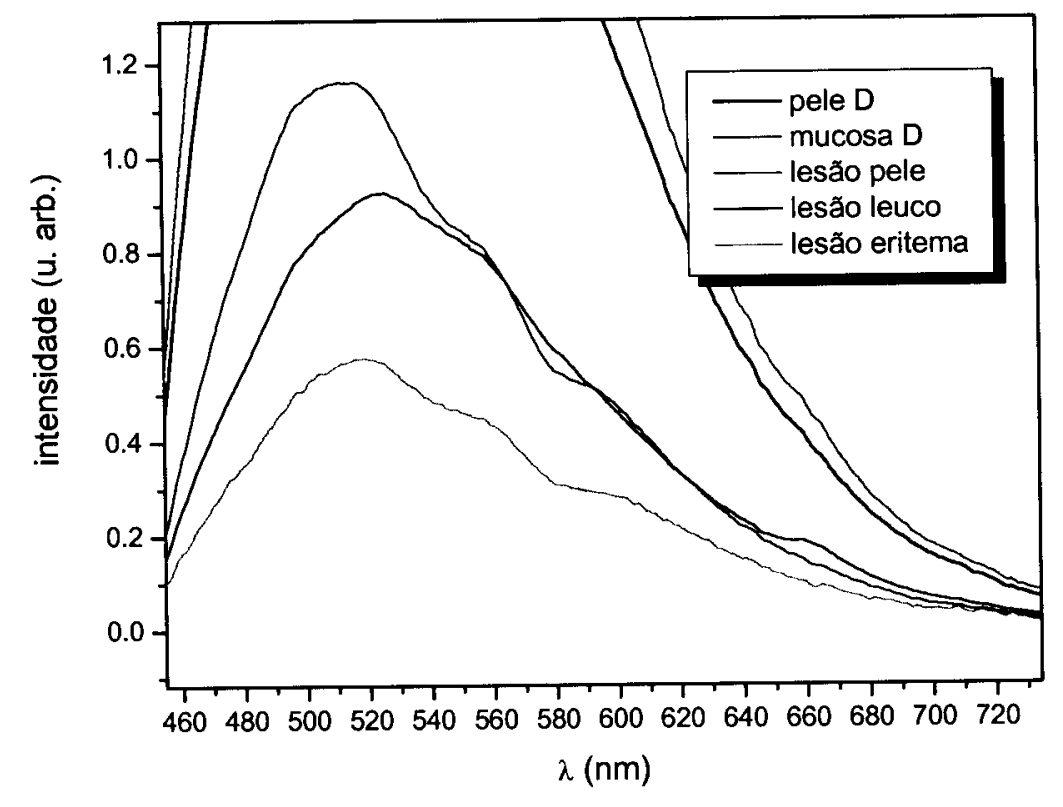

Fig.4 - Detalhe da fluorescência obtida para a mucosa controle e lesão em mucosa (áreas leucoplásica e eritematosa).

O gráfico da figura 5 apresenta os resultados da avaliação realizada após 22 horas da medicação do paciente e anterior à iluminação com laser para a terapia fotodinâmica. A presença da porfirina é identificada pela banda de emissão ao redor de $630 \mathrm{~nm}$. 


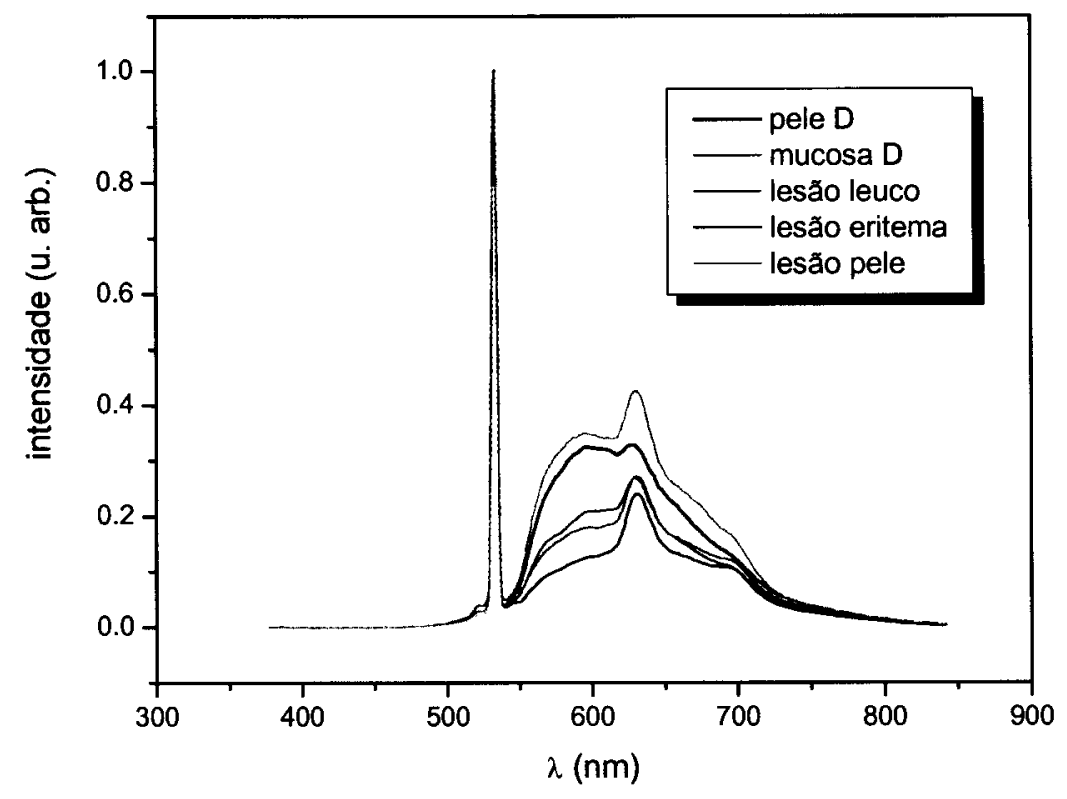

Fig.5 - Espectros de fluorescência com excitação em 532 nm para pele e mucosa controles (lado direito, D) e para lesão.

Comparativamente, a banda de emissão da porfirina presente na fluorescência dos tecidos da lesão foi mais importante em relação ao dos tecidos-controle, evidenciando a maior concentração em células tumorais relatada na literatura.

O coeficiente $a_{\text {porf }}$ foi obtido para cada ponto de leitura dos sítios investigados e os resultados são apresentados no gráfico da figura 6. 


$$
\mathrm{a}_{\text {porf }}=\frac{\int_{620}^{540} I}{\int_{590}^{610} I}
$$

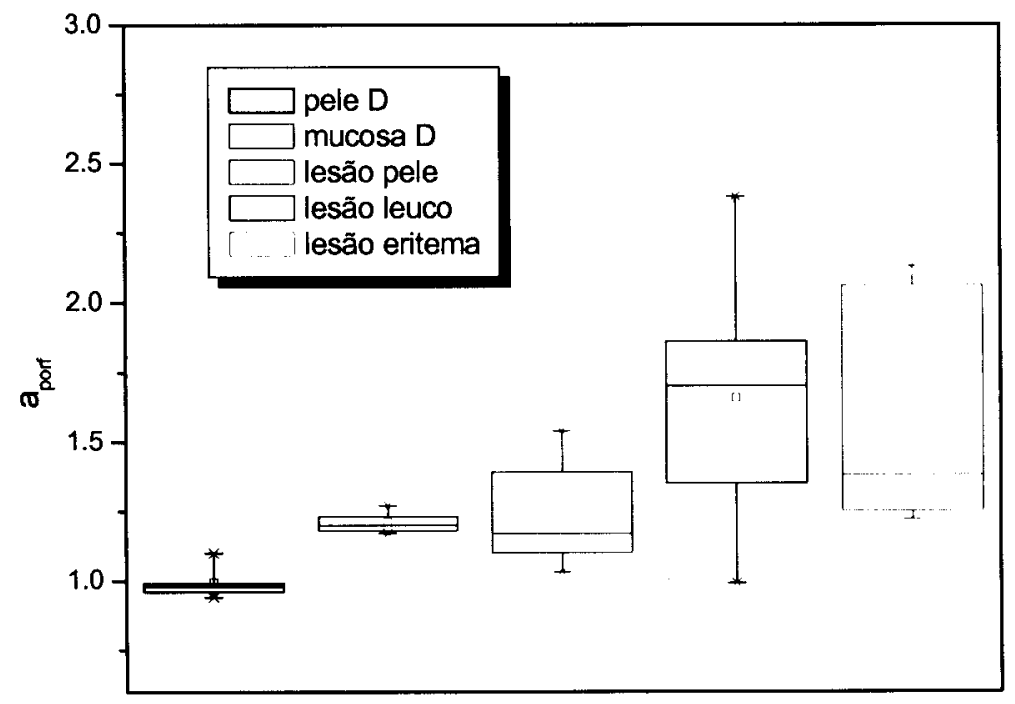

Fig.6 - O gráfico Box chart do coeficiente $a_{\text {porf }}$ dos tecidos controle (pele D e mucosa D) e dos tecidos da lesão (pele, área leucoplásica e área eritematosa).

O coeficiente $a_{\text {porf }}$ para os tecidos da lesão teve valores mais espalhados em comparação com os tecidos controle, evidenciando que a distribuição da porfirina nos tecidos normais foi mais uniforme do que na lesão.

O sistema de fluorescência empregado se mostrou eficiente para a detecção da porfirina nos tecidos do paciente fotossensibilizado. A avaliação é realizada em tempo real e com leitura não-invasiva, possibilitando a investigação de toda a lesão. $\mathrm{O}$ método 
também pode ser empregado para a determinação da janela de espera, ou seja, do tempo ótimo de iluminação após a medicação. Nesse caso apresentado isso não foi realizado, uma vez que o sistema de fluorescência não está localizado no mesmo local em que foi realizado o tratamento. 


\section{REFERÊNCIAS BIBLIOGRÁFICAS}

1. WORLD HEALTH ORGANIZATION. Global cancer rates could increase by $50 \%$ to $15 \%$ million by 2020. Geneva, Mediacentre, 2003.

2. INTERNATIONAL AGENCY FOR RESEARCH ON CANCER. WORLD HEALTH ORGANIZATION. Globocan 2000: Cancer incidence, mortality and prevalence worldwide. Lyon, IARCPress, 2001.

3. INSTITUTO NACIONAL DO CÂNCER. Estimativas. Rio de Janeiro, 2005.

4. BINNIE, W.H.; RANKIN, K.V. Etiology. In: WRIGHT, B.A.; WRIGHT, J.M.; BINNIE, W.H. Oral cancer: clinical and pathological considerations. Boca Raton, CRC Press, 2000. Cap.2, p. 13-32.

5. WYNDER, E.L.; MUSHINSKI, M.H.; SPIRAK, J.C. Tobacco and alcohol consumption in relation to the development of multiple primary cancers. Cancer, v.40, n. 4, p. $1872-1878,1977$.

6. ROTHMAN, K.J. The effect of alcohol consumption on risk of cancer of the head and neck. Laryngoscope, v.88, n.1, p.51-55, 1978.

7. McCOY, G.D. Biochemical approach to etiology of alcohol related cancers of head and neck. Laryngoscope, v.88, n.1, p.59-62, 1978. 
8. WIGHT, A.J.; OGDEN, G.R. Possible mechanisms by which alcohol may influence the development of oral cancer - a review. Oral Oncology, v.34, p.441-447, 1998.

9. RENNIE, J.S.; McDONALD, D.G.; DAGG, J.H. Quantitative analysis of human buccal epithelium in iron deficiency anemia. J. Oral Pathol., v.11, n.1, p.39-46, 1982.

10. SONIS, S.T.; FAZIO, R.C.; FANG, L. Princípios e prática de medicina oral. 2.ed. Rio de Janeiro, Ed. Guanabara Koogan, 1995. Cap.40, p.337-349: Carcinoma de células escamosas da cabeça e do pescoço.

11. COTRAN, R.S.; KUMAR, V.; ROBBINS, S.L.; SCHOEN, F.J. Robbins: Patologia estrutural e funcional. 5.ed. Rio de Janeiro, Ed. Guanabara Koogan, 1996. Cap.16, p.655-671: Cabeça e pescoço.

12. SAUK, J.J.; REYNOLDS, M.A.; COLETTA, R.D. Pathogenesis and progression of oral cancer. In: ORD, R.A.; BLANCHAERT Jr., R.H. Oral cancer: the dentist's role in diagnosis, management, rehabilitation, and prevention. Carol Stream, Quintessense Publishing Co., 2000, Cap.2: 9-19.

13. SHUGARS, D.C.; PATTON, L.L. Detecting, diagnosing, and preventing oral cancer. Nurse Pract., v.22, p.6, 1997.

14. YELLOWITZ, J.A. The oral cancer examination. In: ORD, R.A.; BLANCHAERT Jr., R.H. Oral cancer: the dentist's role in diagnosis, management, rehabilitation, and prevention. Carol Stream, Quintessense Publishing Co., 2000, Cap.3: 21-37.

15. SHAHA, A.R.; PATEL, S.; SHASHA, D.; HARRISON, L.B. Head and Neck Cancer. In: LENHARD Jr., R.E.; OSTEN, R.T.; GANSLER, T. The American Cancer Society's Clinical Oncology. Atlanta, The American Cancer Society, 2001, Cap.12, p. 298-329.

16. WRIGHT, J.M.; O'BRIEN, J.C.; LIEBERMAN, Z.H.; BRADFIELD, J.S.; MENNEL, R.G. Treatment of oral cancer. In: WRIGHT, B.A.; WRIGHT, J.M.; BINNIE, W.H. Oral cancer: clinical and pathological considerations. Boca Raton, CRC Press, 2000. Cap.6, p. 89-123.

17. ORD, R.A.; BLANCHAERT Jr., R.H. Oral cancer: the dentist's role in diagnosis, management, rehabilitation, and prevention. Carol Stream, Quintessense Publishing Co., 2000, Cap.7-10: 81-130. 
18. ZHAO, F.Y.; ZHANG, K.H.; JIANG, F.; WU, M.J. Photodynamic therapy for treatment of cancers in oral and maxillofacial regions: a long-term follow-up study in 72 complete remission cases. Lasers Med. Sci., v.6, p.201-204, 1991.

19. GRANT, W.E.; HOPPER, C.; SPEIGHT, P.M.; PATH, M.R.C.; MACROBERT, A.J.; BOWN, S.G. Photodynamic therapy of malignant and premalignant lesions in patients with 'field cancerization' of the oral cavity. The Journal of Laryngology and Otology, v.107, p.1140-1145, 1993.

20. NAUTA, J.M.; van LEENGOED, H.L.L.M.; SATR, W.M.; ROODENBURG, J.L.N.; WITJES, M.J.H.; VERMEY, A. Photodynamic therapy of oral cancer: a review of basic mechanisms and clinical applications. Eur. J. Oral Sci., v.104, n.2, p.69-81, 1996.

21. SILVERMAN, S. Early diagnosis of oral cancer. Cancer, v.62, p.1796-1799, 1988.

22. ORD, R.A. Diagnostic procedures. In: ORD, R.A.; BLANCHAERT Jr., R.H. Oral cancer: the dentist's role in diagnosis, management, rehabilitation, and prevention. Carol Stream, Quintessense Publishing Co., 2000, Cap.4: 39-48.

23. GEORGAKOUDI, I.; JACOBSON, B.C.; MÜLLER, M.G.; SHEETS, E.E.; BADIZADEGAN, K.; CARR-LOCKE, D.L.; CRUM, C.P.; BOONE, C.W.; DASARI, R.R.; DAM, J.V.; FELD, M.S. NAD(P)H and collagen as in vivo quantitative fluorescent biomarkers of epithelial precancerous changes. Cancer Res., v.62, p.682-687, 2002.

24. TSAI, T.; CHEN, H-M.; WANG, C-Y., TSAI, J-C., CHEN C-T.; CHIANG, C-P. In vivo autofluorescence spectroscopy of oral premalignant and malignant lesions: distortion of fluorescence intensity by submucous fibrosis. Lasers Surg. Med., v.33, p.40-47, 2003

25. ZULUAGA, A.F.; UTZINGER, U.; DURKIN, A.; FUCHS, H.; GILLENWATER, A.N.; JACOB, R.; KEMP, B.; FAN, J.; RICHARDS-KORTUM, R. Fluorescence excitation emission matrices of human tissue: a system for in vivo measurement and method of data analysis. Applied Spectroscopy, v.53, n.3, p.302-311, 1999.

26. WANG, C-Y.; TSAI, T.; CHEN, H-M.; CHEN, C-T.; CHIANG, C-P. PLS-ANN based classification model for oral submucous fibrosis and oral carcinogenesis. Lasers Surg. Med., v.32, p.318-326, 2003. 
27. MÜLLER, M.G.; VALDEZ, T.A.; GEORGAKOUDI, I.; BACKMAN, V.; FUENTES, C.; KABANI, S.; LAVER, N.; WANG, Z.; BOONE, C.W.; DASARI, R.R.; SHAPSHAY, S.M.; FELD, M.S. Spectroscopic detection and evaluation of morphologic and biochemical changes in early human oral carcinoma. Cancer, v.97, n.7, p.1681-1692, 2003.

28. RAMANUJAM, N. Fluorescence spectroscopy in vivo. In: MEYERS, R.A. Encyclopedia of Analytical Chemistry. Chichester, John Wiley \& Sons Ltd, 2000. Pp. 20-56.

29. LAKOWICZ, J.R. Principles of fluorescence spectroscopy. 2 ed. New York, Plenum press, 1999. Cap.1-2: 1-49.

30. GEORGAKOUDI, I.; FELD, M.S.; MÜLLER, M.G. Intrinsic fluorescence spectroscopy of biological tissue. In: MYCEK, M-A.; POGUE, B.W. Handbook of biomedical fluorescence. New York, Marcel Dekker, 2003. Cap.4, p.109-142.

31. RICHARDS-KORTUM, R.; DREZEK, R.; SOKOLOV, K.; PAVLOVA, I.; FOLLEN, M. Survey of endogenous biological fluorophores. In: MYCEK, MA.; POGUE, B.W. Handbook of biomedical fluorescence. New York, Marcel Dekker, 2003. Cap.8, p.237-264.

32. WAGNIÈRES, G.A.; STAR, W.M.; WILSON, B.C. In vivo fluorescence spectroscopy and imaging for oncological applications. Photochem. Photobiol., v.68, n.5, p.603-632, 1998.

33. DaCOSTA, R.S.; ANDERSSON, H.; WILSON, B.C. Molecular fluorescence excitation-emission matrices relevant to tissue spectroscopy. Photochem. Photobiol., v.78, n.4, p.384-392, 2003.

34. PATHAK, I.; DAVIS, N.L.; HSIANG, Y.N.; QUENVILLE, N.F.; PALCIC, B. Detection of squamous neoplasia by fluorescence imaging comparing porfimer sodium fluorescence to tissue autofluorescence: in the hamster cheek-pouch model. Am. J. Surg., v.170, p.423-426, 1995.

35. ONIZAWA, K.; SAGINOYA, H.; FURUYA, Y.; YOSHIDA, H. Fluorescence photography as a diagnostic method for oral cancer. Cancer Letters, v.108, p.61-66, 1996.

36. NAUTA, J.M.; SPEELMAN, O.C.; van LEENGOED, H.L.L.M.; NIKKELS, P.G.J.; ROODENBURG, J.L.N.; STAR, W.M.; WITJES, M.J.H.; VERMEY, A. In vivo photo-detection of chemically induced premalignant lesions and squamous cell carcinoma of the rat palatal mucosa. J. Photochem. Photobiol. B, v.39, p.156-166, 1997. 
37. ONIZAWA, K.; OKAMURA, N.; SAGINOYA, H.; YOSHIDA, H. Characterization of autofluorescence in oral squamous cell carcinoma. Oral Oncology, v.39, p.150-156, 2003.

38. WANG, C-Y.; CHIANG, H.K.; CHEN; C-T.; CHIANG, C-P.; KUO, Y-S.; CHOW, S-N. Diagnosis of oral cancer by light-induced autofluorescence spectroscopy using double excitation wavelengths. Oral Oncology, v.35, p.144-150, 1999.

39. COGLAN, L.; UTZINGER, U.; RICHARDS-KORTUM, R.; BROOKNER, C.; ZULUAGA, A.; GIMENEZ-CONTI, I.; FOLLEN, M. Fluorescence spectroscopy of epithelial tissue throughout the dysplasia-carcinoma sequence in an animal model: spectroscopic changes precede morphologic changes. Lasers Surg. Med., v.29, p.1-10, 2001.

40. MANJUNATH, B.K.; KUREIN, J.; RAO, L.; MURALI KRISHNA, C.; CHIDANANDA, M.S.; VENKATAKRISHNA, K.; KARTHA, V.B. Autofluorescence of oral tissue for optical in oral malignancy. J. Photochem. Photobiol. B, v.74, p.49-58, 2004.

41. HEINTZELMAN, D.L.; UTZINGER, U.; FUCHS, H.; ZULUAGA, A.; GOSSAGE, K.; GILLENWATER., A.M.; JACOB, R.; KEMP, B.; RICHARDS-KORTUM, $\mathrm{R}$. Optimal excitation wavelengths for in vivo detection of oral neoplasia using fluorescence spectroscopy. Photochem. Photobiol., v.72, n.1, p.103-113, 2000.

42. YUANLONG, Y.; YANMING, Y.; FUMING, L.; YUFEN, L.; PAOZHONG, M. Characteristic autofluorescence for cancer diagnosis and its origin. Lasers Surg. Med., v.7, p.528-532, 1987.

43. ONIZAWA, K.; OKAMURA, N.; SAGINOYA, H.; YUSA, H.; YANAGAWA, T.; YOSHIDA, H. Analysis of fluorescence in oral squamous cell carcinoma. Oral Oncology, v.38, p.343-348, 2002.

44. NELSON, D.L.; COX, M.M. Lehninger: Principles of biochemistry. $3^{\text {rd }}$ Ed. New York, Worth Publishers, 2000. P.204-206; 840-842.

45. INAGUMA, M.; HASHIMOTO, K. Porphyrin-like fluorescence in oral cancer - In vivo fluorescence spectral characterization of lesions by use of a near-ultraviolet excited autofluorescence diagnosis system and separation of fluorescent extracts by capillary electrophoresis. Cancer, v.86, n.11, p.2201-2211, 1999.

46. SHOMACKER, K.; FRISOLI, J.; COMPTON, C.; FLOTTE, T.; RICHTER, J.M.; NISHIOKA, N.; DEUTSCH, T. UV LIF of colonic tissue: basic biology and diagnostic potential. Lasers Surg. Med., v.12, p.63-78, 1992. 
47. DREZEK, R.; BROOKNER, C.; PAVLOVA, I.; BOIKO, I.; MALPICA, A.; LOTAN, R.; FOLLEN, M.; RICHARDS-KORTUM, R. Autofluorescence microscopy of fresh cervical tissue sections reveals alterations in tissue biochemistry with dysplasia. Photochem. Photobiol., v.73, n.6; p.636-641.

48. GEORGAKOUDI, I.; JACOBSON, B.C.; MÜLLER, M.G.; SHEETS, E.E.; BADIZADEGAN, K.; CARR-LOCKE, D.L.; CRUM, C.P.; BOONE, C.W.; DASARI, R.R.; DAM, J.V.; FELD, M.S. NAD(P)H and collagen as in vivo quantitative fluorescent biomarkers of epithelial precancerous changes. Cancer Res., v.62, p.682-687, 2002.

49. LEUNIG, A.; RICK, K.; STEPP, H.; GUTMANN, R.; ALWIN, G.; BAUMGARTNER, R.; FEYH, J. Fluorescence imaging and spectroscopy of 5-aminolevulinic acid induced protoporphyrin IX for the detection of neoplastic lesions in the oral cavity. Am. J. Surg., v.172, p.674-677, 1996.

50. WANG, I.; CLEMENTE, L.P.; PRATAS, R.M.G.; CARDOSO, E.; CLEMENTE, M.P.; MONTÁN, S.; SVANBERG, S.; SVANBER, K. Fluorescence diagnosis and kinetic studies in the head and neck region utilizing low-dose $\delta$ aminolevulinic acid sensitization. Cancer Letters, v.135, p.11-19, 1999.

51. ZENZEN, V.; ZANKL, H. Protoporphyrin IX-accumulation in human tumor cells following topical ALA- and h-ALA-application in vivo. Cancer Letters, v.202, p.35-42, 2003.

52. HARRIS, D.M.; HILL, J.H.; WERKHAVEN, J.A.; APPLEBAUM, E.L.; LOBRAICO, R.V.; WALDOW, S.M. Porphyrin fluorescence and photosensitization in head and neck cancer. Arch. Otol. Head Neck Surg., v.112, p.1194-1199, 1986

53. MANG, T.S.; McGINNIS, C.; LIEBOW, C.; NSEYO, U.O.; CREAN, D.H.; DOUGHERTY, T.J. Fluorescence detection of tumors. Cancer, v.71, n.1, p.269-276, 1993.

54. BRAICHOTTE, D.R.; WAGNIÈRES, G.A.; BAYS, R.; MONNIER, P.; van den BERGH, H.E. Clinical pharmacokinetics studies of Photofrin by fluorescence spectroscopy in the oral cavity, the esophagus, and the bronchi. Cancer, v.75, n.11, p.2768-2778, 1995.

55. LAZAREV, V.V.; ROTH, R.A.; KAZAKEVICH, Y.; HANG, J. Detection of premalignant oral lesions in hamsters with an endoscopic fluorescence imaging system. Cancer, v.85, n.7, p.1421-1429, 1999. 
56. BRO, R. Multiway analysis in the food industry - models, algorithms \& applications. Monografia apresentada no Department of Dairy and Food Science of Royal Veterinary and Agricultural University, Dinamarca (disponivel online: http://www.models.kvl/users/rasmus).

57. ANDERSSON, CA; BRO, R. The $N$-way toolbox for MATLAB. Chemometrics and Intelligent Laboratory Systems, v.52, p.1-4, 2000.

58. WANG, C-Y.; CHEN, C-T.; CHIANG, C-P.; YOUNG, S-T.; CHOW, S-N.; CHIANG, H.K. Partial least-squares discriminant analysis on autofluorescence spectra of oral carcinogenesis. Applied Spectroscopy, v.52, n.9, p.1190-1196, 1998.

59. EVESON, I.W. Animal models of intra-oral chemical carcinogenesis: a review. $J$. Oral Pathol., v.10, p.129-146, 1981.

60. WONG, P.N.C.; WILSON, D.F. 4 nitroquinoline 1-oxide induced carcinogenesis in the rat palate. J. Oral Pathol., v.12, p.375-384, 1983.

61. FASSONI, A.A.; SALES, C.L.F.; CONSOLARO, A. Carcinogênese bucal quimicamente induzida por DMBA: estudo em hamsters sírios dourados. Revista Odontológica da USP, v.7, n.4, p.285-291, 1993.

62. ODUKOYA, O.; SHKLAR, G. Initiation and promotion in experimental oral carcinogenesis. Oral Surg., v.54, n.3, p.315-320, 1984.

63. PRINCE, S.; BAILEY, B.M.W. Squamous carcinoma of the tongue: review. Brit. J. Oral Maxillo. Surg., v.37, n.3, p.164-174, 1999.

64. GONZALEZ-MOLES, M.A.; ESTEBAN, F.; RODRIGUEZ-ARCHILLA, A.; RUIZ-AVILA, I.; GONZALEZ-MOLES, S. Importance of tumour thickness measurement in prognosis of tongue cancer. Oral Oncology, v.38, p.394-397, 2002.

65. AGÊNCIA NACIONAL DE VIGILÂNCIA SANITÁRIA, Validade de instrumentos de diagnóstico in Vigilância em Saúde Pública (www.anvisa.org.br).

66. BUSHBERG, J.T.; SEIBERT, J.A.; LEIDHOLDT, E.M.; BOONE, J.M. Image Quality. In: The essential physics of medical imaging. $2^{\text {nd }}$ Ed., Philadelphia, Lippincott Williams \& Wilkins, 2002. P.288-291.

67. SABBATINI, R.M.E. Um programa para o cálculo da acurácia, especificidade e sensibilidade de teste médicos. Revista Informédica, v.2, n.12, p.19-21, 1995. 
68. de VELD, D.C.G.; STERENBORG, H.J.C.M.; ROODENBURG, J.L.N.; WITJES, M.J.H. Effects of individual characteristics on healthy oral mucosa autofluorescence spectra. Oral Oncology, v.40, p.815-823, 2004.

69. DHINGRA, J.K.; XIA ZHANG, M.D.; McMILLAN, K.; KABANI, S.; MANOHARAN, R.; ITZKAN, I.; FELD, S.; SHAPSHAY, S.M. Diagnosis of head and neck precancerous lesions in an animal model using fluorescence spectroscopy. The Laryngoscope, v.108, p.471-475, 1998.

70. BADIZADEGAN, K.; BACKMAN, V.; BOONE, C.W.; CRUM, C.P.; DASARI, R.R.; GEORGAKOUDI, I.; KEEFE, K.; MUNGER, K.; SHAPSHAY, S.M.; SHEETS, E.E; FELD, M.S. Spectroscopic diagnosis and imaging of invisible pre-cancer. Faraday Discuss., v.126, p.265-279, 2004. 


\section{PRODUÇÃO CIENTÍFICA 2000-2005}

\section{ARTIGOS EM PERIÓDICOS INTERNACIONAIS}

1. Fontana, CR; Kurachi, C; Mendonça, CR; Bagnato, VS. Microbial reduction in periodontal pockets under exposition of a medium power diode laser: an experimental study in rats. Lasers in Surgery and Medicine 35(4): 263-268, Oct. 2004.

2. Kurachi, C; Fontana, CR; Melo, CAS; Rosa, LEB; Bagnato, VS. Optical biopsy of chemical-induced tongue lesions in Golden Syrian hamsters: an in vivo study. Laser Physics 14(4): 502-506, Apr. 2004.

3. Ferreira, J; Kurachi, C; Melo, CAS; Moriyama, LT; Zucoloto, S; Bagnato, VS. Necrosis characteristics of photodynamic therapy in normal rat liver. Laser Physics 14(2): 209-212, Feb. 2004.

4. Melo, CAS; Kurachi, C; Grecco, C; Sibata, CH; Silva, O Castro; Bagnato, VS. Pharmacokinetics of Photogem using fluorescence monitoring in Wistar rats. Journal of Photochemistry and Photobiology $B$ 73(3): 183-188, Feb. 2004.

5. Kurachi C; Tuboy AM; Magalhães DV; Bagnato VS. Hardness evaluation of a dental composite polymerized with experimental LEDbased devices. Dental Materials, 17: 309-315, 2001.

6. Bagnato VS; Marcassa LG; Kurachi C; Melo CAS; Ferreira J; Cestari Filho G. Regional profile: PDT in Brazil. Photodynamics News, 4(3): 25,2001 .

7. Lizarelli RFZ; Kurachi C; Misoguti L; Bagnato VS. A comparative study of nanosecond and picosecond laser ablation in enamel: morphological aspects. Journal of Clinical Laser Medicine \& Surgery. 18(3): 151-157, 2000.

\section{ARTIGOS COMPLETOS EM CONFERÊNCIAS INTERNACIONAIS}

1. Kurachi, C; Fontana, CR; Melo, CAS; Rosa, LEB; Bagnato, VSB. Fluorescence spectroscopy for tongue carcinoma detection: study in an animal model. Optical Methods for tumor treatment and detection: mechanisms and techniques in PDT XIV in SPIE - BIOS 2005, Photonics West, 22-27 January, 2005 (no prelo). 
2. Kurachi, C; Ferreira, J; Marcassa, LG; Cestari Filho, GA; Souza, CS; Bagnato, VS. Clinical experience of PDT in Brazil: a 300 patient overview. Optical Methods for tumor treatment and detection: mechanisms and techniques in PDT XIV in SPIE - BIOS 2005, Photonics West, 22-27 January, 2005 (no prelo).

3. Ferreira, J; Moriyama, LT; Kurachi, C; Castro e Silva, O; Sibata, CH; Bagnato, VS. Photobleaching of Photogem ${ }^{\circledR}$ : a spectroscopic study in solution. Optical Methods for tumor treatment and detection: mechanisms and techniques in PDT XIV in SPIE - BIOS 2005, Photonics West, 22-27 January, 2005 (no prelo).

4. Ferreira, J; Kurachi, C; Moriyama, LT; Marcassa, LG; Castro e Silva, O; Zucoloto, S; Bagnato, VS. Determination of the threshold dose using depth of necrosis measurement. Optical Methods for tumor treatment and detection: mechanisms and techniques in PDT XIV in SPIE - BIOS 2005, Photonics West, 22-27 January, 2005 (no prelo).

5. Lizarelli RFZ; Kurachi C; Misoguti L; Bagnato VS. Morphological comparison between nano and picosecond laser ablation in enamel. Lasers in dentistry, Proceedings of SPIE 2000 - 3910, 1(4): 175-183, 2000.

6. Lizarelli RFZ; Kurachi C; Porto Neto ST; Bagnato VS. Compartive study in vitro of microleakage in class $\mathrm{V}$ cavity preparation with and without Er:YAG laser. Lasers in dentistry, Proceedings of SPIE 2000 - 3910, 1(4): 254-260, 2000.

\section{RESUMOS EM CONFERENNCIAS INTERNACIONAIS}

1. Souza, CS; Neves, ABS; Ferreira, J; Kurachi, C; Bagnato, VS. Clinical experience with a LED-based device for non-melanoma skin cancer treatment. Optical Methods for tumor treatment and detection: mechanisms and techniques in PDT XIV in BIOS 2005, Photonics West, 22-27 January, 2005.

2. Kurachi, C; Ferreira, J; Cestari Filho, GA; Bagnato, VS. PDT for the treatment of oral lesions. Congress of the World Association for Laser Therapy - WALT, Guarujá - SP, Brazil, Nov. 2004.

3. Ferreira, J; Kurachi, C; Moriyama, LT; Castro e Silva, O; Zucoloto, S; Bagnato, VS. Depth of necrosis in photogem-pdt using LED-based 
device as a light source. Congress of the World Association for Laser Therapy - WALT, Guarujá - SP, Brazil, Nov. 2004.

4. Kurachi, C; Ferreira, J; Lucato, PDS; Zucoloto, S; Castro e Silva, O; Bagnato, VS. Fluorescence diagnosis of malignant lesions. Congress of the World Association for Laser Therapy - WALT, Guarujá - SP, Brazil, Nov. 2004.

5. Ferreira J; Kurachi, C; Moriyama, LT; Graziano, M; Velasques, J; Bagnato, VS. Experimental determination of threshold dose in Photodynamic Therapy. Congress of the World Association for Laser Therapy - WALT, Guarujá - SP, Brazil, Nov. 2004.

6. Kurachi, C; Fontana, C; Melo, CAS; Rosa, LEB; Bagnato, VS. Optical diagnosis of induced tongue carcinoma in golden Syrian hamsters. $2^{\text {nd }}$ Congress of the European Society for Oral Laser Applications, Florença, Itália, 2003.

7. Lizarelli, RFZ; Moriyama, LT; Kurachi, C; Bagnato, VS. Picosecond laser ablation of permanent and primary teeth. $2^{\text {nd }}$ Forum "III Milenium The Nation's Health", Moscou, Rússia, 2002.

8. Marcassa, JC; Marcassa, LG; Kurachi, C; Castro-e-Silva Jr., O; Zucoloto, $\mathrm{S}$; Bagnato, VS. Fluorescence diagnosis for hepatocarcinoma and other diseases. Laser Physics Workshop'02, July 1-5, Bratislava, 2002.

\section{ARTIGOS EM PERIÓDICOS NACIONAIS}

1. Kurachi C; Melo CS; Marcassa LG; Zílio SC; Bagnato VS; Cestari Filho GA; Javaroni A; Berto JC; Passeri C; Bonilha VS; Silva M; Ferreira J; Veríssimo FM; Souza CS. Implantação clínica da terapia fotodinâmica no Brasil: breve histórico e resultados alcançados. Revista da Sociedade Brasileira de Cancerologia, ano V, no 20: 33-41, 2002.

2. Lizarelli RFZ; Silva PCG; Kurachi C; Porto Neto ST; Bagnato VS. Estudo-piloto comparativo da microinfiltração in vitro entre preparos cavitários classe $\mathrm{V}$, através de ponta diamantada em alta rotação ou laser de Er:YAG seguido ou não de ataque ácido. Jornal Brasileiro de Dentística e Estética (JBD); 1(1): 33-41, 2002. 


\section{RESUMOS EXTENDIDOS EM CONFERÊNCIAS NACIONAIS}

1. Ferreira, J; Kurachi, C; Azoubel, A; Bagnato, VS. Novas Aplicações Clínicas da PDT: Tratamento de Condiloma causado por HPV. I Workshop de Terapia Fotodinâmica: Complexos de Moléculas Fotoativas e suas Aplicações. Aspectos Fisícos, Químicos, Biológicos e Médicos, 27 a 30 de novembro de 2002, São Pedro - SP.

2. Ferreira, J; Castro-e-Silva, TMC; Melo, CAS; Kurachi, C; Bagnato, VS; Zucoloto, S. Efeito da Radiação Ionizante em Células Normais Fotossensibilizadas para PDT - in Vivo. I Workshop de Terapia Fotodinâmica: Complexos de Moléculas Fotoativas e suas Aplicações. Aspectos Fisícos, Químicos, Biológicos e Médicos, 27 a 30 de novembro de 2002, São Pedro.

1. Melo, CAS; Kurachi, C; Bagnato, VS. Monitoramento da distribuição do Photogem usando Espectroscopia de Fluorescência. I Workshop de Terapia Fotodinâmica: Complexos de Moléculas Fotoativas e suas Aplicações. Aspectos Fisícos, Químicos, Biológicos e Médicos, 27 a 30 de novembro de 2002, São Pedro.

2. Kurachi, C; Fontana, CR; Melo, CAS; Bolanho, A; Kitakawa, D; Rosa, LEB; Bagnato, VS.Detecção Óptica no diagnóstico de carcinoma epidermóide em língua de hamster. I Workshop de Terapia Fotodinâmica: Complexos de Moléculas Fotoativas e suas Aplicações. Aspectos Fisicos, Químicos, Biológicos e Médicos, 27 a 30 de novembro de 2002, São Pedro.

\section{RESUMOS EM ANAIS DE CONFERÊNCIAS NACIONAIS}

1. Ferreira, J; Moriyama, LT; Kurachi, C; Sibata, CH; Castro e Silva Júnior, O; Bagnato, VS. Photobleaching of photogem: a spectroscopic study in solution. Congresso Brasileiro de Física Médica, 2004.

2. Kurachi, C; Fontana, CR; Melo, CAS; Rosa, LEB; Bagnato, VS. Laser induced fluorescence for tongue carcinoma detection in an animal model. Congresso Brasileiro de Física Médica, 2004.

3. Souza, CS; Neves, ABS; Ferreira, J; Kurachi, C; Bagnato, VS. Evaluation of the efficacy of a LED-based device for the PDT treatment of non-melanoma skin cancer. Congresso Brasileiro de Física Médica, 2004. 
4. Kurachi, C; Fontana, CR; Melo, CAS; Rosa, LEB; Bagnato, VS. Avaliação por espectroscopia de fluorescência de carcinoma epidermóide em borda lateral de língua de hamsters. $21^{a}$ Reunião Anual da Sociedade Brasileira de Pesquisa Odontológica - SBPqO, Águas de Lindóia - SP, 2004.

5. Figueiredo, ACR; Kurachi, C; Bagnato, VS. Estudo do sinal de fluorescência comparando três comprimentos de onda na avaliação de esmalte e dentina sadios e dentina cariada. $21^{a}$ Reunião Anual da Sociedade Brasileira de Pesquisa Odontológica - SBPqO, Águas de Lindóia - SP, 2004.

6. Rastelli, A; Andrade, MF; Bagnato, VS; Calixto, AL; Kurachi, C. Avaliação da eficiência de um novo dispositivo LEDs utilizado na técnica de fotoativação transdental. $21^{a}$ Reunião Anual da Sociedade Brasileira de Pesquisa Odontológica - SBPqO, Águas de Lindóia - SP, 2004.

7. Souza, CS; Neves, ABS; Ferreira, J; Kurachi, C; Bagnato, VS. Experiência com emprego de dispositivos de diodo (LED) na terapia fotodinâmica. Congresso Brasileiro de Cirurgia Dermatológica, Porto de Galinhas - PE, 2004.

8. Souza, CS; Neves, ABS; Felício, LAB; Kurachi, C; Bagnato, VS. Terapia fotodinâmica: otimização do método com curetagem prévia de tumores cutâneos. Congresso Brasileiro de Cirurgia Dermatológica, Porto de Galinhas - PE, 2004.

9. Kurachi, C; Fontana, CR; Kitakawa, D; Bolanho, A; Rosa, LEB; Bagnato, VS. Espectroscopia de fluorescência para a detecção de carcinoma epidermóide em borda lateral de língua de hamsters. $20^{a}$ Reunião Anual da Sociedade Brasileira de Pesquisa Odontológica, , Águas de Lindóia - SP, 2003.

10. Fontana, CR; Kurachi, C; Mendonça, CR; Bagnato, VS. O laser de diodo de média potencia no tratamento da doença periodontal: aspectos físicos e biológicos. $20^{a}$ Reunião Anual da Sociedade Brasileira de Pesquisa Odontológica, , Águas de Lindóia - SP, 2003.

11. Kurachi, C; Cestari Filho, G; Bagnato, VS. Terapia Fotodinâmica no tratamento de lesões orais. $19^{a}$ Reunião Anual da Sociedade Brasileira de Pesquisa Odontológica, , Águas de Lindóia - SP, 2002.

12. Fontana, CR; Kurachi, C; Mendonça, CR; Bagnato, VS.Redução Bacteriana Proporcionada pelo Laser de média Potência como 
Coadjuvante ao Tratamento da Doença Periodontal. FUTURA , 27 a 29 de junho de 2002, São Paulo.

13. Fontana, CR; Kurachi, C; Lizarelli, RFZ. Laser de CO2 , Nd:YAG, Bisturi de Kirkland para remoção cirurgica de pigmentação melânica fisiológica. FUTURA, 27 de junho de 2002, São Paulo.

14. Souza CS; Felicio LAB; Bentley MV; Tedesco AC; Ferreira J; Kurachi C; Bagnato VS. Photodynamic Therapy (PDT) with 5-delta aminolevulinic acid in Bowen's disease. XIV Congresso Brasileiro de Cirurgia Dermatológica, 22 a 26 de junho de 2002, Goiânia-GO.

15. Souza CS; Felicio LAB; Ferreira J; Kurachi C; Bagnato VS. Photodynamic Therapy (PDT): new option of the treatment for keratoacanthoma marginatum. XIV Congresso Brasileiro de Cirurgia Dermatológica, 22 a 26 de junho de 2002, Goiânia - GO.

16. Felicio LAB; Souza CS; Ferreira J; Kurachi C; Bagnato VS. Photodynamic Therapy (PDT): option of the non-invasive treatment for multiple and superficial skin tumours. XIV Congresso Brasileiro de Cirurgia Dermatológica, 22 a 26 de junho de 2002, Goiânia-GO.

17. Felicio LAB; Souza CS; Ferreira J; Kurachi C; Bagnato VS; Tedesco AC. Evaluation of the absorption of the 5-delta aminolevulinic (5-ALA) used in Photodynamic Therapy (PDT) for superficial skin cancer. XIV Congresso Brasileiro de Cirurgia Dermatológica, 22 a 26 de junho de 2002, Goiânia - GO.

18. Fontana, CR; Kurachi, C; Mendonça, CR; Bagnato, VS. Redução Bacteriana Proporcionada pelo Laser de média Potência como Coadjuvante ao Tratamento da Doença Periodontal. I Encontro Nacional da Associação Brasileira de Laser em Odontologia, 1 a 3 de maio de 2002, Maceió - AL.

19. Fontana, CR; Kurachi, C; Mendonça, CR; Bagnato, VS. Efeito térmico do laser de diodo de média potência em tecido periodontal de proteção e sustentação. I Encontro Nacional da Associação Brasileira de Laser em Odontologia, 1 a 3 de maio de 2002, Maceió - AL.

20. Magnani, C; Kurachi, C; Bevilacqua, FM; Magnani, R; Bagnato, VS; Porto Neto, ST. Análise da microfenda axial em cavidades classe $\mathrm{V}$ de resina composta, polimerizadas com diferentes fontes de luz. I Encontro Nacional da Associação Brasileira de Laser em Odontologia, 1 a 3 de maio de 2002, Maceió - AL. 
21. Kurachi, C; Cestari Filho, GA; Bagnato, VS. Terapia Fotodinâmica no tratamento de lesões orais. I Encontro Nacional da Associação Brasileira de Laser em Odontologia, 1 a 3 de maio de 2002, Maceió - AL.

22. Kurachi, C; Cestari Filho, GA; Fontana, CR; Bagnato, VS. Biópsia Óptica no diagnóstico de lesões tumorais. I Encontro Nacional da Associação Brasileira de Laser em Odontologia, 1 a 3 de maio de 2002, Maceió - AL.

23. Kurachi C; Marcassa LG; Bagnato VS. Biópsia Óptica para lesões malignas. VI Congresso Brasileiro de Física Médica, 4 a 6 de outubro de 2001, Rio de Janeiro.

24. Bagnato VS; Kurachi C; Medeiros IS. Inovação tecnológica no processamento de resinas compostas: o uso de LEDs azuis. $23^{a}$ Jornada Odontológica de Araraquara, 6 a 8 de junho de 2001, Araraquara - SP.

25. Kurachi C; Tuboy AM; Magalhães DV; Bagnato VS. O uso de LEDs na polimerização da resina composta dental. Proposta e avaliação da eficiência de um dispositivo elaborado. $17^{a}$ Reunião Anual da Sociedade Brasileira de Pesquisa Odontológica, 2 a 6 de setembro de 2000, Águas de Lindóia - SP.

26. Kurachi C; Tuboy AM; Magalhães DV; Bagnato VS. O uso do LED azul para a cura de resina composta dental. XXIII Encontro Nacional de Fisica da Matéria Condensada, 9 a 13 de maio de 2000, São Lourenço - MG.

27. Kurachi C; Magalhães DV; Bagnato VS. Dentes humanos expostos à irradiação com laser de argônio: determinação de parâmetros de trabalho. $19^{\circ}$ Congresso Internacional de Odontologia de São Paulo, 25 a 27 de janeiro de 2000, São Paulo - SP.

28. Moriyama LT; Kurachi C; Bagnato VS; Lizarelli RFZ. Biossegurança para a utilização de laser em consultório odontológico. $11^{a}$ Semana Odontológica da Universidade de Ribeirão Preto, 17 a 19 de maio de 2000, Ribeirão Preto - SP.

29. Lizarelli RFZ; Kurachi C; Porto Neto ST; Bagnato VS. Estudo comparativo in vitro da microinfiltração em preaparos cavitários classe V com e sem laser de Er:YAG. $11^{a}$ Semana Odontológica da Universidade de Ribeirão Preto, 17 a 19 de maio de 2000, Ribeirão Preto - SP. 


\section{PRÊMIOS OU DISTINÇÃO}

1. O trabalho Avaliação por espectroscopia de fluorescência de carcinoma epidermóide em borda lateral de lingua de hamsters, C Kurachi, CR Fontana, CAS Melo, LEB Rosa, VS Bagnato foi o vencedor no grupo C7 na $21^{a}$ Reunião Anual da Sociedade Brasileira de Pesquisa Odontológica - SBPqO, Águas de Lindóia - SP, 2004.

2. O trabalho Novas aplicações clínicas da PDT: tratamento de condiloma causado por HPV. ASO Azoubel, VS Bagnato, C Kurachi, J Ferreira. recebeu menção honrosa, prêmio Cervicolp no XIV Encontro de atualização em patologia do trato genital inferior e colposcopia, 22 a 24 de maio de 2003.

3. O trabalho Espectroscopia de fluorescência para a detecção de carcinoma epidermóide em borda lateral de língua de hamsters. $\underline{\mathrm{C}}$ Kurachi, CR Fontana, D. Kitakawa, A Bolanho, LEB Rosa, VS Bagnato, foi vencedor no grupo A7 da sessão de painéis na $20^{\mathrm{a}}$ Reunião Anual da Sociedade Brasileira de Pesquisa Odontológica, 30 de agosto a 3 de setembro de 2003, Águas de Lindóia - SP.

4. O trabalho Avaliação temporal da distribuição de um fotossensibilizador na cavidade oral de hamsters. $\mathrm{C}$ Kurachi, CR Fontana, LEB Rosa, VS Bagnato, foi escolhido como o melhor trabalho da área de Instrumentação Médica na sessão pôster, durante o II Workshop Regional de Engenharia Biomédica e I Simpósio Regional de Instrumentação e Imagens Médicas, 29 a 31 de outubro de 2003, São Pedro - SP.

5. O trabalho Aplicação clínica não-oncológica da PDT: tratamento de condiloma causado por HPV. J Ferreira, C Kurachi, ASO Azoubel, VS Bagnato, foi escolhido como o melhor trabalho na sessão oral da área de Instrumentação Médica, durante o II Workshop Regional de Engenharia Biomédica e I Simpósio Regional de Instrumentação e Imagens Médicas, 29 a 31 de outubro de 2003, São Pedro - SP.

6. O trabalho Biópsia Óptica para lesões malignas, $\underline{\mathrm{C} \text { Kurachi, LG }}$ Marcassa, VS Bagnato recebeu menção honrosa no VI Congresso Brasileiro de Física Médica, Rio de Janeiro - RJ, 2001.

7. O trabalho Dentes humanos expostos à irradiação com laser de argônio: determinação de parâmetros de trabalho, C Kurachi, DV Magalhães, VS Bagnato recebeu o "Prêmio Professor José Gustavo de Paiva" no $19^{\circ}$ Congresso Internacional de Odontologia de São Paulo, 2000. 